\title{
ESTUDO DAS DISTRIBUIÇÕES DE FREQÜẸNCIA DA EVAPOTRANSPIRAÇÃO DE REFERÊNCIA E DA PRECIPITAÇÃO PLUVIAL PARA FINS DE DIMENSIONAMENTO DE SISTEMAS DE IRRIGACÃO
}

\author{
JOTO GARLOS GURY SAAD \\ Engenheiro Agrốnomo
}

Orientador: Prof. Dr. KLAUS REIGHARDT

Dissert.ação apresentada à Escola Superior de Agricultura "Luiz de Queiroz", da Uni versidade de São Paulo, para a obtenção do t.ítulo de Mestre em Irrigação e Drenagem.

$$
\begin{gathered}
\text { P I R A G I A A B A } \\
\text { Est.ado de São Paulo - Brasil } \\
\text { Junho - } 1990
\end{gathered}
$$


Ficha catalográfica preparada pela Seçăo de Livros da Divisão de Biblioteca e Documentação - PCAP/USP

Saad, João Carlos Cury

S111e Estudo das distribuições de frequência da evapotranspiração de referência e da precipitação pluvial para fins de dimensionamento de sistemas de 1 rr 1 gação. Piracicaba, 1990.

\section{$124 \mathrm{p}$}

Diss.(Mestre) - ESALQ

Bibliografia.

1. Evapotranspiração - Frequência - Distribuição 2. Precipitação (meteorologia) - Frequência - Distribuição 3. Irrigação - Sistema - Dimensionamentó I. Es cola Superior de Agricultura Luiz de Queiroz, Piracicaba.

CDD 631.7 
ESTUDO DAS DISTRIBUIÇOES DE FREQUENCIA DA EVAPOTRANSPIRAĢ̃o DE REFERENGIA E DA PREGIPITAGTo PLUVIAL PARA FINS DE DIMENSIONAMENTO DE SISTEMAS DE IRRIGAÇÃo

Aprovado em: 06.08.1990

Comišsão julgadora:

Prof. Dr. Klaus Reichardt

ESALQ /USP

Prof. Dr. José Antonio Frizzone

ESALQ $/$ USP

Prof. Dr. Antonio Roberto Pereira

ESALQ /USP

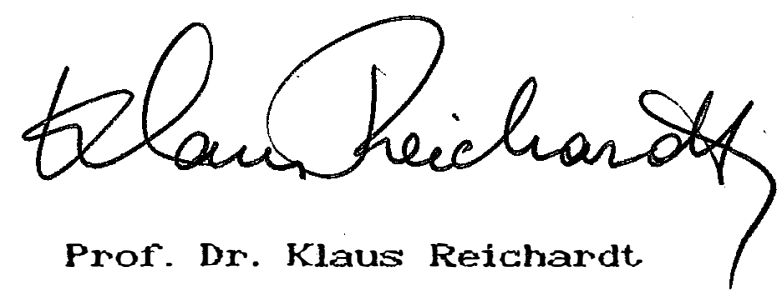

Orientador 
OFEREGo aos meus pais,

NELSON \& JANETE,

e aos meus irmãos,

JORGE ANTONIO, LUIZ HENRIQUE,

JOSE ROBERTO E MARTA GRISTINA,

a quem só DEUS sabe o quanto devo e amo.

AGRADEGO DO Prof. Dr. EDMAR JOSE SGALOPPI pela orientaçăo, incentivo, exemplo e, acima de tudo, pela val i osa amizade.

DEDICO à minha querida nolva, BEATRIZ, pelo precioso apoio e por tudo que ela representa para mim. 


\title{
HINO Ȧ CARIDADE
}

\begin{abstract}
Ainda que falasse linguas, as dos homens e as dos anjos, se eu não tivesse a caridade, sexia como um bronze que soa ou como um címbalo que tine.
\end{abstract}

Ainda que eu tivesse o dom da profecia, o conhecimento de todos os mistérios e de toda a ciéncia, ainda que eu tivesse toda a fe, a ponto de transportar montanhas, se năo tivesse a caridade, eu nada seria.

A caridade jamais passará.

Quanto às profecias, desaparecerão.

Quanto às línguas, cessarão.

Quanto a ciencia, também desaparecerá.

Pois o nosso conhecimento é limitado,

e limitada é a nossa profecia.

Mas, quando vier a perfeição,

o que é limitado desaparecerá.

Agora vemos em espelho

e de maneira confusa, mas, depois, veremos face a face.

Agora meu conhecimento é limitado, mas, depois, conhecerei como sou conhecido.

Agora, portanto, permanecem a fe, esperança, caridade, estas trés coisas. A maior delas, porém, é a caridade. 


\section{AGRADECIMENTOS}

AGRADECOO

- a DEUs, pela fé, perseverança, saúde e por todas as graças concedidas durante o curso;

- ar Prof. Dr. Klaus Reicharat, pela orientacão e pelo total apoio e confiança depositados em meu trabalno;

- ao Conselho Nacional de Desenvolvimento Cientifico e Tecnologico- CNPQ, pelo auxilio financeiro atraves de bolsa de estudos;

- Escola Superior de Agricultura "Luiz de Queiroz" - ESALQRUSP, pela acolhida e assistência dispensados;

- ao Departamento de Engenharia Rural e a coordenaç̃o do curso de pos-Graduaça em Irrigaçăo e Drenagem, pela oportunidade e apoio concedidos; 
- ao Prof. Dr. Jose Antonio Frizzone pela amizade e pelas valiosas sugestoes, as quais muito contribuiram para este trabalno;

- ao Frof. Dr. Antonio Roberto Fereira pela participaça na comissăo julgadora;

- ao Departamento de Fisica e Meteorologia da ESALQNUSP, que gentilmente forneceu os dados meteorologicos utilizados neste trabalho

- ao amigo Mauricio Dutra Zanotio cuja convivencia me possibilitou crescer muito;

- àbibliotecaria Katia M. P. de Andrade pela revisăo das referencias bibliograficas;

- a Prof. Mirva Curi pela revisão gramatical do texto:

- ans professores. colegas de curso e funcionários do Departamento de Engenharia Rural pelas sugestoes e convivio amigo:

- a todos que, direta ou indiretamente; contribuiram para o exito deste trabalio. 


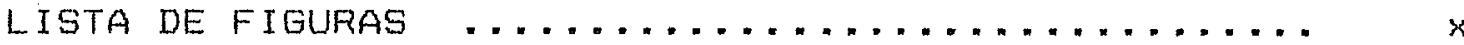

LISTA DE TABELAS $\ldots \ldots \ldots \ldots \ldots \ldots \ldots \ldots \ldots \ldots \ldots \ldots \ldots \ldots \ldots \ldots$

LISTA DE ABREVIATURAS E SIMBDLOS $\ldots \ldots \ldots \ldots \ldots \ldots \ldots \ldots$....

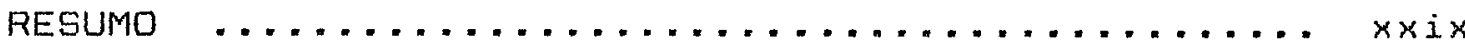

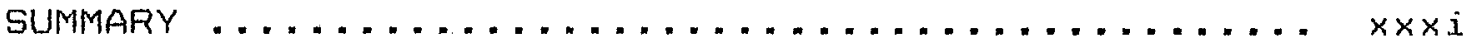

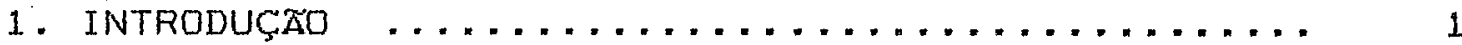

2. REVISÃo de literatuRA $\ldots \ldots \ldots \ldots \ldots \ldots \ldots \ldots$

2.1. Evapotranspimaça de referencia .......... 4

2.1.1. Consideraçชes gerais $\ldots . . . . . . . .44$

2.1.2. Seleção do método para estimativa da evapotranspiraçăo de referbncia $\ldots . .6$

2.1.3. Método de Penman $\ldots \ldots \ldots \ldots \ldots \ldots 7$

2.1.4. Distribuiçăo de frequéncia da evapotranspiraçå $\quad \ldots \ldots \ldots \ldots \ldots \ldots$

2.2. Precipitaçăo pluvial provavel ou dependente 11

2.2.1. Consideraçóes gerais ........... 11

2.2.2. Distribuiçăo de frequencia da precipitação pluvial .................

2.3. Modelo matemático para oimensionamento de de sistemas de irriqaçăo ............. 18 
viii

Página

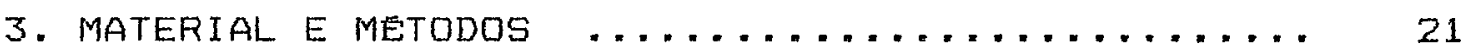

3.1. Descrição geral .................. 21

3.2. Periodo utilizado $\ldots \ldots \ldots \ldots \ldots \ldots$

3.3. Parametros meteorológicos utilizados ..... 24

3.4. Estimativa da evapotranspiraçăo de referen-

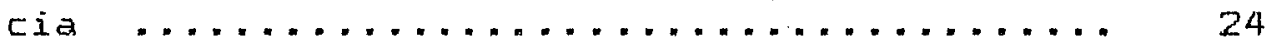

3.4.1. Descrição da versão do método de Penman utilizado ................ 25

3.4.1.1. Estimativa de $\Delta \ldots . \ldots 26$

3.4.1.2. Estimativa de $\gamma \quad \ldots \ldots \ldots . . .27$

3.4.1.3. Estimativa de ed e de ea 28

3.4.1.4. Estimativa da radiaçăo liquida $(R n) \quad \ldots \ldots \ldots \ldots . \ldots 28$

3.4.1.5. Estimativa do termo de transferência aerodinâmica

3.5. Estimativa da distribuição de frequencia da evapotranspiraçăo de referencia ..........

3.6. Estimativa da distribuiçăo de frequência da precipitaçăo pluvial ............... 36

3.7. Teste de Kolmogorov-Smirmov ............. 41

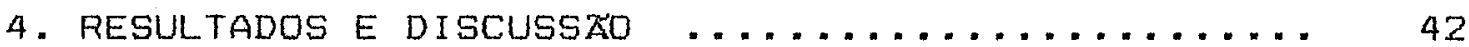

4.1. Evapotranspiraçăo de referência ........... 42

4.1.1. Evapotranspiraçă de referencia para o més de março $\ldots \ldots \ldots \ldots \ldots \ldots \ldots \ldots$

4.1.2. Evapotranspiração de referência para o mês de setembro $\ldots \ldots \ldots \ldots \ldots . . . .$. 
Página

4.2. Precipitaça pluvial ................ 79

4.2.1. Precipitaçăo pluvial para o mês de

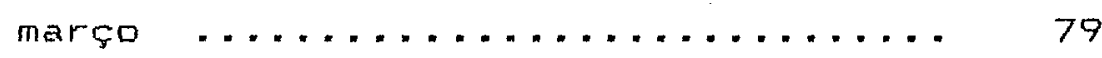

4.2.2. Precipitaçăo pluvial para o mes de setembro $\ldots \ldots \ldots \ldots \ldots \ldots \ldots . \ldots \ldots . \ldots \ldots$

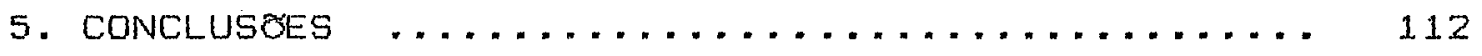

REFERENCIAS BIBLIQGRAFICAS $\ldots \ldots \ldots \ldots \ldots \ldots \ldots \ldots$ 
Figura 1. Funça densidade da distribuiçăo Beta aplicada aos dados de evapotranspiraça para a quarta pentada do més de março... 51

Figura 2. Evapotranspiraçăo para os diferentes niveis de probabilidade obtida atraves da distribuiça Beta, e evapotranspiracão observada para a quarta pentada de

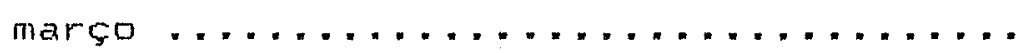

Figura 3. Evapotranspiraçăo para os diferentes niveis de probabilidade obtida atraves da distribuição Beta, e evapotranspiraçăo observada para a primeira quinzena

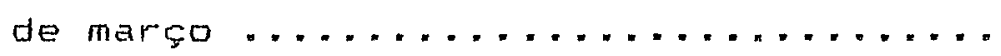

Figura 4. Função densidade da distribuiça Beta aplicada a evapotranspiraçăo para a quarta pentada do mes de setembro ..... 69 
Figura 5. Evapotranspiração para os diferentes miveis de probabilidade obtida atraves da distribuiçăo Beta, e evapotranspiraçăo observada para a quarta pentada de setembro $\ldots \ldots \ldots \ldots \ldots \ldots \ldots \ldots \ldots \ldots$

Figura 6. Evapotranspiraçăo para os diferentes niveis de probabilidade obtida através da distribuicăo Beta, e evapotranspiracăo para a primeira quinzena do mês de setembro $\ldots \ldots \ldots \ldots \ldots \ldots \ldots \ldots \ldots \ldots . \ldots \ldots$ 76

Figura 7. Precipitaçăo pluvial dependente obtida através da distribuição Mista, e precipitaço observada para a quarta pentada

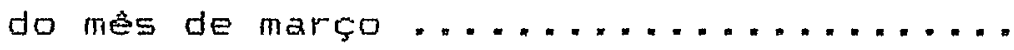

Figura 8. Precipitaça pluvial dependente obtida através da distribuiçăo Mista, e precipitaça observada para a primeira quin-

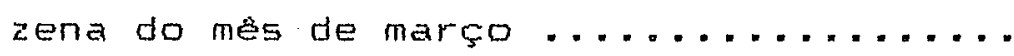

Figura 9. Precipitação pluvial dependente obtida atraves da distribuição Mista, e precipitaça observada para a quarta pentada do mess de setembro ................... 106 
Fiqura 10. Precipitaça pluvial dependente obtida atraves da distribuiçăo Mista, e precipitaçăo observada para a primeira quinzena do més de setembro ............ 107

Figura 11. Função densidade da distribuiçăo Gama Ltilizada na distribuiça Mista aplicada aos dados de precipitaça da primeira

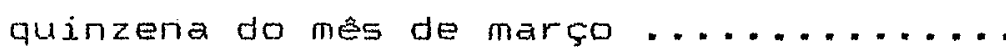

Figura 12. Funçăo densidade da distribuiçăo Gama utilizada na distribuição Mista aplicada aos dados de precipitaça da primeira

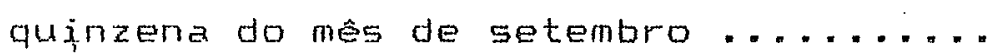

Figura 13. Esquema mostrando o balanço entre a evapotranspiraçăo ao nivel de $75 \%$ de probabilidade e a precipitaçăo ao nivel de 75\% de probabilidade, visando a estimativa da exigência em áqua para fins de dimensionamento de sistemas de irrigaço 
Tabela 1. Valores de $\Gamma(\alpha)$ para $1 \leq \alpha \leq 2 \ldots .$.

Tabela 2. Valores dos coeficientes de assimetria e curtose para os dados de evapotranspiraça do mes de março, para os periodos de $5,10,15$ e 30 dias $\ldots \ldots \ldots \ldots$

Tabela 3. Valores dos coeficientes de assimetria e curtose para os dados de evapotranspiraçăo do mês de setembro, para os periodos de $5,10,15$ e 30 dias ........

Tabela 4. Valores da evapotranspiraça de referencia para as pentadas do mes de marco, para um periodo de 30 anos $\ldots .$. 
Tabela 5. Valores da evapotranspiraça de referêncja para os periodos de 10,15 e 30 dias do mes de marco, para um

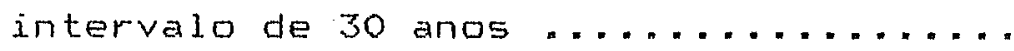

Tabela b. Parametros estatisticos referentes aos dados de evapotranspiração do mês de marco, para os periodos de $5,10,15$ e 30 dias, de um intervalo de 30 anos....

Tabela 7. Parâmetros $P$ e $q$ da distribuçăo Beta para os dados de evapotranspiraça do més de março, para os períodos de 5, 10 ,

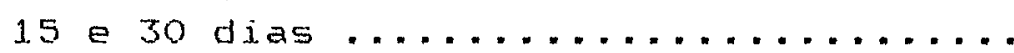
50

Tabela 8. Evapotranspiraçăo de referencia calculada atraves da distribuição Beta para as pentadas do mes de março, em funçăo de diversos niveis de probabilidade de ocorrencia $\ldots \ldots \ldots \ldots \ldots \ldots \ldots \ldots$

Tabela 9. Evapotranspiraça de referencia obtida atraves da distribuiço Beta para os periodos de 10,15 e 30 dias do més de marco, em funça de diversos niveis de pro-

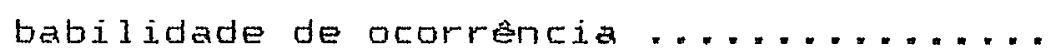


Tabela 10. Relação entre a evapotranspiraçăo ao nivel de $75 \%$ de probabilidade em um determinado periodo e a evapotranspiracáo a $75 \%$ de probabilidade para o periodo de 30 dias, para o mes de marco ..........

Tabela 11. Estudo comparativo entre a evapotranspiraça ao nível de $75 \%$ de probabilidade e a evapotranspiraçăo média, para os perlodos de $5,10,15 e 30$ di.as do mês de $\operatorname{margo} \ldots \ldots \ldots \ldots \ldots \ldots \ldots$

Tabela 12. Evapotranspiraço de referencia obtida atraves da distribuicóso Normal para as pentadas do mês de março, en funçăo de diversos niveis de probabilidade de

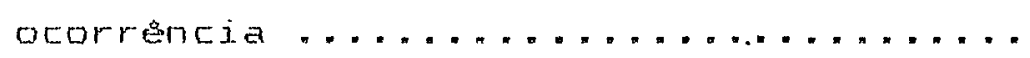

Tabela 13. Evapotranspirarăo de referencia obtida atraves da distribuicão Normal para os perílodos de 10,15 e 30 dias do més de marco, em funçăo de diversos niveis de

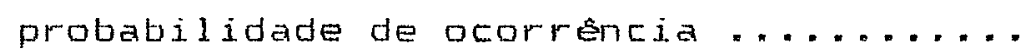


Tabela 14. Valores da evapotranspiraça de referencia para as pentadas do més de setembro, para um periodo de 30 anos...

Tabela 15. Valores da evapotranspiraçóo de referencia para os periodos de 10,15 e 30 dias do mes de setembro. para um

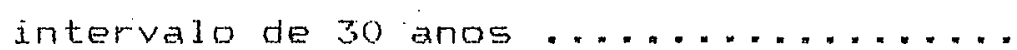

Tabela 16. Parametros estatisticos referentes aos dados de evapotranspiração do mes de setembro, para os periodos de $5,10,15$ e 30 dias, de um intervalo de 30 anos ..

Tabela 17. Parametros p e q da distribuição Beta para os dados de evapotranspiraçăo do mes de setembro, para os periodos de $5,10,15$ e 30 dias $\ldots \ldots \ldots \ldots \ldots \ldots \ldots$

Tabela 18. Evapotranspiração de referência calculada atraves da distribuiça Beta para as pentadas do mes de setembro, en funçăo dos diversos niveis de probabilidade de

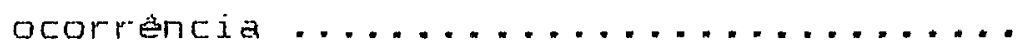


Tabe1a 19. Evapotranspiraçăo de referência obtida através da distribuiçäo Beta para os periodos de 10,15 e 30 dias do més de setembro, em função dos diversos niveis de probabilidade de ocorrencia ........

Tabela 20. Relaçăo entre a evapotranspiraçăo ao nivel de $75 \%$ de probabilidade em un determinado periodo e a evapotranspiração a $75 \%$ de probabilidade para o periodo de 30 dias, para o mess de setembro ......

Tabela 21. Estudo comparativo entre a evapotranspiraçăo ao nivel de $75 \%$ de probabilidade e a evapotranspiraçăo média, para os periodos de $5,10,15$ e 30 dias do més de

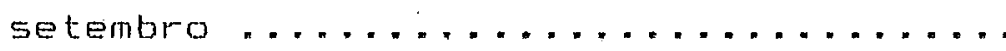

Tabela 22. Evapotranspiraçăo de referencia obtida atraves da distribuiçăo Normal para as pentadas do mês de setembro, em funça de diversos niveis de probabilidade de

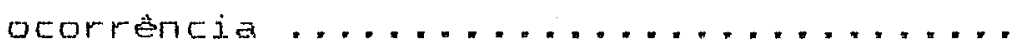


Tabela 23. Evapotranspiraço de referéncia obtida atraves da distribuiçăo Normal para os periudos de 10,15 e 30 dias do més de setembro, em função de diversos niveis de probabilidade de ocorrência ..........

Tabela 24. Valores da precipitaçăo pluvial, em ordern decrescente, para as pentadas do mès de março, para um periodo de 71 anos

80

Tabela 25. Valores da precipitacăo pluvial, em ordem decrescente, para os perfodos de 10,15 e 30 dias do més de março, para

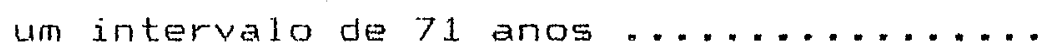

Tabela 26. Parâmetros estatisticos referentes aos dados da precipitaçăo pluvial do mes de marco, para os períodos de 5, 10, 15 e 30 dias, de um intervalo de 71 anos....

Tabela 27. Parsmetros $\alpha \quad \beta \quad \beta$ da distribuiça Gama litilizada na distribuiça Mista, para os dados de precipitação pluvial do més de marco, para os periodos de $5,10,15$ e 30 dias $\ldots \ldots \ldots \ldots \ldots \ldots \ldots \ldots$ 
Tabela 28. Precipitaçăo pluvial obtida atraves da distribuicăo Mista para as pentadas do mês de março, en função dos diversos níveis de probabilidade de ocorrencia..

Tabela 29. Precipitaça pluvial obtida através da da distribuição Mista para os periodos de 10,15 e 30 dias do mês de março, em funçăo de diversos míveis de probabili-

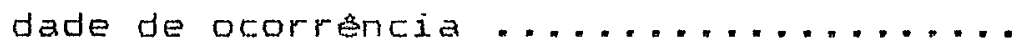

Tabela 30. Estudo comparativo entre a precipitaçao pluvial ao nivel de $75 \%$ e a precipitaça pluvial media, para os períados de 5 , 10,15 e 30 dias do mês de março .......

Tabela 31 . Valores da precipitaço pluvial, em ordem decrescente, para as pentadas do més de setembro, para um periodo de 71

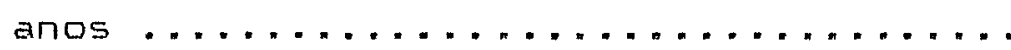


Tabela 32. Valores da precipitaçăo pluvial, em ordem decrescente, para os periodos de 10, 15 e 30 dias do mes de setembro,para un intervalo de 71 anos $\ldots \ldots \ldots \ldots \ldots$

Tabela 33. Parametros estatisticos referentes aos dados da precipitaçăo pluvial do mess de setembro, para os perfodos de 5, 10, 15 e 30 dias, de um intervalo de 71 anos..

Tabela 34. Parämetros $\alpha e \beta$ da distribuiçăo Gama utilizada na distribuiçăo Mista para os dados de precipitaçăo pluvial do mes de setembro, para os periodos de 5, 10 e

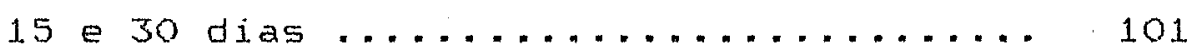

Tabela 35. Precipitaçăo pluvial obtida atraves da distribuiçăo Mista para as pentadas do més de setembro, em funçăo de diversos niveis de probabilidade de ocorrencia.. 
Tabela 3b. Precipitaçăo pluvial obtida atraves da distribuicăo Mista para os periodos de 10, 15 e 30 dias do mes de setembro, em funçăo de diversos niveis de probabili-

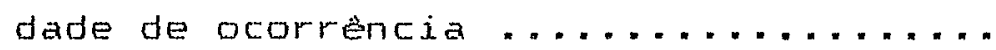

Tabela 37 . Estudo comparativo entre a precipitacăo pluvial ao nivel de $75 \%$ de probabilidade e a precipitaçăo pluvial media, para os periodos de 5, 10, 15 e 30 dias do mes de setembro $\ldots \ldots \ldots \ldots \ldots \ldots \ldots \ldots \ldots$ 
$x \times i i$

\section{LISTA DE ABREVIATURAS E SIMBOLOS}

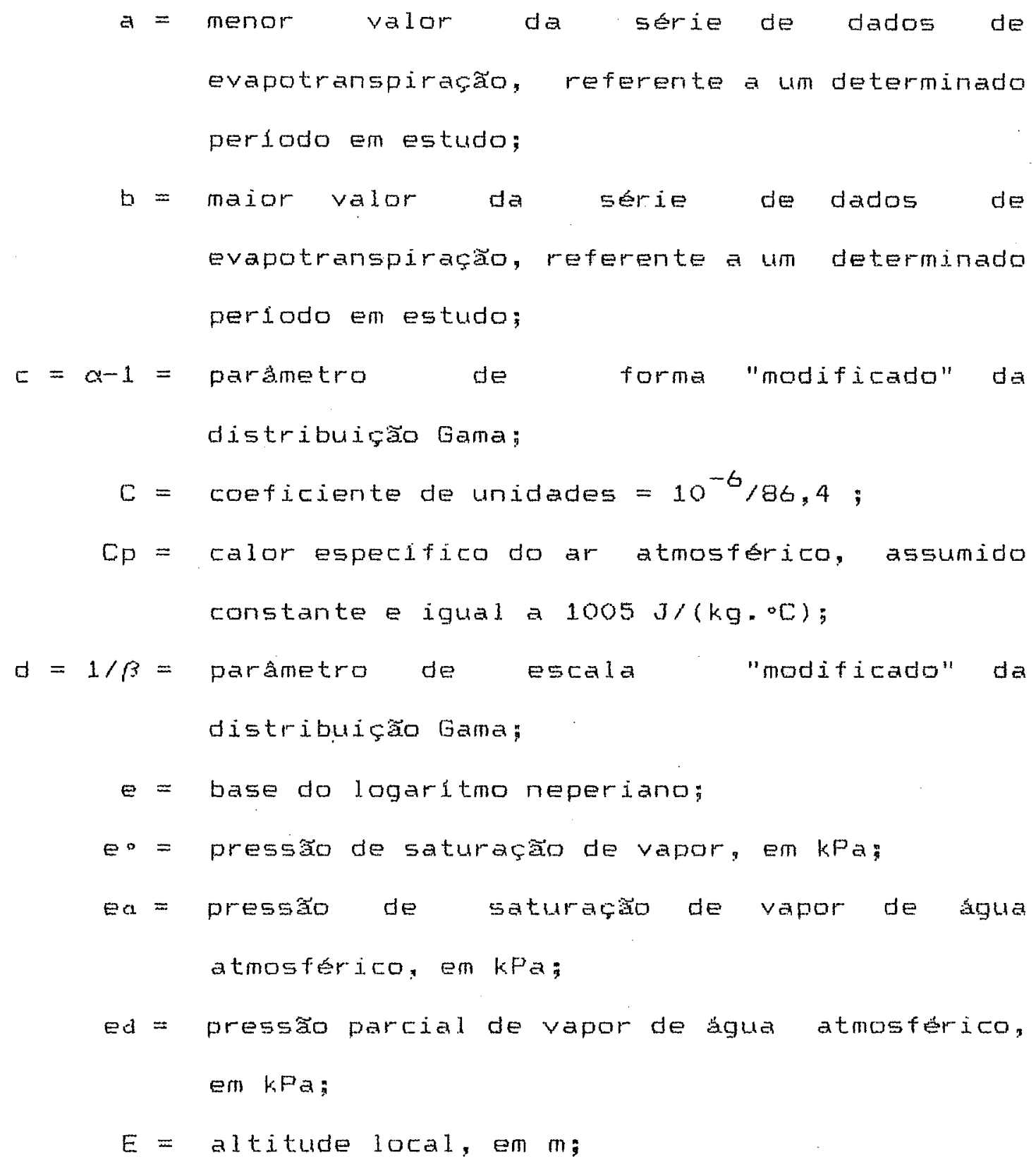


Ea = termo aerodinamico de vapor de água ou poder evaporante do ar, em $\mathrm{w} / \mathrm{m}^{2}$;

Ef = eficiência da irrigaçăo:

ETo = evapotranspiraça da cultura de referencia (neste estudo, grama), em $\mathrm{mm} / \mathrm{dia}$

(ETo)p = evapotranspiraçăo da cultura de referencia no nivel de probabilidade desejado;

$f(x)=$ funçăo densidade de probabilidade da distribuiçăo Beta para asx cb;

$f\left(x^{\prime}\right)=$ funçăo densidade de probabilidade da distribuicăo Beta para $0 \leq x^{\prime} \leq 1$;

$F\left(x^{\prime}\right)=$ distribução acumulada Beta incompleta para $0 \leq x^{\prime} \leq 1$, ou probabilidade de que a evapotranspiracào de um dado periodo não exceda um valor $x^{\prime}$;

$g(y)=$ funçăo densidade de probabilidade da distribuça Gama incompleta, para $y \geq 0$

$G=f l u \times o$ de calor para o solo, en $\mathrm{w} / \mathrm{m}^{2}$;

$G(y)=$ distribuiço acumulada Gama incompleta, ou probabilidade de que a precipitaçăo em um dado perífodo nado exceda un valor y seja menor ou igual a y);

$G\left(y^{\prime}\right)=$ distribuiça acumulada Gama incompleta, calculada utilizando valores de y maiores ou iguais a 1 , ou seja, utilizando $y^{\prime}$;

$G(v)=$ distribuiço acumulada Gama incompleta, calculada atraves do desenvolvimento en série, 
ou seja, E a probabilidade de ocorrencia de um valor menor ou igual a $y^{\prime}$, uma vez que $v=y^{\prime} / \beta$

$h=$ tamanio do sub-intervalo adotado para aplicacăo do método de simpson de calculo aproximado de integrais definidas;

$I=$ probabilidade de ocorrencia de precipitaça pluvial (y)1), utilizada na distribuifão Mista

$j$ = total de dados que compóm a serie analisada de valores de evapotranspiraçăo ou número de anos de observaçáo deste evento;

$J=$ número de valores iguais a zero na serie de dados de precipitação pluvial do periodo considerado;

$K=$ probabilidade de não ocorrencia na precipitaça pluvial (y=0), utilizada na distribuição Mista

$K c=$ coeficiente de cultura durante o persodo de máxima exigencia hidrica;

In = operador do logarltmo neperiano;

$m=$ numero de orden de un determinado valor de precipitaço pluvial, pertencente a uma sórie decrescente de dados ( $m$ varia de 1 a $n$ ):

$M=$ abreviatura indicativa do mes de Marco;

$M(y)=$ distribujçăo acumulada Mista ou probabilidade de que a precipitaço de um dado periodo nao 


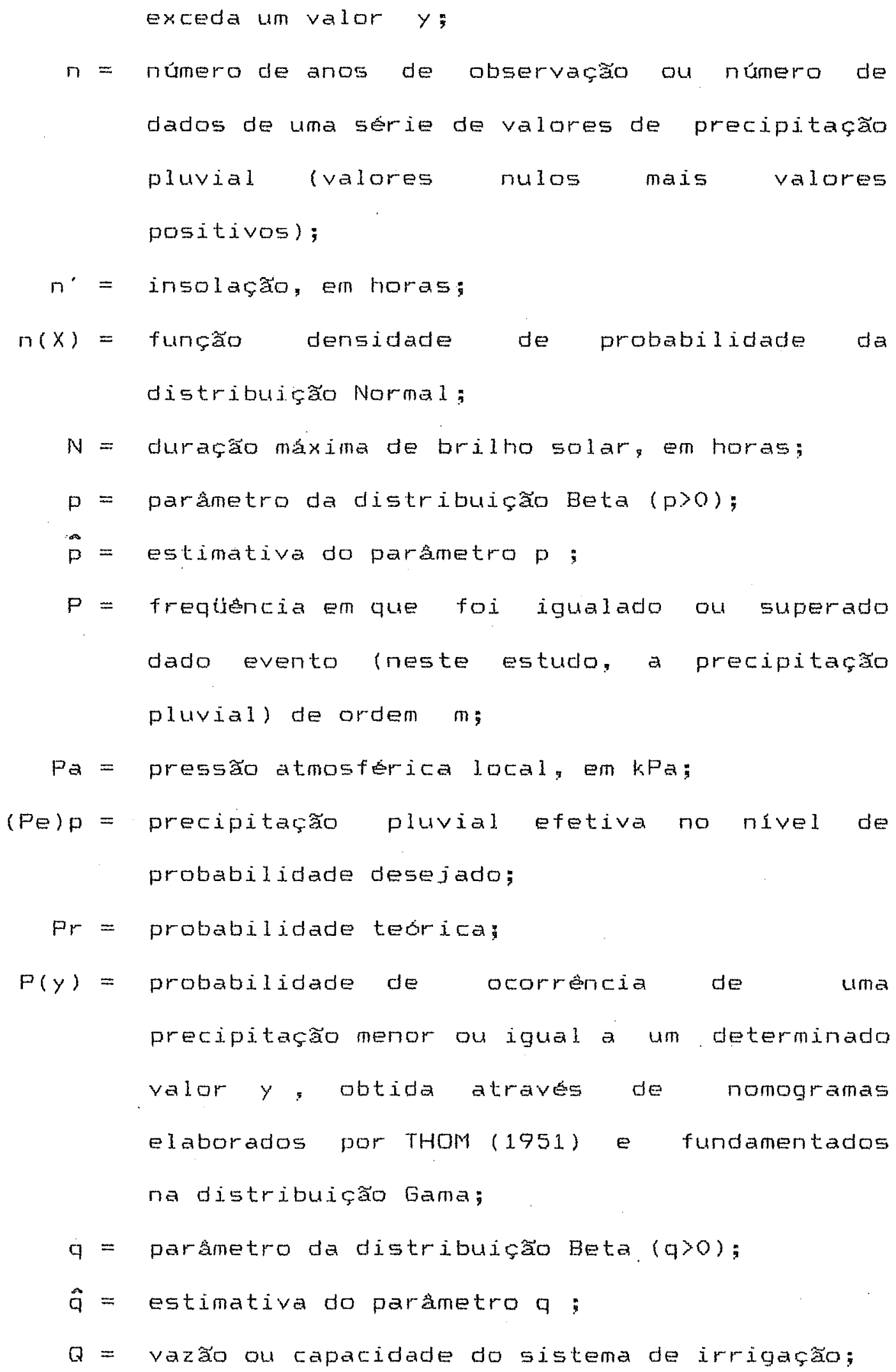




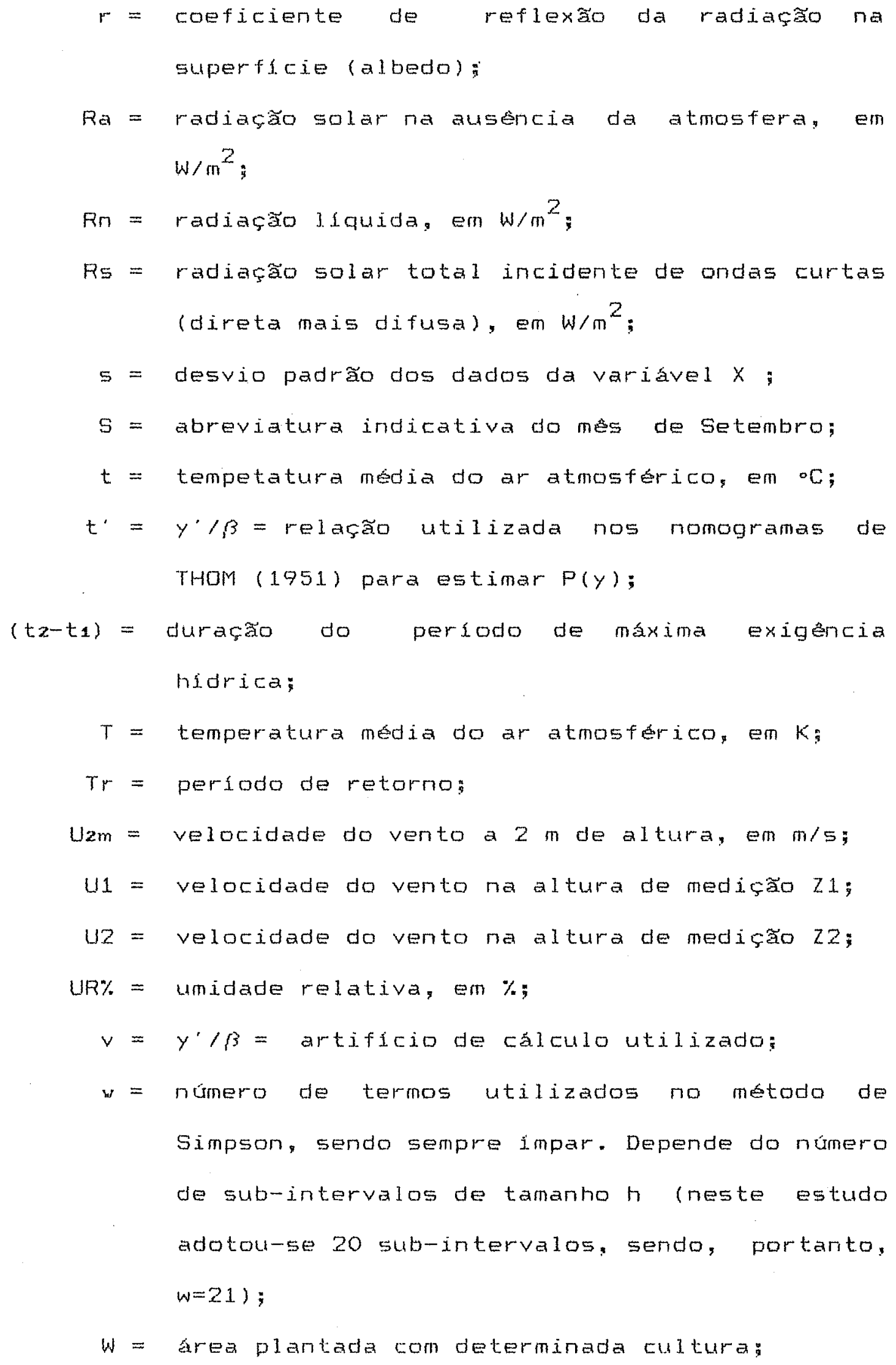




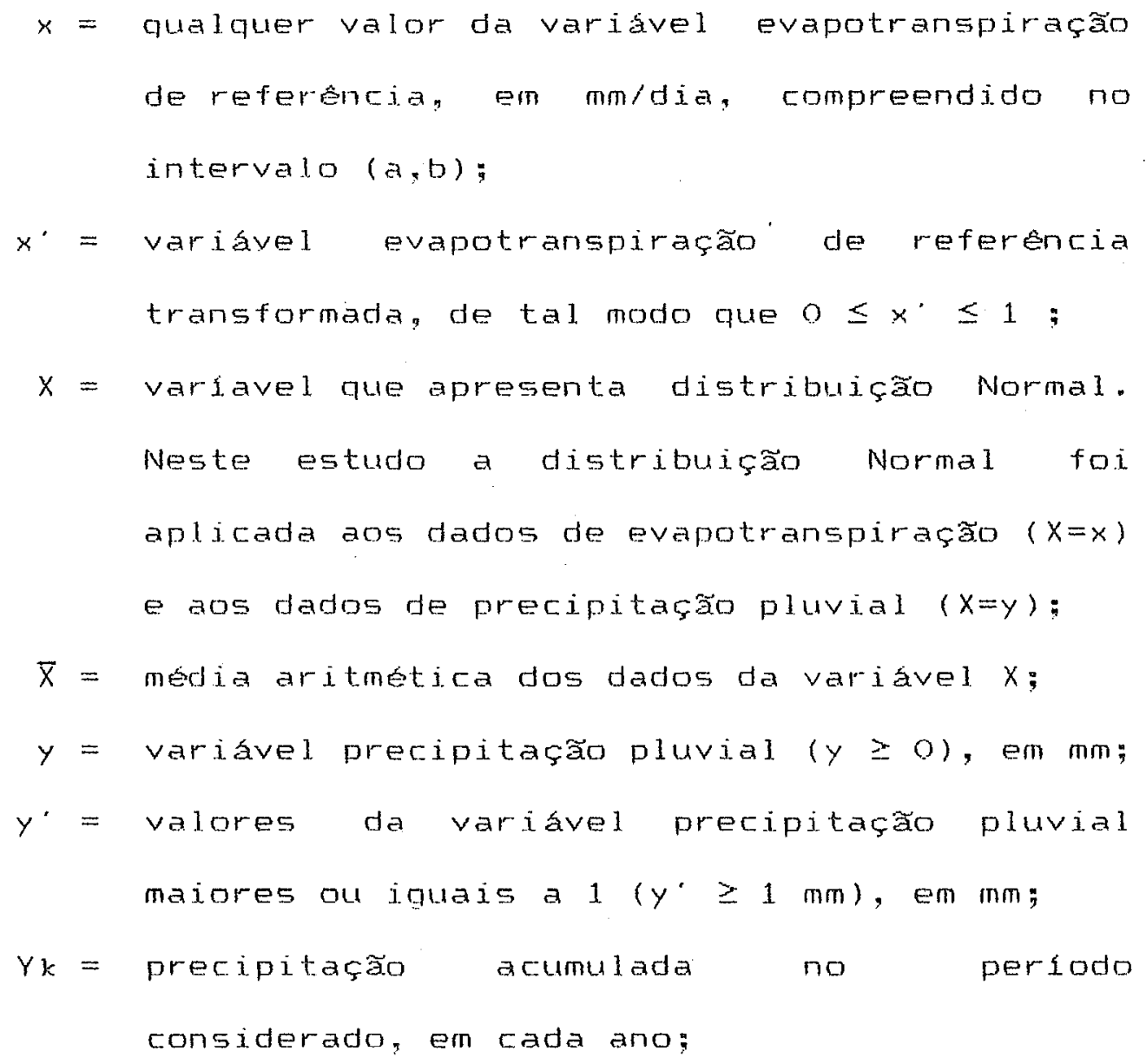


$\Delta=$ inclinaçăo da curva de variação da pressão de saturaçăo de vapor de água com a temperatura (de*/dt);

$\Delta e=$ deficit de pressão de vapor de aqua atmosferico, em kPa;

$\lambda=$ calor latente de vaporização da água, en $\mathrm{J} / \mathrm{kg}$

$\mu_{1}=$ momento de ordem 1 da variável $x^{\prime}$;

$\mu z=$ momento de ordem 2 da variável $x^{\prime}$;

$\pi=3,14159$

ow = massa especifica da água, en $\mathrm{kg} / \mathrm{m}^{3}$;

$\sigma=$ constante de Stefan-Boltzmann $=5,673114.10^{-B}$ $w /\left(m^{2} \cdot k^{4}\right)$. 
ESTUDO DAS DISTRIBUIÇOES DE FREQUENCIA DA EVAPOTRANSPIRAÇX̃O DE REFERENGIA E DA PREGIPITAĢOO PLUVIAL PARA FINS DE DIMENSIONAMENTO DE SISTEMAS DE IRRIGAGAOO

Autor: JOAO GARLOS CURY SAAD Orientador: PROF. DR. KLAUS REI GHARDT

\section{RESUMO}

Utilizando dados de 71 anos de precipitaçăo pluvial e de 30 anos de evapotranspiraçăo de referencia, estimada pelo método de Penman, procedeu-se à análise da distribuigão de frequência destes eventos, aplicada aos periodos de 5 dias, 10 dias, 15 dias e mensal, referentes aos meses de março e setembro, para a região de Piracicaba, SP.

Atraves do teste de Kolmogorov-Smirnov, verificou-se que os dados de precipitaçăo podem ser representados por uma distribuição Mista, envolvendo a distribuição Gama, enquanto que os de evapotranspiração de referência podem ser caracterizados pelas distribuiçóses Beta e Normal, sendo esta última de maior praticidade na aplicação.

Analisando os dados de evapotranspiração verificou-se que os mesmos estavam relativamente 
agrupados, sendo recomendável o estudo de distribuição de frequiência. Os dados revelaram que à medida que diminui o intervalo em dias, aumenta o valor da evapotranspiraçăo.

Já os dadoss de precipitação pluvial apresentaram grande dispersão, sendo fundamental a análise de frequiencia a fim de se proceder a um dimensionamento adequado dos sistemas de irrigação.

o uso de valores médios mensais de precipitação, quando comparados ao critério de dimensionamento que estabelece a probabilidade de $75 \%$ como sendo a mais indicada, mostrou ser uma prática que conduz ao subdimensionamento dos sistemas de irrigação.

o dimensionamento de sistemas de irrigação depende do uso criterioso de estimativas da v evapotranspiração e, fundamentalmente, das est.imativas da pinecipitação pluvial. 
STUDY OF REFERENCE EVAPOTRANSPIRATION AND RAINFALL FREQUENCY DISTRIBUTIONS AS RELATED TO IRRIGATION SYSTEMS DESIGN.

Author: JOAO GARLOS GURY SAAD Adviser: PROF. DR. KLAUS REI GHARDT

SUMMARY

Using 71 year rainfall and 30 year reference evapotranspiration data an analysis of their frequency distributions was made with the objective of improving irrigation systems design. These parameters were studied using time periods of $5,10,15$ and 30 days, during the months of March to September, for the region of county of Piracicaba, SP.

Through the Kolmogorov-Smirnov test it was verified that rainfall data can be represented by Gamma distributions, whereas reference evapotranspiration data follow Beta distributions and Normal distributions.

The analysis of evapotranspiration data showed that values are relatively gathered, leading to the conclusion that distribution analysis is useful. Data indicated that as time intervals are decreased, the value of evapotranspiration increases. 
On the other hand, rainfall data presented high dispersion, indicating the need of frequency analysis in order to use the data for the design of irrigation systems.

The use of monthly mean rainfall values, when compared to the design criterium that establishes the probability of $75 \%$ as being the most suitable, showed to be a procedure that leads to underestimations in irrigation systems design.

The design of irrigation systems depends on the criterious use of evapotranspiration estimates and, mainly, of rainfall estimates. 


\title{
1. INTRODUÇ̃̃O
}

\begin{abstract}
A água é fator fundamental na produção vegetal, tendo sua falta ou excesso influencia decisiva no desenvolvimento das plantas. Por esta razão, o conhecimento da exigencia em água das culturas, bem como o manejo racional dos recursos hídricos, são fatores fundamentais na maximização da produçăo agrícola.
\end{abstract}

Segundo MAROUELLI \& SEDTYAMA (1987), o Brasil, apesar de não contar com rigores climáticos excessivos, é dotado de uma diversidade de tipos climáticos. A distribuição da precipitaçăo atmosférica sobre seu território e bastante variável, estando, contudo, a maior parte das regiores sob clima úmido e semi-úmido. Nestas regiōes, de maneira geral, a quantidade de precipitação é suficiente para o bom desenvolvimento das culturas no periodo chuvoso, porém, frequentemente, ocorrem períodos de escassez de chuva durante os estádios mais criticos da cultura, resultando em sensiveis perdas de produçăo. Para solucionar este problema, utiliza-se a irrigação suplementar, que visa, justamente, corrigir a distribuição irregular das precipitaçöes. Entretanto, 
quase todos os projetos de irrigação desenvolvidos no Brasil săo dimensionados em termos de irrigaçăo total, ou seja, visando suprir toda a demanda hidrica da cultura, sem levar em conta a precipitação pluvial.

o dimensionamento de sistemas de irrigação em termos de irrigação total é valido quando se trata de regiós áridas e semi-áridas, como e o caso de determinadas regiơes do nordeste brasileiro. Em se tratando de regiôes úmidas e semi-úmidas, tal prática resulta num superdimensionamento dos sistemas de irrigação.

A evapotranspiração e a precipitação săo parâmetros fundamentais na estimativa da exigência em água das culturas. Apesar de numerosos, nenhum método de estimativa da evapotranspiração parece desfrutar de uma preferencia absoluta. Segundo SAAD \& SCALOPPI (1988a), na maioria das vezes, a indisponibilidade de parâmetros específicos limita o emprego de métodos mais precisos e favorece os métodos mais simples, nem sempre proporcionando resultados satisfatórios. Além disso, a grande variabilidade de valores assumidos pelos parametros meteorológicos durante o periodo de máxima exigência hidrica das culturas irrigadas, acarreta consideravel dispersão dos valores calculados da evapotranspiração,

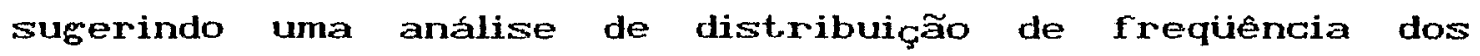
valores estimados, para fins de dimensionamento de sistemas de irrigação (SAAD \& SCALOPPI, 1988b). 
Uma vez que a precipitação é o parametro mais variável dos modelos de estimativa da exigência em água das culturas, é fundamental o estudo de distribuição de frequéncia de seus valores num determinado intervalo de anos. Segundo FRIZZONE (1979), em muitos casos utiliza-se - valor da precipitação média mensal no balanço hídrico para fins de dimensionamento de sistemas de irrigação, o que, em geral, acarreta um subdimensionamento do projeto.

o uso de estimativas da necessidade de água das culturas obtidas sem nenhum criterio ou resultantes de modelos nem sempre capazes de proporcionar resultados confiáveis, tem se refletido, na maioria das vezes, num dimensionamento inadequado dos sistemas de bombeamento, de adução e distribuição, de aplicação de água às culturas, e de remoção da água excedente, caracteristicos de cada sistema de irrigação.

A identificiaçäio da necessidade de agua também influencia no planejamento e operação de programas estrategicos de desenvolvimento local ou regional, baseados na utilizaçăo de recursos hidricos.

Est.e trabalho tem como objetivo estudar a distribuição de frequienciass da evapotranspiração de referencia e, tambem, da precipitação pluvial, para a região de Piracicaba, SP, visando a obtençăo de estimativas criteriosas da exigencia em água das culturas, que f fator fundamental no dimensionamento de sistemas de irrigação. 


\section{REVISTOO DE LITERATURA}

\subsection{Evapotranspiraçăo de referência}

\subsubsection{Consideraçöes gerais}

Antes de caracterizar o metodo de estimativa da evapotranspiraçăo adotado neste trabalho, torna-se oportuno caracterizar a terminologia empregada nesta dissertação.

Segundo BURMAN et alii (1983), a evapotranspiraçăo pode ser definida como um processo combinado de transferéncia de água do solo para atmosfera, incluindo a evaporação da agua diretamente da superficie do solo ou da vegetação e, também, o processo de transpiração através dos tecidos vegetais. A evapotranspiração pode ser expressisa como calor latente transferido para o ar atmosférico por unidade de área $\left(W / m^{2}\right)$ ou a quantidade equivalente de agua evapotranspirada por unidade de tempo, geralmente expressa como lâmina por unidade de tempo (mm/dia).

A evapotranspixação potencial de referencia 
(ETO) é definida como sendo a quantidade de ácua evapotranspirada por uma cultura de baixo porte, verde, cobrindo totalmente o solo, de altura uniforme e sem deficiencia hidrica. Para esta superfície, as condiçŏes climáticas comandam o processo evapotranspirativo. Em vista disto, a evapotranspiração potencial de referencia é tomada como um elemento meteorológico de referéncia para estudos comparativos de perda de água pela vegetação, em diferentes situaçöes e locais (REICHARDT, 1987 ).

Em relação a cultura de referencia, os pesquisadores dividem-se entre a srama e a alfafa. DOORENBOS \& PRUIT (1984) adotaram como sendo a evapotranspiração potencial de referencia, a evapotranspiração de uma extensa superfície totalmente coberta com grama verde, tendo altura uniforme, variável entre 8 e $15 \mathrm{~cm}$, em fase de crescimento ativo, e adequadamente suprida com agua. No Brasil, adota-se a grama forquilha (Paspalum notatum, L.).

WRIGHT \& JENSEN (1972) defenderam a idéa de que uma cultura de referencia deveria apresentar características aerodinámicas e morfológicas semelhantes as principais culturas. As características aerodinâmicas afetam a adveçăo de calor sensivel, enquanto uma arquitetura foliar na qual as folhas eståo dispostas em camadas, resulta em maior absorçăo da radiação solar, antes desta atingir a superficie do solo. Por estas razóes, elegeram a alfafa que possui de 30 a $50 \mathrm{~cm}$ de 
altura, em fase de crescimento ativo e sem restriçöes no fornecimento de ácua no solo, como cultura de referéncia.

$$
\text { A determinação da evapotranspiração }
$$

potencial para uma unica cultura de referência simplifica a estimativa da evapotranspiração de outras culturas irrigadas em diferentes estádios fenológicos, através de relações empiricas denominadas coeficientes de cultura.

Tanto o método de estimativa da evapotranspiração como o coeficiente de cultura devem estar baseados na mesma cultura de referencia. Assim, os coeficientes de cultura determinados em função da alfafa como cultura de referencia não devem ser utilizados com os métodos propostos para estimar a evapotranspiração da cultura de referência-grama. O inverso também deve ser evitado.

2.1.2. Seleção do método para estimativa da da evapotranspiração de referência

JENSEN (1974) analisou quinze métodos de estimativa da evapotranspiraçăo de referência, comparando seus resultados com valores observados em dez localidades apresentando condiçöes climaticas bastante distintas. Concluiu que equaçós que ut.ilizam o balanço de energia ou balanço de energia associado ao termo aerodinâmico fornecem os resultados mais precisos, uma vez que baseiam-se em leis físicas e relaçöes racionais. Dentre 
estas, o método de Penman destaca-se como o mais apropriado.

\subsubsection{Método de Penman}

A equação de PENMAN (1948) foi proposta para estimativa da evaporaçăo em superficies livres d’agua e para solo nu. Ela é muito eficiente, pois utiliza um modelo associativo aero-energético no cáculo da estimativa da evapotranspiração. Como as superficies vegetadas diferem significativamente das superficies livres d’água, no que concerne à rugosidade e, consequientemente, na estrutura do vento, algumas modificaçŏes foram introduzidas para possibilitar seu uso na estimativa da evapotranspiração das culturas.

ALLEN (1986) comparou 10 formas do método de Penman com mediçóes feitas em lisimetros instalados em Kimberly,Idaho; Coshocton, Ohio; e Davis, Califórnia; representantes, respectivamente, de região arida irrigada, região ümida com indice de precipitação pluvial suficiente e região de clima mediterraneo - Dentre as versós analisadas, o modelo de Penman-Monteith foi o que forneceu melhores estimativas, porém sua utilização e bastante limitada devido aos parámetros requeridos, os quais não são convencionalmente medidos, como e o caso da temperatura da folha. 
programa multi-alternativo de estimativa da evapotranspiração de referência, utilizando o método de Penman-Monteith com algumas adaptaçöes. o programa foi aplicado a dados referentes a Kimberly, Idaho, num total de 35 alternativas de cálculo, sendo que o maior desvio entre os valores estimados e o valor medido da evapotranspiração foi de $-17,5 \%$.

O método de Penman-Monteith requer estudos mais intensos para que possa ser utilizado de forma criteriosa, em nossas condi cós.

2.1.4. Distribuição de frequência da
evapotranspiração

Poucos locais do mundo apresentam registros de evapotranspiração de uma única cultura por um período suficiente para possibilitar uma analise de distribuição de frequência. Um desses locais refere-se aos dados obtidos com lisimetro em Davis, Califórnia, continuamente cultivado com grama desde junho de 1959 CPRUITT et alii, 19723. Estes dados permitiram a estes autores estabelecer a distribuição de frequencia da evapotranspiração diaria para todos os meses do ano, em períodos de $1,3,5,7,15$ e 30 dias consecutivos, para a regiăo central da Califórnia. Trabalho semelhante foi apresentado por NIXON et alii (1972) para a região costeira da Califórnia. 
evapotranspiração de uma cultura de alfafa bem suprida de agua, obtidos durante dois anos em lisimetro pesável de precisão para desenvolver e avaliar procedimentos para estimativa da evapotranspiração, a partir de parámetros climaticos, para a região sul de Idaho, EUA. Estes procedimentos foram utilizados para cálculo da evapotranspiração por um periodo de cinco anos, cujos resultados permitiram avaliar a distribuiģão de frrequencia para periodos consecutivos de $1,3,5,7,15$ e 30 dias. Através dos resultados obtidos foi possivel identificar significativas diferenças entre os valores de evapotranspiração computados. Além disso, os períodos de maior exigência hídrica puderam ser facilmente identificados, demonstrando a necessidade de se efetuar esta análise em planejamentos precisos de engenharia de irriģação.

o emprego da análise de distribuiğăo de frequencia aos dados mensais de evaporação do tanque IA-58, para Ribeirão Preto, SP, foi conduzido por ARRUDA \& BARROSO (1984). Utilizando dados registrados no periodo de 1967 a 1975 e aplicando a distribuição Normal, os autores concluiram que os valores médios mensais correspondentes ao nivel de $75 \%$ de probabilidade foram significativamente superiores aos valores médios mensais registrados no periodo. Estas diferenças atingiram valores máximos de $34 \%$ no mês de dezembro e $32 \%$ no mes de março. Esta análise, porém, não foi aplicada a períodos mais curtos, 
representativos dos periodos de máxima exigéncia hídrica das culturas irrigadas, normalmente desenvolvidas na regiăo.

SAAD \& SGALOPPI (1988b) aplicaram o método de Penman-Monteith a dados meteorológicos de Piracicaba, SP, e realizaram, então, estudos sobre a diştribuição de frequéncia das estimativas da evapotranspiração, através do uso da distribuição Normal. Os resultados obtidos permitem que se proceda à seleção de valores representativos da evapotranspixaçăo, em períodos consecutivos de 1 a 30 dias, e niveis de probabilidade variáveis entre 2 e $98 \%$.

YAO (1969) verificou que a distribuição de frequéncia de $u m$ indice $R$ relacionado com a evapotranspiração de referência, ajustou-se satisfatoriamente com a distribuiçăo Beta, para períodos de quinze dias e mensais.

Os dados de umidade relativa de 19 Estaçōes Meteorológicas dos EUA, para períodos médios de $5,10,15$ e 30 dias, ajustaram-se, de forma estatisticamente consistente, à distribuiçăo Beta cYAo, 1974).

o indice de umidade definido por BISHNOI (1980) como sendo a relaçăo entre a evapotranspiração atual e a evapotranspiração potencial de referência, também ajustou-se significativamente à distribuição Beta. 


\subsection{Precipitaçăo pluvial provável ou dependente}

\subsubsection{Consideraçöes gerais}

A precipitação provável ou dependente aquela precipitação mínima que tem uma probabilidade especifica de ocorrência, baseada na análise de uma longa série de dados.

Segundo HOLTZ (1973), os dados observados nos postos hidrométricos são analisados estatisticamente, ou seja, verifica-se com que frequência eles assumiram determinada magnitude e, em seguida, pode-se analisar as probabilidades teóricas de ocorrencia dos mesmos. os dados de precipitaçăo săo classificados em ordem decrescente e a cada dado é atribuído um número de ordem $m<m$ variando de 1 a $n$, sendo $n$ o número de anos de observação). Três equaçóses podem ser utilizadas para determinar a frequéncia (P) em que foi igualado ou superado dado evento de ordem $m$ (FRIZZONE, 1979): equaçăo de Hazen, equação de Kimball e equaçăo da Califónnia.

A equaçäo de Hazen tem a seguinte forma:

$$
P=\frac{(2 \cdot m)-1}{2 \cdot n}
$$


As equaçŏes de Kimball e Califónnia săo descritas, respectivamente, por:

$$
\begin{aligned}
& P=\frac{m}{n+1} \\
& P=\frac{m}{n}
\end{aligned}
$$

Admitindo-se que a frequencia (P) é uma boa estimativa da probabilidade teórica (Pr) e definindo-se o periodo de retorno (Tr) como sendo o intervalo médio de anos em que um determinado evento deve ser igualado ou superado, pelo menos uma vez, tem-se a seguinte relação:

$$
\mathbf{T r}=\frac{-1}{P}, \quad \text { ou } \quad T \mathbf{T}=\frac{1}{\mathrm{Pr}}
$$

Para periodos de recorrencia bem menores que o número de anos de observação, o valor encontrado para $P$ pode resultar numa boa aproximaçăo do valor real de Pr. Entretanto, para grandes periodos, deve-se adotar outro procedimento, ou seja, a distribuição de frequència deve ser ajustada a uma lei de probabilidade teórica, de modo a possibilitar um calculo mais preciso da probabilidade (MAROUELLI \& SEDIYAMA, 1987 ). 
2.2.2. Distribuição de frequiencia da precipitação pluvial

Considerando uma simples curva de
distribuição de frequências, a média aritmética é uma das
variaveis utilizadas para determinar a distribuição Normal. Nessa distribuição, a linha vertical de simetria passa pela média da distribuição, sendo trambém o valor da mediana e da moda. A distribuição Normal ajusta-se bem a muitas variáveis climáticas que não são limitadas superior e inferiormente. Porém, as precipitaçöes em pequenos periodos são, em geral, limitadas inferiormente pelo yalor zero, o que dificilmente thes confere uma distribuição Normal.

BARGER \& THOM (1949), através de análises em histogramas de rrequencia de precipitação, verificaram que as distribuiçớs de precipjtaçớes diárias e semanais ajustam-se a uma curva exponencial negativa. Já para periodos iguais ou superiores a quatro meses, estas aproximam-se da distribuiçăo Normal. Entretanto, constataram, támbém, que qualquer dos periodos anteriormente citados, poderia ser ajustado através de uma curva de Pearsons tipo III. Forģando esta curva a passar pela origem, a fim se evitar valores negativos de precipitação, os autores verificaram que ela passa a ser a distribuição Gama incompleta, a qual recomendaram para estudos de precipitação em pequenos periodos. 
Seja y uma varibvel aleatória que assume apenas valores näo negativos. Diz-se que y tem uma distribuição de probabilidade Gama incompleta, caso sua tunģ̄o densidade de probabilidade g(y), apresentada por THOM (1958), seja dada por:

$$
\delta(y)=\frac{1}{\alpha+\rho(\alpha)} \cdot y^{\alpha-1} \ldots e^{-y / \beta}
$$

sendo, $\beta>0, \alpha>0,0 \leq y<\infty$ e $6(y)=0$ para outros intervalos; onde $\beta$ e parametro de esciala Cdepende da variabilidade das precipitaçóes no periodo $; \quad \alpha \quad e$ o parametro de forma cseu valor é proporcional à precipitação no período); $\Gamma^{-}$é o simbolo da função Gama; e e a base do logaritmo neperiano. Neste estudo, y e a precipitação pluvial no periodo.

A runção Gama, segundo MILLER \& WEAVER (1968), é definida por:

$$
\Gamma(\alpha)=r_{0}^{\infty} e^{-y} \cdot y^{\alpha-1} \cdot d y
$$

sendo $0 \leq y \leq w . \quad$ e $a>0$

A formula de recorrência para a função Gama é (SPIEGEL, 1976):

$$
\Gamma(\alpha+1)=\alpha \cdot \Gamma(\alpha)
$$


onde $\Gamma(1)=1$. Através da eq. (7) possivel se determinar $\Gamma(\alpha)$ para todo $\alpha>0$, desde que se conheça os valores de $\Gamma(\alpha)$ para $1 \leq \alpha \leq 2$ (Tabela 1 ) ou qualquer outro intervalo de valor unitário.

Tabela 1 - Valores de $\Gamma(\alpha)$ para $1 \leq \alpha \leq 2$.

\begin{tabular}{cc}
\hline$\alpha$ & $\Gamma(\alpha)$ \\
\hline 1,00 & \\
1,10 & 1,0000 \\
1,20 & 0,9514 \\
1,30 & 0,9182 \\
1,40 & 0,8975 \\
1,50 & 0,8873 \\
1,60 & 0,8862 \\
1,70 & 0,8935 \\
1,80 & 0,9086 \\
1,90 & 0,9314 \\
2,00 & 0,9618 \\
& 1,0000 \\
\hline
\end{tabular}

Fonte: SPIEGEL (1976)

Em particular, se $\alpha$ é um numero inteiro positivo, então :

$$
\Gamma(\alpha+1)=(\alpha) !
$$

(B)

Se $\alpha$ for muito grande, o cálculo de $\Gamma(\alpha)$ pela eq.(7) torna-se muito trabalhoso. Neste caso, utiliza-se a série assintótica de Stirling para a função Gama, dada por :

$$
\Gamma(a+1)=(2 \cdot \pi \cdot a)^{1 / 2} \cdot a^{\alpha} \cdot e^{-\alpha} \cdot\left[1+\frac{1}{12 a}+\frac{1}{288 \alpha^{2}}-\frac{139}{51840 \alpha^{3}}+\cdots 1\right.
$$


A funçăo densidade de probabilidade da distribuiģăo Gama $g(y)$ e possitivamente assimetrica e o grau de assimetria depende inversamente do parametro de forma $\alpha$. A moda da distribuiçăo é $\beta(\alpha-1)$ se $\alpha>1$, e zero se $0 \leq \alpha \leq 1$

A probabilidade de que a precipitação em um dado periodo não exceda um valor $y$, denominada $\theta(y), 6$ dada pela distribuição acumulada Gama incompleta, apresentada por MLLER \& WEAVER (1968), FRIZZONE (1979) e TOLEDO FILHO (1988), como sendo :

$$
G(y)=\frac{1}{\alpha \beta^{\alpha} \cdot \Gamma(\alpha)} \cdot s_{0}^{y} e^{-y / \beta} \cdot y^{\alpha-1} \cdot d y
$$

Fazendo-se $\alpha=c+1$ e $\beta=(1) / d)$, onde $c$ e parámetro de forma e d o de escala, pode-se escrever a eq. (10) da seguinte forma, conforme apresenta BERNARDO $(1975):$

$$
G(y)=f_{0}^{y} \frac{e^{-d \cdot y} \cdot y^{c} \cdot d^{(c+1)}}{\Gamma(c+1)} \cdot d y
$$

\begin{abstract}
a qual é também apresentada por BARGER \& THOM (1949), FRIEDMAN \& JANES (1957), WEAVER \& MILLER (1967), VIVALDI (1973), HARGREAVES (1973), GOODWIN \& SANS (1976), autores estes que utilizaram a distribuição acumulada Gama
\end{abstract}


incompleta na forma da eq. (11) para determinar a probabilidade de precipitaçäo.

As integrais definidas pelas eqs. (10) e (11), representam a área sob a curva $g(y)$, no intervalo de 0 a $y$. Estas integrais podem ser determinadas atraves de desenvolviment.o em serie CVIVALDI, 1973 ; GALATE, 1987 ; TOLEDO FILHO, 1988), através da aproximação de Newton-Raphson (BERNARDO, 1975; FRIZZONE, 1979), OU ainda, por meio de metodos numericos de calculo aproximado de integrais definidas, como é o caso do metodo de Simpson.

o maior problema no uso de qualquer procedimento estatistico está na estimativa dos parâmetros. Através do metodo da Máxima Verossimilhança, THOM (1958) estimou os parametros $\alpha \quad \beta \quad \beta \quad$ distribução Gama, utilizando as equaçóes :

$\hat{\beta}=\frac{Y \mathbf{m}}{\hat{\alpha}}$

$$
\hat{\alpha}=\frac{1+[1+(4 \cdot A / 3)]^{1 / 2}}{4 \cdot A}
$$

$$
A=\ln (Y \mathrm{Ym})-\frac{1}{n} \cdot \sum_{k=1}^{n} \ln (Y k)
$$

onde Ym e o valor médio da precipitação no periodo; Yk 
é a precipitação acumulada no periodo, em cada ano; $\mathbf{n}$ é - número de anos com dados de precipitação diária e ln é o operador do logaritmo neperiano.

THOM (1951) elaborou nomogramas para determinação da probabilidade de ocorréncia $P(y)$ de uma precipitação menor ou igual a um determinado valor $y$, fundamentados na distribuição Gama incompleta. Nesses nomogramas os niveis de probabilidade $P(y)$ aparecem na abscissa e os valores $t^{\prime}=y / \beta$ na ordenada, sendo cada curva traçada para um valor de $\alpha$.

A distribuiçăo Gama incompleta tem proporcionado resultados satisfatórios na estimativa da distribuição de frequiencia de dados de precipitação para períodos mensais CBARGER \& THOM, 1949 ; VIVALDI, 1973 ; FRIZZONE, 1979 ; GALATE, 1987 ; TOLEDO FILHO, 1988 ).

Segundo FRIZZONE (1979), a distribuição Gama proporcionou estimativas satisfatórias nos periodos de $5,10,15$ dias e mensal, para dados de 30 anos da região de Viçosa, MG.

2.3. Modelo matemático para dimensionamento de sistemas de irrigação

Existem muitas formas de se estimar a exigencia em água das culturas e, desta forma, dimensionar os sistemas de irrigação. 
JENSEN (1974) propós um modelo que tem a seguinte forma :

$$
\left.Q=\left[\int_{t 1}^{t z} K c \cdot(E T O)_{p} \cdot d t-\delta_{z}-(P e)_{p}\right] /\left[E f(t)-t_{1}\right)\right]
$$

onde $Q$ é a vazăo ou capacidade do sistema ; Kc é o coeficiente de cultura durante o período de máxima exigência hídrica ; (ETo $p \quad \Leftarrow$ a evapotranspiração da cultura de referencia, no nivel de probabilidade desejado ; $\mathcal{S}_{z} \in$ a quantidade de agua disponivel fornecida pelo solo durante o periodo de máxima exigência hídrica; (Pe)p é a precipitação pluvial efetiva, no nivel de probabilidade desejado; Ef e a eficiência da irrigação definida pela relação entre a quantidade líquida de agua requerida, expressa pelo numerador da eq.(15), e a quantidade introduzida no sistema adutor do projeto ; (t.2 - tr) é a duração do perfodo de máxima exigcencia hídrica considerado.

E oportuno observar que, para reduzir a capacidade do sistema, o procedimento assume que as condiçбes de evapotranspiração nas fases anteriores ao perfodo de pico possibilitam o acúmulo de certa quantidade de água disponfvel no solo, para utilização durante este período. Além disso, havendo exigencia de lixiviaçäo, esta deverá ser satisfeita fora deste periodo.

No caso de projetos dimensionados para 
atender varias culturas, a capacidade $(Q)$ do sistema deve ser determinada considerando os periodos de pico sobrepostos das culturas, ponderados em função das áreas (W) correspondentes a cada uma delas, conforme propos JENSEN (1974) :

$$
Q=\left\langle Q_{1} \cdot W_{1}+Q_{2} \cdot W_{2}+\ldots+Q{ }^{2} \cdot W_{n}\right\rangle /\left(W_{1}+W_{2}+\ldots+W_{n}\right\rangle
$$

Este modelo e un exemplo de aplicação da distribução de frequência da evapotranspiração e da precipitação, no dimensionament.o de sistemas de irrigação. 


\section{MATERIAL E METOdOS}

\subsection{Descrição geral}

o presente estudo foi desenvolvido

utilizando dados meteorologicos coletados no Posto Ağrometeorológico pertencente ao Departamento de Física e Meteorologia da Escola Superior de Agricultura "Luiz de Queiroz"-ESALQ-USP , localizado em Piracicaba, SP . 0 Posto esta situado na latitude de $22^{\circ} 42^{\prime} 30^{\circ}$ sul e lóngitude de $47^{\circ} 38^{\prime} 00^{\circ}$ oeste, tendo altitude de 546 metros.

Segundo dados meteorológicos coletados no referido posto, a precipitação pluvial, em termos médios anuais, é de $1247,1 \mathrm{~mm}$, ocorrendo a maior parte no verão (de novembro a fevereiro), principalmente como chuvas de alta intensidade e curta duração; a temperatura do ar é de $20,8^{\circ} \mathrm{C}$, sendo a mínima da ordem de $10^{\circ} \mathrm{C}$, em julho, e a máxima da ordem de $30^{\circ} \mathrm{C}$, em janeiro; a umidade relativa do ar é de $69 \% ; a$ velocidade do vento é de $2,5 \mathrm{~m} / s$ e o periodo de brilho solar é de $6 \mathrm{~h} /$ dia CGERVELLINI et alii, 1973). 
o clima da região é do tipo mesotérmico Cwa, pela classificação climática de Köppen, ou seja, sub-tropical úmido, com estiagem no inverno, com temperatura média do mês mais frio inferior a $18^{\circ} \mathrm{C}$ e a do mess mais quente superior a $22^{\circ} \mathrm{C}$, também denominado de tropical de altitude por CAMARGo et alii (1974).

\subsection{Período utilizado}

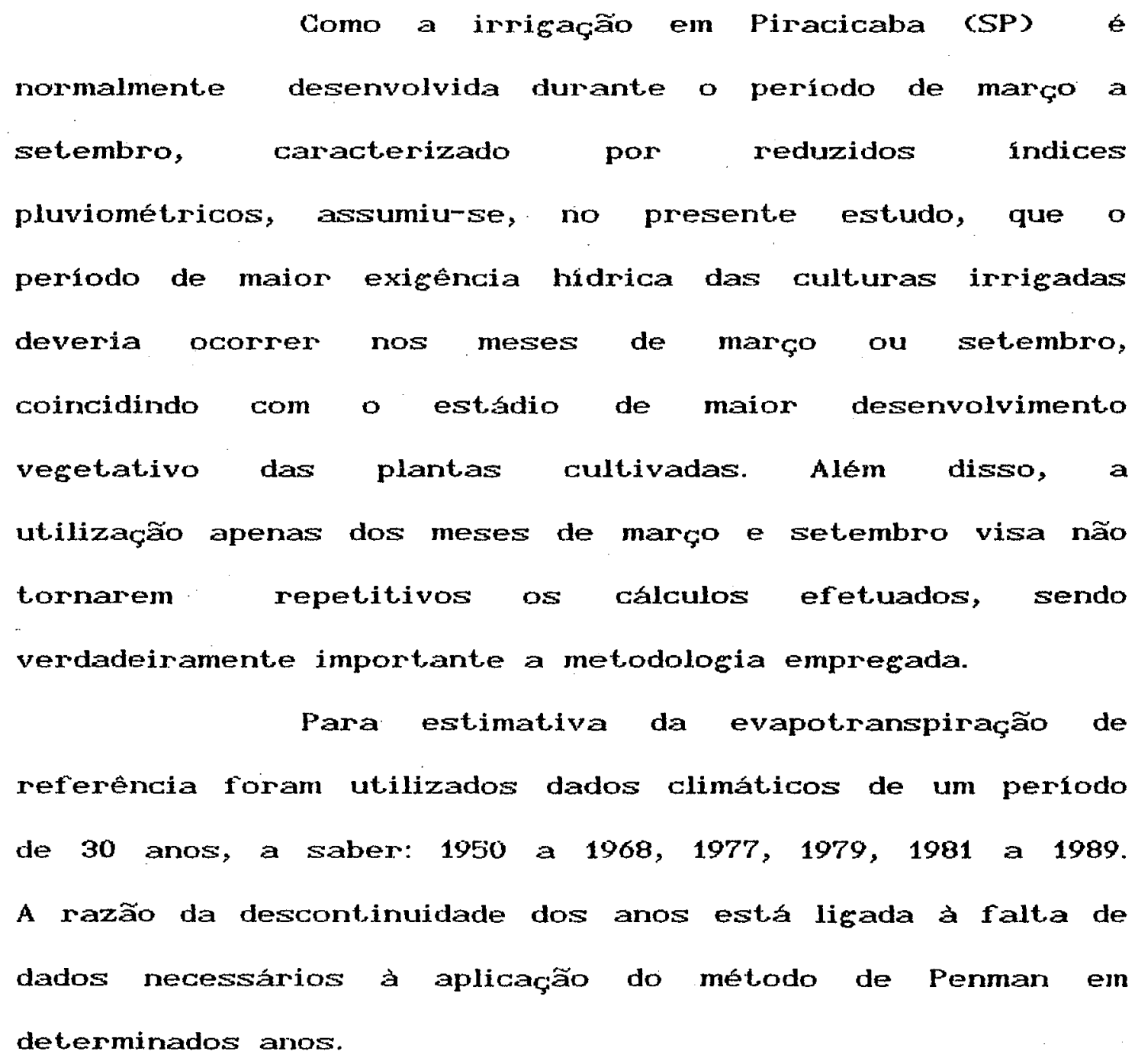

Para analisar a distribuição de frequiencia 
dos dados de precipitação, foram utilizados mediçбes de 71 anos, a saber : de 1917 a 1971 e de 1973 a 1989.

Tanto para o estudo da distribuição da evapotranspiraçăo de referencia como para o da precipitação pluvial, os meses de março e setembro foram divididos em periodos de 5, 10, 15 dias e mensal. Foram estabelecidos os seguintes criterios para a divisăo dos periodos :

a) Periodos de 5 dias: cada mês foi dividido em 6 periodos que, para facilitar a identificaçăo, foram caracterizados pelas legendas do tipo M(5)1, que no caso representa a primeira (número 1 ) pentada cnúmero 5 entre parênteses) do mês de marçolletra MD. $O$ mess de março tem 31 dias, ficando, desta forma, a última pentada com 6 dias.

b) Períodos de 10 dias: cada mês foi dividido em 3 períodos de 10 dias, ficando a última dezena do mês de março com 11 dias.

c) Periodos de 15 dias: os meses foram divididos em 2 periodos de 15 dias, ficando a segunda quínzena de março com 16 dias.

d) Periodos mensais: o més de março ficou com 31 dias, enquanto o mes de setembro ficou com 30 dias.

$$
\text { Os dados de evapotranspiraçăo foram }
$$

utilizados na forma de valor médio expressos em $\mathrm{mm} / \mathrm{dia}$. Por exemplo: para uma determinada quinzena de março o valor da evapotranspiração foi de $4,3 \mathrm{~mm} / \mathrm{dia}$.

Os dados de precipitação foram utilizados 
na forma de total do periodo analisado, e não na forma de valor médio.

3.3. Parâmetros meteorológicos utilizados

Na estimativa da evapotranspiração foram utilizados, basicamente, dados de temperatura média do ar atmosférico, umidade relativa do ar, insolação e velocidade do vento.

No Posto Agrometeorológico da ESALQ, a temperatura média diária do ar atmosférico é obtida a partir da média aritmética entre a temperatura máxima e a temperatura minima. Os termómetros estão instalados no abrigo termometrico padrão a $1,50 \mathrm{~m}$ da superfície do solo. A umidade relativa é medida via psicrómetro e a insolação e registrada via heliógrafo do tipo Campbell-Stokess. Já a velocidade do vento é medida por anemógrafo, tipo universal, acoplado a um catavento e disposto a $10 \mathrm{~m}$ de altura.

Os dados de precipitação são obtidos via pluviômetro.

3.4. Estimativa da evapot,ranspiração de referência

o método selecionado para estimativa da evapotranspiração de referencia foi o de Penman, por apresentar elevada precisào. 


\subsubsection{Descriçäo da versão do método de Penman} ut. I I zada

O método de Perman, segundo ALLEN (1986), pode ser descrito pela equação :

$$
G \cdot \rho w \cdot x \cdot E T o=\frac{\Delta}{\Delta+\gamma} \cdot(\mathrm{Rn}-G)+\frac{\gamma}{\Delta+\gamma} \cdot \mathrm{Ea}
$$

onde $a$ é $o$ coeficiente de unidades $\left(10^{-6} / 86,4\right) ; \quad \rho w$ e a massa especifica da água, em $\mathrm{km} / \mathrm{m}^{3} ; \lambda$ é o calor latente de vaporizaçăo da água, en $\mathrm{J} / \mathrm{kg}$; ETo é a evapotranspiraçăo da cultura de referencia grama, em mm/dia ; $\Delta$ é a inclinação da curva de variação da pressão de saturaçäio de vapor de agua com a temperatura (deo/dt), calculada em função da temperatura média diária do ar atmosférico, $\mathrm{kPa} /{ }^{\circ} \mathrm{C} ; \gamma$ é constante psicrométrica, em $\mathrm{kPa} /{ }^{\circ}$; kn é o fluxo de energia radiante para a superficie, ou radiagăo liquida, em $W / \mathrm{m}^{2} ; \theta \dot{\xi}$ o fluxo de calor para o solo, em $\mathrm{W} / \mathrm{m}^{2}$, assumido desprezivel em periodos iguais ou superiores a um dia; e Ea é o termo aerodinâmico de vapor de agua ou poder evaporante do ar, em $W m^{2}$

A cultura de referencia adotada foi a errama forquilha (Paspalum notatum, L.) por ser a mais utilizada para estes fins, em nossas condiçöes. 


\subsubsection{Estimativa de $\Delta$}

Os termos $\Delta$ e $\gamma$ podem ser considerados fatores de ponderação que determinam a divisão da energia radiante incidente entre os processos de evaporação e Conveç̧ão (MONTEITH, 1973). O valor de $\Delta$ pode ser calculado a partir da fórmula proposta por BOSEN (1960) para determinação da pressão de saturação de vapor sobre água :

$$
\begin{aligned}
e^{0}= & 3,38639\left[(0,00738 \cdot t+0,8072)^{8}-0,000019 \cdot \mid 1,8 . t\right. \\
& +48 \mid+0,001316]
\end{aligned}
$$

onde e é pressão de saturaçăo de vapor, em kPa; e t é a temperatura média do ar atmosférico, em o $\left(-51^{\circ} \mathrm{C}<\mathrm{t}<54 \circ \mathrm{C}\right)$.

Derivando a eq. (18) em relação a $t$, obtém-se :

$$
\begin{aligned}
\Delta=\frac{\mathrm{de}^{\circ}}{\mathrm{dt}}= & 3,38639\left[0,05904(0,00738 . t+0,8072)^{7}+\right. \\
& -0,0000342]
\end{aligned}
$$




\subsubsection{Estimativa de $\gamma$}

A constante psicrometrica $\gamma$ pode ser calculada por (BOSEN, 1960):

$$
\gamma=\frac{\mathrm{Cp} \cdot \mathrm{Pa}}{0,622 \cdot \lambda}
$$

onde $\mathrm{Cp}$ é o calor especifico do ar atmosterico, assumido const.ante e igual a $1005 \mathrm{~J} /\left(\mathrm{Kg} \cdot{ }^{\circ} \mathrm{G}\right) ; \mathrm{Pa} \&$ pressão atmosférica local, em $\mathrm{kPa} ; 0,622$ é a constante correspondente a relaçăo entre o peso molecular do vapor de agua $(18,016 \mathrm{~g} / \mathrm{mol})$ e o peso molecular aparente do ar seco $(28,900 \mathrm{~g})$.

A pressão atmosférica (Pa) foi estimada utilizando a expressão CTUBELIS \& NASGIMENTo, 1980):

$$
P a=101,3250\left(1-\frac{0,0065 . E}{288}\right)^{5.2568}
$$

onde $\mathrm{Pa} e$ dado em $\mathrm{kPa} e \mathrm{E} e \mathrm{a}$ altitude local, em $\mathrm{m}$. Para este estudo $\mathrm{Pa}=94,90832 \mathrm{kPa}$, uma vez que a altitude do Posto Agrometeorológico é de $548 \mathrm{~m}$.

o calor latente de vaporização da água, $\lambda$, pode ser estimado pela expressäo (BRUNT, 1952):

$$
\lambda=2491146-2135,268 . \mathrm{t} \quad,(\mathrm{J} / \mathrm{kg})
$$


3.4.1.3. Estimativa de ed e de ea

GUENCA \& NICHOLSON (1982) analisaram vários procedimentos de cálculo do deficit de presisão de vapor, recomendando que a escolha da forma de calculo seja coerente com o método de estimativa utilizado. A forma adotada neste estudo foi a seguinte :

$$
\Delta e=e a-e d=e a-(e a . U R \%),(k P a)
$$

onde $\Delta e \quad e$ deficit de pressão de vapor de água at.mosférico, em kPa; ea e a pressão de saturação de vapor de água atmosférico, em kPa, calculada pela eq. (18), utilizando a temperatura média do ar ; ed e a pressão parcial de vapor de água atmosférico, em kPa, calculada pela relaçăo ea $=e d . U R \% ; U R \%$ e a umidade relativa expressa em percentagem.

3.4.1.4. Estimativa da radiação liquida (Rn)

o fluxo liquido de energia radiante na superficie ou radiação líquida representa o principal parâmetro meteorológico envolvido na evapotranspiraçăo CPELTON et alii, $1960 ;$ DOSS et alii, 1964 ; TANNER, 1968 ; MONTEITH, 1973 3. Muitas formas de estimativa da radiação líquida são encontradas na literatura CJENSEN, 
1974 ; WRIGHT, 1982). O procedimento adotado neste trabalho foi aquele apresentado por DOORENBOS \& PRUITT (1984) e tem a seguinte forma :

$$
\begin{aligned}
\text { Rn }= & \left.(1-r) \cdot R s-o \cdot T^{4} \cdot[0,34-0,1391402 \cdot(\mathrm{ed}))^{0,5}\right] \\
& \left(0,1+0,9 \cdot \frac{n^{\prime}}{N}\right)
\end{aligned}
$$

onde $\mathrm{Rn} e$ a radiaçăo liquida, em $w / \mathrm{m}^{2} ; \mathbf{r} e$ e coeficiente de reflexão da radiação na superficie (albedo), que para a grama tem valor igual a 0,24 (MONTEITH, 1973) ; Rs e a radiaçăo solar total incidente de ondas curtas (direta mais difusa), em $\mathrm{W} / \mathrm{m}^{2} ; \sigma$ a constante de Stefan-Boltzmann, cujo valor é $5,673114.10^{-8}$ $W / \mathrm{cm}^{2}$. $K^{4} ; \mathrm{T}$ e a temperatura media do ar expressa em $K$; $n^{\prime}$ e a insolação, em horas; $N$ e a duraçăo máxima de brilho solar, em horas, em função da latitude local e pexiodo considerado. Para Piracicaba, SP, $N=12,1$ horas para o mési de março e $N=12,0$ hovas para o mes de setembro.

A radiação solar total incidente de ondas curtas (Rs) foi estimada utilizando a equaçăo obtida por OMETTO (1981), para a regiăo de Piracicaba, SP, cuja forma e :

$$
\operatorname{Rs}=\left(0,26+0,51 \cdot \frac{n^{3}}{N}\right) \cdot \operatorname{Ra} ;\left(W / m^{2}\right)
$$


onde $\mathrm{Ra}$ é a radiação solar na ausência da atmosfera crecebida no topo da atmosferas, em $W / \mathrm{m}^{2}$, cujo valor para a regiăo de Piracicaba, $S P$, e de $418,20 \mathrm{~W} / \mathrm{m}^{2}$ para o mès de marģo e de $387,67 \mathrm{~W} / \mathrm{m}^{2}$ para o mes de setembro.

\subsubsection{Estimativa do termo de trans f erência aerodinâmica}

A transferência aerodinámica de vapor foi estimada por (PENMAN, 1948):

$$
\mathrm{Ea}=2,63 \cdot(1+0,537 \cdot \mathrm{Uzm}) \cdot(\mathrm{e} a-\mathrm{ed}) \lambda \cdot \mathrm{pw} \cdot \mathrm{G} \quad ;\left(\mathrm{W} / \mathrm{m}^{2}\right)
$$

onde Ea é o termo de tranșerência aerodinàmica, expresso em $W / m^{2} ; U z m e$ a velocidade do vento a $2 m$ de altura, em $\mathrm{m} / \mathrm{s}$

Os dados de velocidade do vento fornecidos pelo Posto Agrometeorológico, foram medidos a $10 \mathrm{~m}$ de altura. Para converter a velocidade do vento de $10 \mathrm{~m}$ para $2 \mathrm{~m}$ de altura foi utilizada a relação cTuBELIS \& NASCIMENTO, 19803 :

$$
\frac{\mathrm{u}_{2}}{\mathrm{u} 1}=\left(\mathrm{Z}_{2} / \mathrm{Z}_{1}\right)^{1 / 7}
$$

onde U1 é a velocidade do vento na altura de mediçăo Z1 e 
U2 é a velocidade do vento na altura de medição $Z 2$.

Neste estudo assumiu-se, para facilitar a aplicação do método de Penman, que a atmosfera permaneceu na condição de neutralidade (adiabatica), embora isto ocorra muito raramente, ou talvez nunca, durante periodos de alta taxa de evapotranspiração. Geralmente, o que prevalece e a condição de não neut.ralidade da atmosfera, ou seja, existe fluxo de calor sensivel da superficie para a atmosfera (instável) ou no sentido oposto (estável, havendo necessidade de se proceder correçōes nos cálculos da evapotranspiração (SILVA, 1986$).$

3.5. Estimativa da distribuição de frequéncia da evapotranspiração de referencia

\begin{abstract}
Atraves da revisăo bibliográfica, foram encontrados indicios de que a evapotranspiração de referencia poderia ser representada pelas distribuiçós Beta CYAO, 1969 ; FALLS, 1973 ; HAAN \& BARFIELD, 1973 ; YAO, 1974 ; RAVELO \& DEGKER, $1979 ;$ BISHNOI, $1980>$ e NOTmal CARRUDA \& BARROSO, 1984 ; SAAD \& SCALOPPI, 1988b3, as quais foram estudadas e aplicadas aos dados deste estudo.
\end{abstract}

Segundo FALLS (1973), a função de densidade de probabilidade da distribuição Beta para o 
intervalo $(a, b)$ e :

$$
f(x)=\frac{1}{(b-a)} \cdot \frac{\Gamma(p+q)}{\Gamma(p) \cdot \Gamma(q)} \cdot\left(\frac{x-a}{b-a}\right)^{p-1} \cdot\left(1-\frac{x-a}{b-a}\right)^{q-1}
$$

sendo $a \leq x \leq b, p>0, q>0$; onde a é o menor valor da série de dados; b é o maior valor da série de dados; $p$ e $q$ são os parâmetros da distribuiçăo Beta; $x$ e um valor qualquer da variável em estudo (evapotranspiraçăo), compreendido no intervalo $(a, b)$.

A distribuição Beta na forma em que se encontra sua funçào densidade de probabilidade na eq. (28) não pode ser aplicada, devendo ser transformada para utilização no intervalo $(0,1)$, através da seguinte relação :

$$
\mathrm{x}^{\prime}=\frac{\mathrm{x}-\mathrm{a}}{\mathrm{b}-\mathrm{a}}
$$

onde $x^{\prime}$ é a variável evapotranspiração transformada pela eq. $(29)$, de tal forma que $0 \leq x^{2} \leq 1$.

A função de densidade de probabilidade da distribuiçăo Beta assume, então, a forma de :

$$
f\left(x^{\prime}\right)=\frac{\Gamma(p+q)}{\Gamma(p) \cdot \Gamma(q)} \cdot x^{p-1} \cdot\left(1-x^{\prime}\right)^{q-1}
$$

sendo $0 \leq x^{3} \leq 1, p>0, q>0$

A forma da função densidade depende da 
magnitude dos parămetros $p$ e $q$ Quando $p>1$ e $q>1$, a distribuição apresenta un pico; quando $p<1$ e $q<1$, a distribuição tem a forma de um $U$; quando $p<1$ e $q \geq 1$, a forma $e$ de um $J$ invertido; quando $p \geq 1$ e $q<1$, a forma e de um $\mathrm{J} ; \mathrm{e}$ quando $\mathrm{p}=\mathrm{q}$, a distribuiçăo é simétrica, sendo um caso especial quando $p=q=1$ que representa a distribuição retangular.

A distribuição acumulada Beta incompleta $F(x)$ fornece a probabilidade de que, neste caso, a evapotranspiração em um dado período não exceda um valor x', sendo representada pela equação (FALLS, 1973):

$$
F\left(x^{\prime}\right)=\frac{\Gamma(p+q)}{\Gamma(p) \cdot \Gamma(q)} s_{0}^{x^{\prime}} x^{p-1} \cdot\left(1-x^{\prime}\right)^{q-1} \cdot d x^{\prime}
$$

sendo $0 \leq x^{\prime} \leq 1$.

Estimativas dos parâmetros $p$ e $q$ da distribuição Beta são dificilmente obtidas utilizando o método da Máxima Verossimilhança. o procedimento aplicado foi o metodo dos Momentos, segundo o qual (PEARSON, 1934):

$$
\begin{aligned}
& \hat{\mathbf{p}}=\mu 1 \cdot(\mu 1-\mu z) /\left[\mu z-(\mu 1)^{2}\right] \\
& \hat{\mathrm{q}}=(1-\mu 1) \cdot(\mu 1-\mu z)-\left[\mu z-(\mu 1)^{2}\right]
\end{aligned}
$$




$$
\begin{aligned}
& \mu_{1}=\sum_{i=1}^{j} x_{i}^{\prime} / j \\
& \mu_{2}=\sum_{i=1}^{j} x_{i}^{\prime 2}, j
\end{aligned}
$$

onde $\mu 1$. $\&$ o momento de ordem 1 para a variavel $x^{\prime} ; \mu z$ e o momento de ordem 2 para a variavel $x^{\prime} ; \mathbf{x}_{i}$; representa a evapotranspiraçăo transformada pela eq. (29); j o número total de dados que compćem a serie analisada de valores de evapotranspiração cneste estudo $\mathbf{j = 3 0}$, uma vez que o periodo utilizado foi de 30 anoss.

A eq. (31) fol resolvida pelo método de Simpson de cálculo aproximado de integrais definidas, que pode ser descrito por:

$s_{a}^{b} f(x) d x \cong(h / 3) \cdot\left[f(x 1)+4 . f(x 2)+2 . f\left(x_{3}\right)+\ldots+4 . f(x v-1)+f(x v)\right]$

A eq. (36) exige um número par de sub-intervalos de tamanho $h$, sendo, consequentemente, w impar. Neste estudo utilizaram-se 20 sub-intervalos.

Os niveis de probabilidade calculados foram de $5,10,20,25,30,40,50,60,70,75,80,90$, e $95 \%$, sendo que estes indices revelam a probabilidade de que a evapotranspiraçăo seja menor ou igual a um 
determinado valor.

A eq. (31) fornece a probabilidade de

ocorrencia de um determinado valor de evapotranspiração. Para se obter o inverso, ou seja, partindo-se de um valor de probabilidade encontrar o valor correspondente da evapotranspiraçăo, podem-se utilizar processos iterativos, como o de Newton-Raphson, construir gráficos e deles tirar os valores, ou mesmo, utilizar a técnica de interpolação. o procedimento aqui adotado foi a interpolação linear, uma vez que, para efetuar o teste estatistico de Kolmogorov-Smirnov, foi necessário calcular os valores da probabilidade segundo a distribuição Beta para todos os valores observados de evapotranspiração. Desta forma, as frequiências foram amplamente identificadas, favorecendo o processo de interpolação e diminuindo sua imprecisão. Além disso, a evapotranspiração com uma casa decimal é suficiente para a finalidade de estimativa da exigéncia em água, visando o dimensionamento de sistemas de irrigaçăo.

A função densidade de probabilidade da distribuição Normal é dada pela equação (SPIEGEL, 1985):

$$
n(x)=\frac{1}{s \cdot(2 \pi)^{1 / 2}} \cdot e^{-(x-\bar{X})^{2} / 2 \cdot s^{2}}
$$

onde $\bar{X}$ é a média aritmética e $s$ e o desvio padrão dos dados da variável $X$. 
3.6. Estimativa da distribuição de frequência da precipitação pluvial

Em periodos reduzidos (5 dias, por exemplo), frequentemente não há ocorrencia de chuva, ou seja, a precipitação é igual a zero. o valor zero não pode sex utilizado na estimativa doss parâmetross $\alpha$ e $\beta$ da distribuiçăo Gama, atraves do método da Maxima Verossimilhança, Abandonar esta informação e trabalhar somente com os valores não nulos ocasiona uma superestimativa da precipitação para um determinado nível de probabilidade. THOM (1951), para solucionar esta questăo, introduziu o conceito de distribuição Mista para a. precipitação pluvial e para outras variáveis climatológicas.

Na distribuição Mista, a precipitaçăo e considerada um fenómeno aleatório, com probabilidade I de ocorréncia e com probabilidade $K$ de não ocorréncia, de t.al forma que, $I+K=1$. Portanto, a distribuição acumulada Mista, M(y), que fornece a probabilidade de que a precipitação de um dado periodo não exceda um valor $y$, tem a forma (THOM, 1951 ; THOM, 1966; THOM, 1968; VIVALDI, 1973 ; GALATE, 1987) :

$$
M(y)=k+I . G\left(y^{\prime}\right)
$$


sendo

$$
K=\frac{J}{n}
$$

e

$$
I=1-k
$$

onde $J$ é a número de valores iguais a zero na série de dados de precipitação pluvial; $n$ é o tamanho da série de dados de precipitação pluvial cvalores nulos mais valores positivos); e $G\left(y^{\prime}\right)$ é a distribuição acumulada Gama incompleta, calculada utilizando-se os valores não nulos da serie ( $\left.y^{\prime}\right)$, ou seja, valores maiores ou iguais a 1 , uma vez que para valores de precipitaçăo compreendidos entre o e 1 adotou-se o criterio de aproximação para 1 no caso de $0,5 \mathrm{~mm} \leq y<1 \mathrm{~mm}$, e aproximaçăo para o no caso de $0<y<0,5 \mathrm{~mm} ; y^{\prime}$ săo os valores de precipitaçäo pluvial (y) maiores ou iguais a $1 \mathrm{~mm}$.

Desta forma, de acordo com os valores da série de dados de precipitaçăo pluvial, duas situações podem ocorrer (VIVALDI, 1973; GALATE, 1987):

a) a servie năo contem valores nulos: neste caso, a estimativa da frequência de ocorrència é obtida através da distribuiçäo acumulada Gama incompleta a(y'). Sendo os valores de precipitaçăo pluvial da serie năo nulos, ou seja, maiores ou iguais a 1 , segundo a aproximação adotada neste estudo, é possivel calcular os paràmetros $\alpha e \beta$ da distribuição Gama pelo método da Máxima Verossimilhança; 
b) a série contém valores nulos: neste caso, utiliza-se a distribuição Mista, a qual contabiliza de maneira distinta a probabilidade de não ocorrência de precipitação (K) e a probabilidade de ocorrência (I). Desta forma, a distribuiçăo Gama e aplicada somente aos dados de precipitação maiores ou iguais a 1 , sendo possivivel, então, estimar os parâmetros $\alpha$ e $\beta$ pelo método da Máxima Verossimilhança. E interessante notar que, quando näo se tem valores nulos na série (caso a), $I=1$ e $K=0$, fazendo com que a distribuição Mista se reduza à distribuiçăo acumulada Gama incompleta G(y'), ou seja, $M(y)=G\left(y^{\prime}\right)$

Neste estudo, para as duas situaçöes expostas anteriormente, os parâmetros $\alpha$ e $\beta$ da distribuiçăo Gama foram determinados através do método da Máxima Verossimilhança, descrito pelas eqs. (12), (13) e (14).

A distribuição acumulada Gama incompleta Q(y') é dada por:

$$
\theta\left(y^{\prime}\right)=\frac{1}{\beta^{\alpha} \cdot \Gamma(\alpha)} s_{0}^{y^{\prime}} e^{-y^{\prime} / \beta} \cdot y^{, \alpha-1} d y^{\prime}
$$

A eq. (41) que propicia calcular a distribuição acumulada Gama incompleta, ou seja, a probabilidade de ocorrencia, foi resolvida através do 
desenvolvimento em série CVIVALDI, 1973; GALATE, 1987; TOLEDO FILHO, 1988 ).

$$
\text { Fazendo-se } v=y^{\prime} / \beta, \text { tem-se que } y^{\prime}=v \cdot \beta \text { e }
$$

$d y^{\prime}=\beta . d v$, assumindo a eq.(41) a seguinte forma, para a variável $v$ :

$$
\begin{aligned}
& G(v)=\frac{1}{\Gamma^{\prime}(\alpha) \cdot \beta^{\alpha}} \cdot s_{0}^{v} e^{-v} \cdot(v \cdot \beta)^{\alpha-1} \cdot \beta d v \\
& G(v)=\frac{1}{\Gamma(\alpha)} \cdot s_{0}^{v} e^{-v} \cdot v^{\alpha-1} d v
\end{aligned}
$$

o termo $e^{-v}$ pode ser resolvido pelo desenvolvimento em série de Maclaurin (PISKounov, 1984), sendo:

$$
e^{-v}=1-v+\frac{v^{2}}{2 !}-\frac{v^{3}}{3 !}+\ldots+(-1)^{z} \cdot \frac{v^{z}}{z !}+\ldots
$$

Desta forma, a eq. 443 ) assume a forma de :

$$
\begin{gathered}
G(v)=\frac{1}{\Gamma(\alpha)} f_{0}^{v}<v^{\alpha-1}-v^{\alpha}+\frac{1}{2} \cdot v^{\alpha+1}-\frac{1}{6} \cdot v^{\alpha+2} \\
\pm \ldots)
\end{gathered}
$$




$$
\begin{aligned}
g(v)= & \frac{v^{\alpha}}{\Gamma(a)}\left[\frac{1}{\alpha}-\frac{v}{(\alpha+1) 1 !}+\frac{v^{2}}{(\alpha+2) 2 !}-\frac{v^{3}}{(a+3) 3 !}\right. \\
& \pm \ldots]
\end{aligned}
$$

Atraves do desenvolvimento em série de Maclaurin (PISKOUNOV, 1984), tem-se que $e^{v}$ e dado por:

$$
e^{v}=1+v+\frac{v^{2}}{2 !}+\frac{v^{3}}{3 !}+\ldots+\frac{v^{2}}{z !}+\ldots
$$

$$
\text { Multiplicando-se e dividindo-se a eq.(46) }
$$

por $e^{v}$, tem-se:

$$
\begin{aligned}
& G(v)=\frac{v^{\alpha}}{a \cdot \Gamma(\alpha) \cdot e^{v}}\left[1+\frac{v}{(\alpha+1)}+\frac{v^{2}}{(\alpha+1)(\alpha+2)}+\right. \\
& \left.\frac{v^{3}}{(\alpha+1)(\alpha+2)(\alpha+3)}+\ldots\right]
\end{aligned}
$$

A eq.(48) fornece a probabilidade de ocorrência de um valor menor ou igual a $y^{\prime}$, que é dada por G(v), onde $v=y^{*} / \beta$. Quanto maior o número de termos utilizados no desenvolvimento em serie, melhor a estimativa da frequéncia esperada. Neste estudo, a série de Maclaurin foi utilizada com 13 termos.

Os valores de precipitação correspondentes 
aos niveis de probabilidade de $5,10,20,25,30,40,50$, $60,70,75,80,90$ e $95 \%$ foram calculados via interpolação linear, conforme o procedimento descrito e utilizado para a evapotranspiração.

\subsection{Teste de Kolmogorov-Smirnov}

Para verificar o ajuste dos dados de precipitação pluvial e da evapotranspiração de referencia as distribuiçoes de probabilidade teóricas, aplicou-se o teste de Kolmogorov-Smirnov. No caso da evapotranspiração, - teste foi utilizado para analisar as distribuiçóes Beta e Normal, e no caso da precipitaçăo, para verificar a adaptação das distribuiçōes Mista e Normal.

Segundo GAMPOS (1983), este teste verifica a adaptação de uma especifica e bem conhecida distribuição a dados provenientes de uma distribuição desconhecida. Sua vantagem sobre o teste de $x^{2}$ é que ele pode ser aplicado, sem restriçós, para pequenas amostras. Alem disso, ele trata os dados individualmente, não perdendo informações devido a agrupamentos, como ocorre no teste $x^{2}$. 


\section{RESUltados e discussta}

\subsection{Evapotranspiração de referencia}

As estimativas da evapotranspiração de referência para os meses em estudo, março e setembro, foram submetidas ao teste de Kolmogorov-Smirnov para verificar se poderiam ser representadas pelas distribuiços Beta e Normal. A hipótese Ho foi aceita para todos os periodos analisados dos dois meses, ao nível de significancia de $5 \%$, para as duas distribuiçöes citadas. Desta forma, conclui-se que as distribuiçoes Beta e Normal estão estatisticamente aptas para representar os dados de evapotranspiraçäo de referencia deste estudo.

Os coeficientes de assimetria de curtose foram calculados (Tabela 2 e 3 ) e analisados, verificando-se uma grande proximidade dos valores caracteristicos da distribuiçăo Normal Cassimetria=0 e curtose $=3$ ), reforçando a conclusăo obtida através do teste de Kolmogorov-Smirnov.

A distribuição Normal é bastante conhecida e facilmente aplicável, uma vez que apresenta tabulados os 
Tabela 2 - Valores dos coeficientes de assimetria e curtose para os dados de evapotranspiração do mês de março, para os periodos de $5,10,15$ e 30 dias.

\begin{tabular}{lcc}
\hline PERIODO & ASSIMETRIA & CURTOSE \\
\hline$M(5) 1^{*}$ & $-0,152$ & 2,930 \\
$M(5) 2$ & 0,616 & 2,481 \\
$M(5) 3$ & $-0,013$ & 2,837 \\
$M(5) 4$ & 0,021 & 2,758 \\
$M(5) 5$ & $-0,566$ & 2,197 \\
$M(5) 6$ & $-0,133$ & 2,997 \\
$M(10) 1$ & 0,639 & 1,965 \\
$M(10) 2$ & $-0,093$ & 2,910 \\
$M(10) 3$ & $-0,006$ & 3,039 \\
$M(15) 1$ & 0,787 & 2,516 \\
$M(15) 2$ & $-0,292$ & 3,150 \\
$M(30)$ & 0,105 & 4,735 \\
\hline
\end{tabular}

* $M(5) 1$ - simboliza a primeira (1) pentada (5) do mêt de março (M). 
Tabela 3 - Valores dos coeficientes de assimetria e curtose para os dados de evapotranspiração do nês de setembro, para os períodos de 5, 10, 15 e 30 dias.

\begin{tabular}{lcc}
\hline PERIODO & ASSIMETRIA & CURTOSE \\
\hline$S(5) 1$ & $-0,273$ & 2,475 \\
$S(5) 2$ & 0,130 & 2,606 \\
$S(5) 3$ & 0,350 & 2,916 \\
$S(5) 4$ & $-0,699$ & 2,830 \\
$S(5) 5$ & $-0,089$ & 2,177 \\
$S(5) 6$ & 0,224 & 3,899 \\
$S(10) 1$ & $-0,071$ & 3,726 \\
$S(10) 2$ & $-0,080$ & 4,168 \\
$S(10) 3$ & $-0,174$ & 5,141 \\
$S(15) 1$ & 0,128 & 3,376 \\
$S(15) 2$ & 0,450 & 2,673 \\
$S(30)$ & $-0,070$ & 3,161 \\
\hline
\end{tabular}


valores de sua distribuiçăo acumulada. Já a distribuiçẵo Beta apresenta maior capacidade de adaptação, pois os parâmetros $p \quad e \quad q$ podem assumir diversos valores, proporcionando as mais variadas formas para a função densidade de probabilidade da distribuif̧ăo. Pode-se concluir que a distribuiçäo Normal $\&$ mais facilmente aplicável, sendo recomendada para situaçóes onde não se dispőe de recursos de cálculo mais elaborados, enquanto a distribuição Beta tem maior potencial de adaptaçăo, porem requer procedimentos de cálculo mais elaborados e trabalhosos.

Recomenda-se, para fins praticos, o uso da distribuição Normal para o estudo de frequiencia de ocorrencia da evapotranspiração de referencia para os meses de março e setembro, em Piracicaba, SP. Caso năo se verifique um bom ajuste, deve-se tentar o uso da distribui çăo Beta.

4.1.1. Evapotranspiraçăo de referéncia para o mess de março

Os valores da evapotranspiração de referencia obtidos pelo método de Penman, para os periodos de 5, 10, 15 dias e mensal, encontram-se dispostos em ordem decrescente nas Tabelas 4 e 5 .

Analisando os parametros estatísticos da Tabela 6 , verifica-se que a amplitude de variação dos 
Tabela 4 - Valores da evapotranspiração de referência para as pentadas do mês de março, para um período de 30 anos.

Evapotranspiração de referência (mm/dia)

\begin{tabular}{|c|c|c|c|c|c|}
\hline \multirow[b]{2}{*}{$M(5) 1$} & \multirow[b]{2}{*}{$M(5) 2$} & \multicolumn{2}{|c|}{ PERIODO } & \multirow[b]{2}{*}{$M(5) 5$} & \multirow[b]{2}{*}{$M(5) 6$} \\
\hline & & $M(5) 3$ & $M(5) 4$ & & \\
\hline $\begin{array}{l}5,9 \\
5,7 \\
5,6 \\
5,3 \\
5,3 \\
5,3 \\
5,2 \\
5,2 \\
5,0 \\
5,0 \\
5,0 \\
5,0 \\
5,0 \\
4,8 \\
4,7 \\
4,7 \\
4,6 \\
4,6 \\
4,5 \\
4,5 \\
4,4 \\
4,2 \\
4,0 \\
4,0 \\
3,9 \\
3,9 \\
3,8 \\
3,8 \\
3,6 \\
2,8\end{array}$ & $\begin{array}{l}5,8 \\
5,7 \\
5,6 \\
5,5 \\
5,5 \\
5,4 \\
5,4 \\
5,1 \\
4,9 \\
4,7 \\
4,8 \\
4,6 \\
4,5 \\
4,2 \\
4,1 \\
4,1 \\
4,0 \\
3,9 \\
3,8 \\
3,8 \\
3,7 \\
3,7 \\
3,7 \\
3,6 \\
3,6 \\
3,5 \\
3,5 \\
3,0 \\
3,0 \\
2,0\end{array}$ & $\begin{array}{l}5,7 \\
5,5 \\
5,4 \\
5,4 \\
5,4 \\
5,3 \\
5,3 \\
5,0 \\
4,9 \\
4,9 \\
4,9 \\
4,8 \\
4,8 \\
4,6 \\
4,5 \\
4,4 \\
4,3 \\
4,2 \\
4,2 \\
4,1 \\
4,1 \\
4,1 \\
4,1 \\
4,0 \\
3,8 \\
3,8 \\
3,3 \\
2,9 \\
2,7 \\
2,5\end{array}$ & $\begin{array}{l}5,8 \\
5,3 \\
5,3 \\
5,1 \\
5,0 \\
4,9 \\
4,9 \\
4,8 \\
4,7 \\
4,7 \\
4,7 \\
4,6 \\
4,5 \\
4,4 \\
4,3 \\
4,3 \\
4,2 \\
4,2 \\
4,0 \\
4,0 \\
4,0 \\
3,9 \\
3,9 \\
3,7 \\
3,7 \\
3,6 \\
3,5 \\
3,5 \\
3,4 \\
2,7\end{array}$ & $\begin{array}{l}5,6 \\
5,4 \\
5,2 \\
5,2 \\
5,2 \\
5,1 \\
5,1 \\
5,1 \\
5,1 \\
5,1 \\
4,9 \\
4,9 \\
4,8 \\
4,7 \\
4,7 \\
4,5 \\
4,5 \\
4,3 \\
4,3 \\
4,2 \\
3,9 \\
3,9 \\
3,9 \\
3,8 \\
3,7 \\
3,7 \\
3,4 \\
3,3 \\
3,1 \\
2,8\end{array}$ & $\begin{array}{l}5,7 \\
5,6 \\
5,4 \\
5,4 \\
5,1 \\
5,1 \\
4,9 \\
4,9 \\
4,8 \\
4,7 \\
4,7 \\
4,7 \\
4,7 \\
4,6 \\
4,5 \\
4,5 \\
4,4 \\
4,2 \\
4,2 \\
4,2 \\
4,2 \\
4,1 \\
4,0 \\
4,0 \\
4,0 \\
3,9 \\
3,8 \\
3,7 \\
3,2 \\
2,9\end{array}$ \\
\hline
\end{tabular}


Tabela 5 - Valores da evapotranspiração de referência para os períodos de 10, 15 e 30 dias do nês de março, para um intervalo de 30 anos.

Evapotranspiração de referência (mm/dia)

PERIODO

$M(10) 1 \quad M(10) 2 \quad M(10) 3 \quad M(15) 1 \quad M(15) 2 \quad M(30)$

$\begin{array}{llllll}5,5 & 5,6 & 5,5 & 5,4 & 5,3 & 5,1 \\ 5,5 & 5,3 & 5,5 & 5,3 & 5,1 & 5,0 \\ 5,3 & 5,1 & 5,4 & 5,3 & 5,0 & 5,0 \\ 5,3 & 5,0 & 5,1 & 5,2 & 4,9 & 5,0 \\ 5,3 & 5,0 & 5,0 & 5,2 & 4,9 & 4,9 \\ 5,2 & 4,9 & 4,9 & 5,2 & 4,8 & 4,9 \\ 5,2 & 4,8 & 4,8 & 5,1 & 4,8 & 4,9 \\ 5,1 & 4,8 & 4,8 & 5,1 & 4,7 & 4,8 \\ 5,1 & 4,8 & 4,7 & 5,0 & 4,6 & 4,8 \\ 5,0 & 4,7 & 4,7 & 5,0 & 4,6 & 4,7 \\ 4,9 & 4,7 & 4,6 & 4,9 & 4,6 & 4,5 \\ 4,8 & 4,6 & 4,6 & 4,7 & 4,5 & 4,4 \\ 4,7 & 4,5 & 4,6 & 4,6 & 4,5 & 4,4 \\ 4,6 & 4,4 & 4,5 & 4,5 & 4,5 & 4,4 \\ 4,4 & 4,4 & 4,5 & 4,3 & 4,5 & 4,4 \\ 4,3 & 4,4 & 4,4 & 4,3 & 4,4 & 4,4 \\ 4,3 & 4,3 & 4,4 & 4,3 & 4,4 & 4,4 \\ 4,3 & 4,3 & 4,3 & 4,2 & 4,3 & 4,3 \\ 4,3 & 4,3 & 4,3 & 4,2 & 4,3 & 4,3 \\ 4,2 & 4,2 & 4,3 & 4,1 & 4,3 & 4,3 \\ 4,2 & 4,1 & 4,2 & 4,1 & 4,2 & 4,3 \\ 4,0 & 4,1 & 4,2 & 4,0 & 4,2 & 4,2 \\ 3,9 & 4,1 & 4,1 & 4,0 & 4,2 & 4,2 \\ 3,8 & 4,0 & 4,1 & 4,0 & 4,1 & 4,2 \\ 3,7 & 4,0 & 4,1 & 3,9 & 4,0 & 4,2 \\ 3,7 & 3,7 & 4,0 & 3,9 & 3,9 & 4,2 \\ 3,7 & 3,7 & 3,7 & 3,8 & 3,9 & 4,1 \\ 3,5 & 3,4 & 3,7 & 3,8 & 3,9 & 4,1 \\ 3,4 & 3,1 & 3,6 & 3,5 & 3,7 & 3,7 \\ 3,0 & 3,0 & 3,2 & 2,8 & 3,3 & 3,1\end{array}$


Tabela 6 - Parâmetros estatísticos referentes aos dados de evapotranspiração do mês de março, para os períodos de $5,10,15$ e 30 dias, de um intervalo de 30 anos.

\begin{tabular}{|c|c|c|c|c|c|}
\hline PERIODO & $\begin{array}{l}\text { AMPL I- } \\
\text { TUDE } \\
(\mathrm{mm} / \mathrm{dia})\end{array}$ & $\begin{array}{l}\text { MEDIA } \\
(\mathrm{mm} / d i a)\end{array}$ & $\begin{array}{l}\text { DESVIO } \\
\text { PADRAO }\end{array}$ & VARIANCIA & $\begin{array}{c}\text { COEF. DE } \\
\text { VAR IACAO } \\
(\%)\end{array}$ \\
\hline$M(5) 1$ & 3,1 & 4,6 & 0,689 & 0,475 & 14,8 \\
\hline$M(5) 2$ & 3,8 & 4,3 & 0,935 & 0,874 & 21,7 \\
\hline$M(5) 3$ & 3,2 & 4,4 & 0,817 & 0,667 & 18,4 \\
\hline$M(5) 4$ & 3,1 & 4,3 & 0,666 & 0,443 & 15,4 \\
\hline$M(5) 5$ & 2,8 & 4,5 & 0,727 & 0,529 & 16,4 \\
\hline$M(5) 6$ & 2,8 & 4,5 & 0,645 & 0,416 & 14,5 \\
\hline$M(10) 1$ & 2,5 & 4,5 & 0,680 & 0,463 & 15,2 \\
\hline$M(10) 2$ & 2,6 & 4,4 & 0,604 & 0,365 & 13,8 \\
\hline$M(10) 3$ & 2,3 & 4,5 & 0,528 & 0,279 & 11,8 \\
\hline$M(15) 1$ & 2,6 & 4,5 & 0,628 & 0,395 & 14,1 \\
\hline$M(15) Z$ & 2,0 & 4,4 & 0,430 & 0,185 & 9,8 \\
\hline$M(30)$ & 2,1 & 4,4 & 0,424 & 0,180 & 9,6 \\
\hline
\end{tabular}


dados e reduzida, estando as estimativas bastante agrupadas, como pode ser confirmado ao se observarem os valores dos coeficientes de variaçăo.

Neste estudo trabalhou-se com os dados provenientes da distribuiçăo Beta, dada sua maior capacidade de adaptação.

os parâmetros $p$ e $q$ da distribuiçăo Beta encontram-se na Tabela 7 , sendo que em todos os periodos foram maiores que 1 , 0 que indica que a curva que descreve a função densidade tem um pico. A Figura 1 representa a funçäo densidade de probabilidade da distribuição Beta para a quarta pentada do mes de março, denominada por MC5)4.

At.raves da distribuição Beta aplicada aos dados de evapotranspiraçäo, obtiveram-se os valores de evapotranspiração para os níveis de $5,10,20,25,30,40$, $50,60,70,75,80,90$ e $95 \%$ de probabilidade (Tabelas 8 e 9). Convém esclarecer, que estes niveis de probabilidade representam os limites de ocorrencia de valores iguals ou inferiores aos estabelecidos. Assim, por exemplo, existe $75 \%$ de probabilidade de que o valor da evapotranspiração de referencia para a primeira quinzena do mês de março năo ultrapasse $5,0 \mathrm{~mm} /$ dia. Outra forma de interpretação consiste em supor que, em tres de cada quatro anos, o valor da evapotranspiraçăo sera igual ou menor que 5,0 $\mathrm{mm} /$ dia. Este tipo de enfoque e muito útil ao dimensionamento de sistemas de irrigaçăo, pois conduz a 
50.

Tabela 7 - Parânetros p e q da distribuição Beta para os dados de evapotranspira ção do mês de margo, para os períodos de $5,10,15$ e 30 dias.

\begin{tabular}{llc}
\hline PERIODO & $\hat{p}$ & $\hat{q}$ \\
\hline$M(5) 1$ & 2,220595 & 1,470314 \\
$M(5) 2$ & 1,791331 & 1,156216 \\
$M(5) 3$ & 1,629892 & 1,070686 \\
$M(5) 4$ & 2,238072 & 2,019091 \\
$M(5) 5$ & 1,550616 & 1,145425 \\
$M(5) 6$ & 2,082957 & 1,656637 \\
$M(10) 1$ & 1,364033 & 1,009394 \\
$M(10) 2$ & 1,936209 & 1,715183 \\
$M(10) 3$ & 2,104774 & 1,675883 \\
$M(15) 1$ & 1,888454 & 1,157223 \\
$M(15) 2$ & 2,427304 & 1,816892 \\
$M(30)$ & 2,859039 & 1,440786 \\
\hline
\end{tabular}


51.

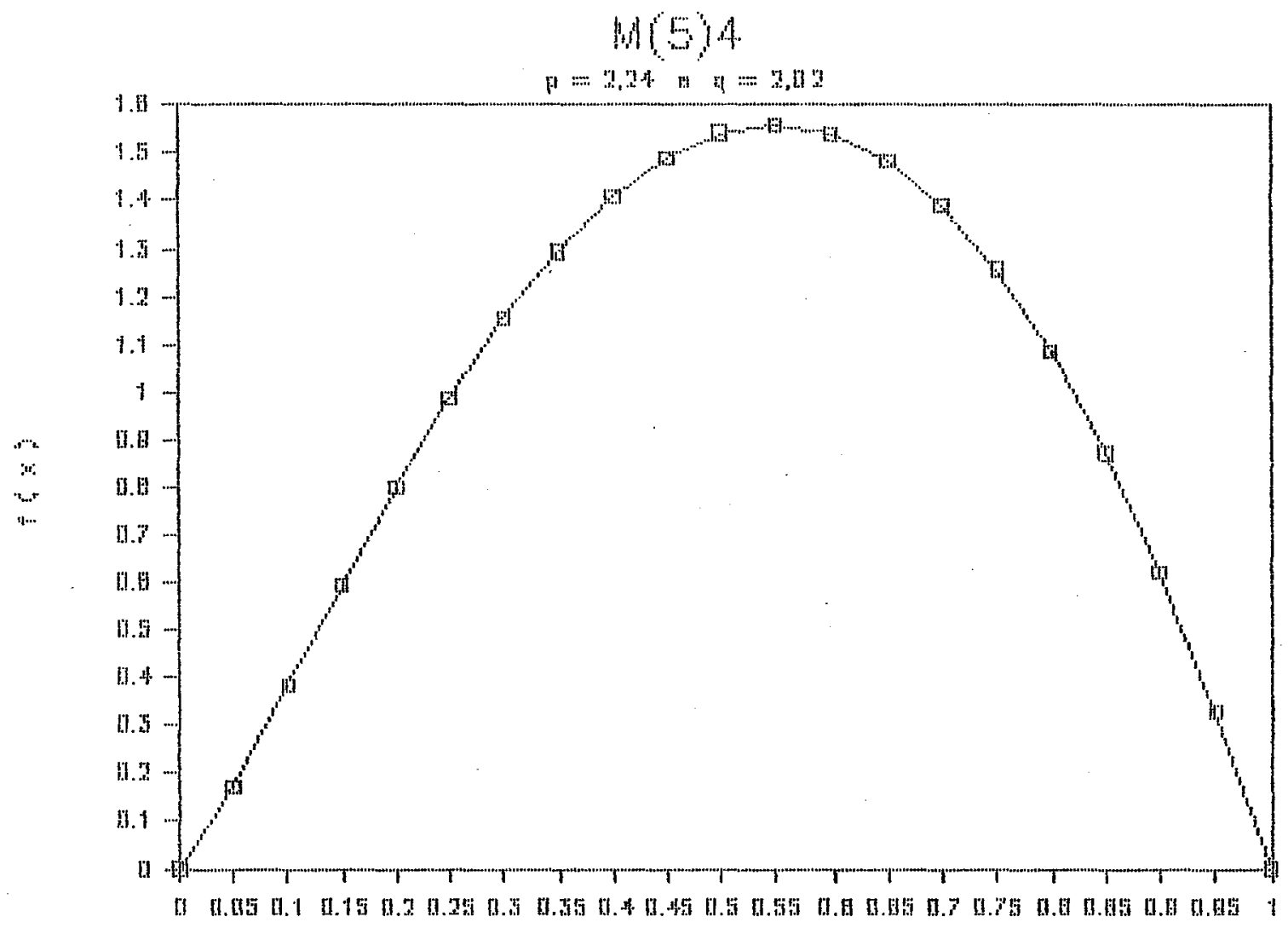

Figura 1 - Função densidade da distribuição Beta aplicada aos dados de evapotranspiração para a quarta pentada do mês de março. 
Tabela 8 - Evapotranspiração de referência calculada através da distribuição Beta para as pentadas do mês de março, em função de diversos níveis de probabilidade de ocor rência.

NIVEL DE PROBAB I LIDADE $(\%)$

EVAPOTRANSPIRACAD DE REFERENCIA (mm/dia)

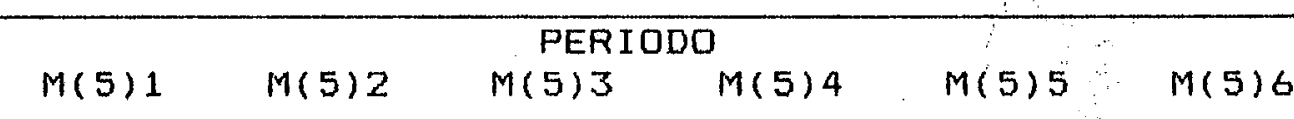

$M(5) 1-M(5) 2 \quad M(5) 3$

\begin{tabular}{lllllll}
5 & 3,3 & 2,5 & 3,0 & 3,1 & 3,2 & 3,3 \\
10 & 3,7 & 3,0 & 3,2 & 3,4 & 3,4 & 3,5 \\
20 & 4,0 & 3,4 & 3,6 & 3,7 & 3,7 & 3,8 \\
25 & 4,1 & 3,6 & 3,8 & 3,8 & 3,9 & 4,0 \\
30 & 4,3 & 3,8 & 4,0 & 3,9 & 4,0 & 4,1 \\
40 & 4,5 & 4,1 & 4,3 & 4,1 & 4,3 & 4,3 \\
50 & 4,7 & 4,4 & 4,5 & 4,4 & 4,5 & 4,5 \\
60 & 4,7 & 4,7 & 4,8 & 4,5 & 4,7 & 4,7 \\
70 & 5,1 & 5,0 & 5,0 & 4,7 & 5,0 & 4,9 \\
75 & 5,2 & 5,1 & 5,1 & 4,8 & 5,1 & 5,0 \\
80 & 5,3 & 5,2 & 5,3 & 5,0 & 5,2 & 5,1 \\
90 & 5,5 & 5,5 & 5,5 & 5,2 & 5,4 & 5,3 \\
95 & 5,7 & 5,6 & 5,6 & 5,4 & 5,5 & 5,5 \\
\hline
\end{tabular}


Tabela 9 - Evapotranspiração de referência obtida através da dị tribuição Beta para os períodos de 10,15 e 30 dias do mês de março, em função de diversos níveis de probabilidade de ocorrência.

NIVEL DE PROBABI LIDADE

$(\%)$
EVAPOTRANSPIRACAO DE REFERENCIA ( $\mathrm{mm} / \mathrm{dia})$

PEFIODO

$M(10) 1 . M(10) 2 \quad M(10) 3 \quad M(15) 1 \quad M(15) 2 \quad M(30)$

\begin{tabular}{|c|c|c|c|c|c|c|}
\hline 5 & 3,3 & 3,4 & 3,5 & 3,2 & 3,6 & 3,6 \\
\hline 10 & 3,5 & 3,5 & 3,7 & 3,5 & 3,8 & 3,8 \\
\hline 20 & 3,8 & 3,8 & 4,0 & 3.9 & 4,0 & 4,1 \\
\hline 25. & 3,9 & 3,9 & 4,1 & 4,0 & 4,1 & 4,1 \\
\hline 30 & 4,1 & 4,0 & 4,2 & 4,1 & 4,2 & 4,2 \\
\hline 40 & 4,3 & 4,2 & 4,3 & 4,3 & 4,3 & 4,4 \\
\hline 50 & 4,5 & 4,4 & 4,5 & 4,5 & 4,5 & 4,5 \\
\hline 60 & 4,8 & 4,6 & 4,6 & 4,7 & 4,6 & 4,6 \\
\hline 70 & 5,0 & 4,8 & 4,8 & 4,9 & 4,7 & 4,7 \\
\hline 75 & 5,1 & 4,9 & 4,9 & 5,0 & $4, B$ & 4,8 \\
\hline 80 & 5,2 & 5,0 & 5,0 & 5,1 & 4,8 & 4,8 \\
\hline 90 & 5,4 & 5,2 & 5,2 & 5,3 & 5,0 & 5,0 \\
\hline 95 & 5,5 & 5,3 & 5,3 & 5,4 & 5,1 & 5,0 \\
\hline
\end{tabular}


projetos mais racionais e a uma exploraçăo mais otimizada dos recursos hídricos e energéticos.

o periodo de máxima exigencia hídrica das culturas anuais irrigadas não se restringe a um único dia, ou mesmo, três, cinco ou sete dias. Parece razoavel admitir um periodo variável entre 10 e 30 dias. JENSEN (1974) considera que este periodo, geralmente, compreende duas ou três semanas. Analisando a Tabela 10, verifica-se que, de forma seral, à medida que diminui o periodo, aumenta o valor da evapotranspiração de referéncia para um mesmo nível de probabilidade, no caso, $75 \%$. A maior diferença entre um dos periodos e o periodo mensal foi de 8,3\%, justamente um periodo de 5 dias cas diferenças variaram de 0,0 a $8,3 \%$ ). Isto leva a concluir que os sistemas de irrigação dimensionadoș com base na evapotranspiração de uma pentada são superdimensionados, prejudicando o desempenho e a economia da irrigaçăo. Por outro lado, sistemas dimensionados com base em periodos mensais podem, muitas vezes, estar subdimensionando o sistema, no caso do periodo de máxima exigência hídrica ser menor que 30 dias. No caso do mês de março, este risco de super e subdimensionamento é real, porém, em pequenas proporçŏes, pois a amplitude e o coeficiente de variação dos valores da evapotranspiração são reduzidos, estando os dados agrupados. Além disso, os procedimentos de estimativa da evapotranspiraçăo trazem sempre um grau de imprecisão que, dependendo do método e da disponibilidade 
Tabela 10 - Relação entre a evapotranspiração ao nivel de 75\% de probabilidade em um determinado período e a evapotranspiração a $75 \%$ de probabilidade para o período de 30 dias, para o mês de março.

\begin{tabular}{lcl}
\hline PERIODO & $\begin{array}{c}\text { ETo a } 75 \% \\
(\mathrm{~mm} / \mathrm{dia})\end{array}$ & $\begin{array}{c}\text { \%em relacao a ETo a } 75 \% \\
\text { do periodo de } 30 \text { dias }\end{array}$ \\
$M(5) 1$ & 5,2 & $8,3 \%$ \\
$M(5) 2$ & 5,1 & 6,3 \\
$M(5) 3$ & 5,1 & 6,3 \\
$M(5) 4$ & 4,8 & 0,0 \\
$M(5) 5$ & 5,1 & 6,3 \\
$M(5) 6$ & 5,0 & 4,2 \\
$M(10) 1$ & 5,1 & 6,3 \\
$M(10) 2$ & 4,9 & 2,1 \\
$M(10) 3$ & 4,9 & 2,1 \\
$M(15) 1$ & 5,0 & 4,2 \\
$M(15) 2$ & 4,8 & 0,0 \\
$M(30)$ & 4,8 & 0,0 \\
\hline
\end{tabular}


e confiabilidade dos dados meteorológicos, superam, em muito, este nivel de $8,3 \%$

o valor da evapotranspiração que serve de base para o dimensionamento de sistemas de irrigaçăo depende da duraçäo do periodo de máxima exigência hidrica da cultura e do nivel de probabilidade desejado para as condiçäes especificas do projeto em consideraçăo. 0 critério recomendável deve estar baseado em análise económica, considerando os prejuizos associados à redução da quantidade e qualidade da produçăo decorrentes da deficiencia hidrica, e no aumento de custos do sistema para satisfazer niveis mais elevados de probabilidade. Normalmente, níveis mais elevados de probabilidade são selecionados para culturas de maior valor económico e condiçăo de reduzida quantidade de agua disponivel no solo (PRUITT et alii, 1972; JENSEN, 1974).

Em condiçoses de irrigaçăo tipicamente suplementar, como se verifica na região centro-sul do Brasil e, consequentemente, na regiăo de Piracicaba, SP, dificilmente a economia dos projetos de irrigação justifica a escolha de niveis de probabilidade superiores a $90 \%$. Na grande prática, os valores usuais adotados variam de 50 a $75 \%$, dependendo das implicaçós economicas assisociadas ao projeto em considerạ̧ăo. DOORENBOS 8 PRUTTT (1984) admitem que na maioria das regiơes irrigadas esses niveis estejam entre 75 e $80 \%$ o que se verifica, a nivel de Brasil, é a adoção da média dos valores estimados da 
evapotranspiração como parâmetro de dimensionamento. Na distribuição Normal a média corresponde ao nivel de $50 \%$ de probabilidade, dando-se a impressăo de que este critério subdimensiona o sistema de irrigação. Para verificar tal suposição, foi montada a Tabela 11, onde se tem a relação entre a evapotranspiraçăo esperada ao nível de $75 \%$, calculada pela distribuição Beta, e a evapotranspiração média, para os vários periodos em estudo. Observarse que os valores médios estão muito próximos do nível de $50 \%$ de probabilidade. Além disso, verifica-se que a faixa de variação fica entre 9,1 e $18,6 \%$, que é um intexvalo relativamente pequeno, caso se considere eventuais erros desta ordem. Logo, considerando que o procedimento mais adequado é aquele que adota a evapotranspiração em torno do nivel de $75 \%$ de probabilidade, verifica-se que existe um subdimensionamento ao se utilizar o valor médio, porém, é de significância relativa.

Após esta discussăo, pode-se dizer que, de uma forma seral, para fins de dimensionamento de sistemas de irrigaçăo, o valor da evapotranspiração de referência deve ser escolhido em funçăo de níveis de probabilidade de ocorrencia em torno de $75 \%$ e para um periodo coerente com a duração do intervalo de máxima exigencia hidrica da cultura a ser irrigada. Porém, sempre que possivel, deve-se fazer uma análise criteriosa dos fatores envolvidos ccultura, aspectos económicos, disponibilidade de água, etcl antes de se adotar um determinado valor de 
Tabela 11 - Estudo comparativo entre a evapotranspiração ao nível de $75 \%$ de probabilidade e a evapotranspiração média, para os periodos de $5,10,15$ e 30 dias do mês de março.

\begin{tabular}{|c|c|c|c|c|}
\hline PERIODO & $\begin{array}{c}\text { ETo a } 75 \% \\
(\mathrm{~mm} / \mathrm{dia})\end{array}$ & $\begin{array}{l}\text { ETo media } \\
(\mathrm{mm} / \mathrm{dia})\end{array}$ & $\begin{array}{l}\text { ETo media } \\
\text { probabili- } \\
\text { dade }(\%)\end{array}$ & $\frac{\text { ETo a } 75 \%}{\text { ETo media }}$ \\
\hline$M(5) 1$ & 5,2 & 4,6 & 45 & 1,130 \\
\hline$M(5) 2$ & 5,1 & 4,3 & 47 & 1,186 \\
\hline$M(5) 3$ & 5,1 & 4,4 & 45 & 1,159 \\
\hline$M(5) 4$ & 4,8 & 4,3 & 47 & 1,116 \\
\hline$M(5) 5$ & 5,1 & 4,5 & 50 & 1,133 \\
\hline$M(5) 6$ & 5,0 & 4,5 & 50 & 1,111 \\
\hline$M(10) 1$ & 5,1 & 4,5 & 50 & 1,133 \\
\hline$M(10) 2$ & 4.9 & 4,4 & 50 & 1,114 \\
\hline$M(10) 3$ & 4,9 & 4,5 & 50 & 1,089 \\
\hline$M(15) 1$ & 5,0 & 4,5 & 50 & 1,111 \\
\hline$M(15) Z$ & 4,8 & 4,4 & 45 & 1,091 \\
\hline$M(30)$ & 4,8 & 4,4 & 40 & 1,091 \\
\hline
\end{tabular}


evapotranspiração para fins de projeto.

Embora se verifique que a evapotranspiraçäo de referencia năo varia muito, como e o caso da precipitação pluvial, nota-se que se obtém uma serie de pequenos desvios ao se proceder a análise $e$ ao uso incorreto das estimativas. Metodos de estimativa pouco precisos e dimensionamento baseado em periodos muito pequenos (5 dias) ou muito grandes (mensal), utilizando sem nenhum critério a média, conduzem, quando juntos, a sistemas de irrigação mal dimensionados e ineficientes.

Para ilustrar o ajust.e da distribuição Beta aos dados de evapotranspiração de referencia estimados, são apresentadas as Figuras $2 \in 3$.

Nas Tabelas 12 e 13 estäo os valores de evapotranspiração para os diferentes níveis de probabilidade, obtidos atraves da distribuição Normal. Os resultados são semelhantes àqueles obtidos utilizando-se a distribuição Beta (Tabelas 8 es.

4.1.2. Evapotranspiração de referencia para o mess de setembro

As estimativas da evapotranspiraçăo de referencia para o més de setembro encontram-se nas Tabelas 14 15. 0 més de setembro foi escolhido para exemplificar este estudo por ser, na maioria das vezes, a periodo onde se concentra a máxima exigencia hidrica das 
$1,15,4$

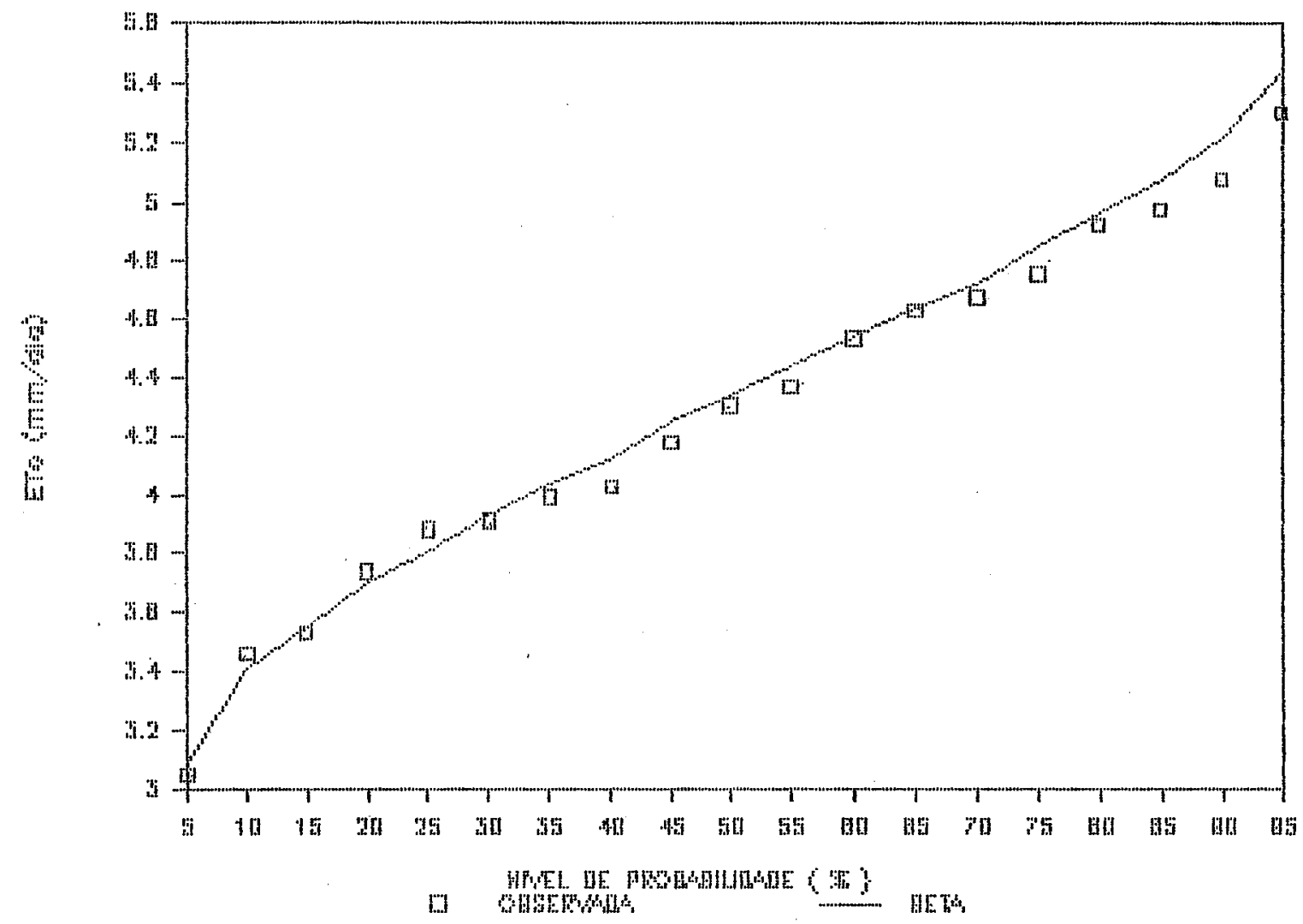

Figura 2 - Evapotranspiração para os diferentes niveis de probabilidade obtida através da distribuição Beta, e evapotranspiração observada para a quarta pentada de março. 
61.

$M(15)$

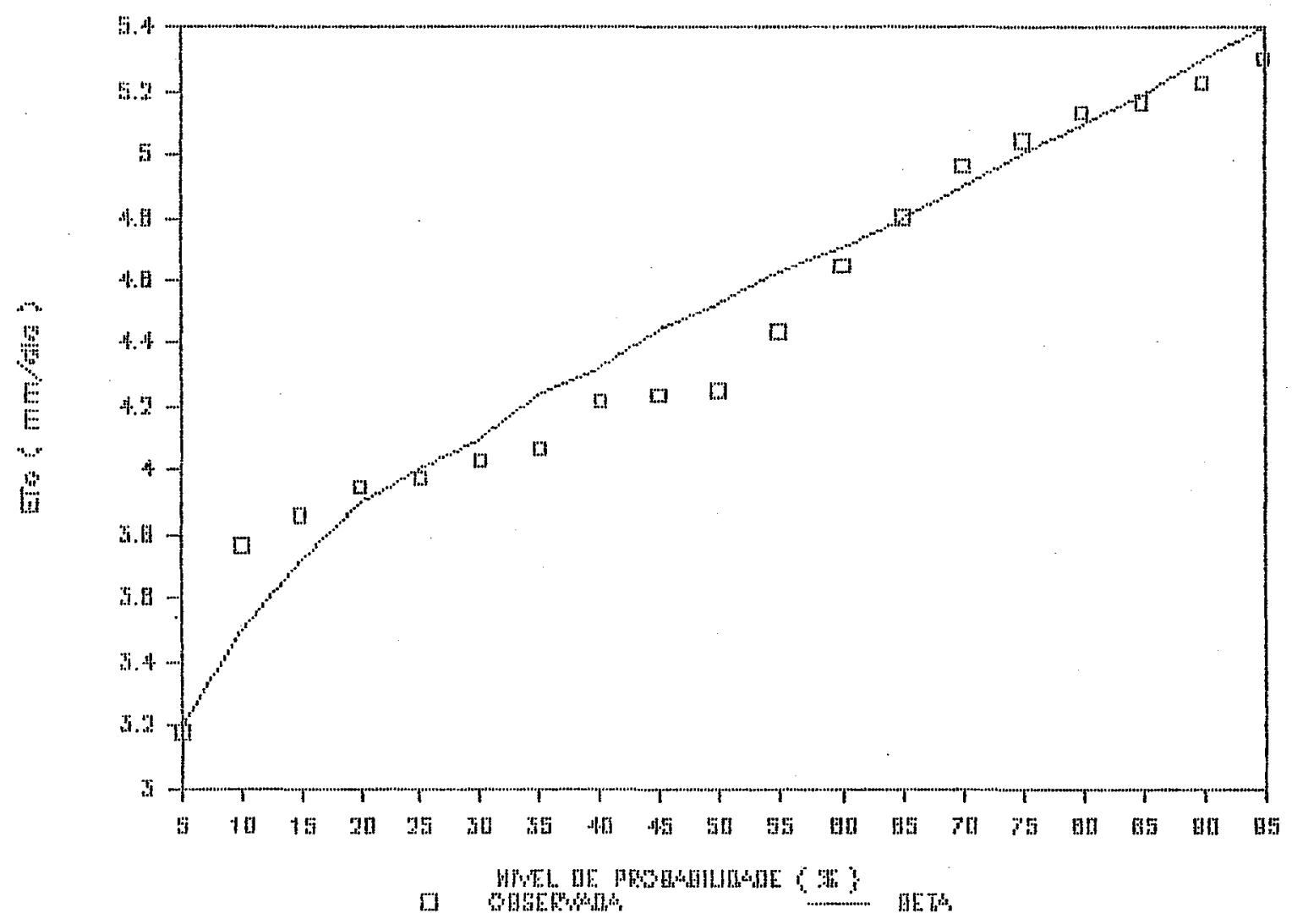

Figura 3 - Evapotranspiraça para os diferentes niveis de probabilidade obtida através da distribuição Eeta, e evapotranspiração observada para a primeira quinzena de março. 
Tabela 12 - Evapotranspiração de referência obtida através da distribuição Normal para as pentadas do mês de marco, em função de diversos níveis de probabilidade de ocorrência.

NIVEL DE PROBABI LIDADE $(\%)$
EVAPQTRANSPIRACAO DE REFERENCIA ( $\mathrm{mm} / \mathrm{di} a)$

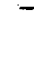

PERIODO

$M(5) 1$

\section{$M(5) 3$}

$M(5) 4$

$M(5) 5$

$M(5) 6$

5

3,5

2,8

3,1

3,2

3,2

3,4

10

3,8

3,1

3,4

3,5

3,5

3,6

20

$$
4,1
$$

3,5

3,8

3,8

3,8

3,9

25

4,2

3,7

3,9

3,9

4,0

4,0

4,2

4,2

4,4

4,3

4,6

4,5

4.9

4,7

5,0

4,9

5,2

5,1

5,1

5,5

5,5

5,8

4,8

4,0

4,0

90

5,5

5,8

$5, \theta$

5,4

4,1

4,1

95
4,3

4,3

4,4

4,5

4,6

4,6

4,8

4,8

4,9

4,9

4.9

5,1

5,0

5,2

5,4

5,3

5,6

5,5

5,8 
Tabela 13 - Evapotranspiração de referência obtida através da distribuição Normal para os períodos de 10,15 e 30 dias do mês de março, em função de diversos níveis de probabilidade de ocorrência.

NIVEL DE PROBABI LIDADE

$(\%)$
EVAPQTRANSPIRACAO DE REFERENCIA (mm/dia)

(r)

EVAPOTRANSPIRACAQ DE REFERENEIA (mm/dia)

M(10)1 PERIODO

$M(10) 1$
$M(10) 2 M(10) 3 \quad M(15) 1 \quad M(15) 2 \quad M(30)$

\begin{tabular}{lllllll}
\hline 5 & 3,4 & 3,4 & 3,6 & 3,4 & 3,7 & 3,7 \\
10 & 3,6 & 3,6 & 3,8 & 3,7 & 3,7 & 3,9 \\
20 & 3,9 & 3,9 & 4,0 & 3,9 & 4,1 & 4,1 \\
25 & 4,0 & 4,0 & 4,1 & 4,0 & 4,1 & 4,1 \\
30 & 4,1 & 4,1 & 4,2 & 4,1 & 4,2 & 4,2 \\
40 & 4,3 & 4,2 & 4,3 & 4,3 & 4,3 & 4,3 \\
50 & 4,5 & 4,4 & 4,5 & 4,5 & 4,4 & 4,4 \\
60 & 4,6 & 4,5 & 4,6 & 4,6 & 4,5 & 4,5 \\
70 & 4,8 & 4,7 & 4,7 & 4,8 & 4,6 & 4,7 \\
75 & 4,9 & 4,8 & 4,8 & 4,9 & 4,7 & 4,7 \\
80 & 5,0 & 4,7 & 4,9 & 5,0 & 4,8 & 4,8 \\
90 & 5,3 & 5,2 & 5,1 & 5,3 & 5,0 & 5,0 \\
75 & 5,6 & 5,4 & 5,3 & 5,5 & 5,1 & 5,1 \\
\hline
\end{tabular}


Tabela 14 - Valores da evapotranspiração de referência para as pentadas do mês de setembro, para um periodo de 30 anos.

Evapotranspiração de referência (mm/dia)

\begin{tabular}{|c|c|c|c|c|c|}
\hline \multicolumn{6}{|c|}{ PERIODO } \\
\hline$S(5) 1$ & $S(5) 2$ & $S(5) 3$ & $S(5) 4$ & $5(5) 5$ & $5(5) 6$ \\
\hline $\begin{array}{l}5,2 \\
5,1 \\
5,0 \\
4,7 \\
4,6 \\
4,5 \\
4,5 \\
4,4 \\
4,4 \\
4,3 \\
4,3 \\
4,3 \\
4,3 \\
4,3 \\
4,1 \\
4,0 \\
3,9 \\
3,8 \\
3,7 \\
3,7 \\
3,6 \\
3,5 \\
3,5 \\
3,5 \\
3,5 \\
3,5 \\
3,1 \\
3,1 \\
2,9 \\
2,6\end{array}$ & $\begin{array}{l}5,8 \\
5,3 \\
5,2 \\
5,0 \\
4,9 \\
4,8 \\
4,7 \\
4,6 \\
4,6 \\
4,5 \\
4,4 \\
4,3 \\
4,3 \\
4,3 \\
4,1 \\
4,1 \\
3,9 \\
3,9 \\
3,8 \\
3,8 \\
3,8 \\
3,8 \\
3,8 \\
3,5 \\
3,5 \\
3,4 \\
3,2 \\
3,2 \\
3,1 \\
2,7\end{array}$ & $\begin{array}{l}5,5 \\
5,3 \\
5,0 \\
4,9 \\
4,9 \\
4,9 \\
4,8 \\
4,6 \\
4,6 \\
4,4 \\
4,4 \\
4,3 \\
4,2 \\
4,2 \\
4,0 \\
4,0 \\
3,9 \\
3,9 \\
3,9 \\
3,9 \\
3,8 \\
3,8 \\
3,7 \\
3,7 \\
3,7 \\
3,5 \\
3,4 \\
2,8 \\
2,6 \\
2,4\end{array}$ & $\begin{array}{l}5,2 \\
5,2 \\
5,2 \\
5,1 \\
4,9 \\
4,9 \\
4,8 \\
4,8 \\
4,8 \\
4,7 \\
4,6 \\
4,6 \\
4,5 \\
4,4 \\
4,4 \\
4,3 \\
4,2 \\
4,1 \\
4,1 \\
4,0 \\
3,9 \\
3,8 \\
3,8 \\
3,7 \\
3,6 \\
3,6 \\
3,3 \\
2,9 \\
2,7 \\
2,5\end{array}$ & $\begin{array}{l}5,4 \\
5,3 \\
4,9 \\
4,9 \\
4,9 \\
4,8 \\
4,7 \\
4,7 \\
4,6 \\
4,5 \\
4,4 \\
4,3 \\
4,3 \\
4,2 \\
4,2 \\
4,2 \\
4,1 \\
4,0 \\
4,0 \\
3,8 \\
3,7 \\
3,7 \\
3,7 \\
3,7 \\
3,4 \\
3,4 \\
3,3 \\
3,1 \\
3,1 \\
2,9\end{array}$ & $\begin{array}{l}5,5 \\
5,4 \\
5,1 \\
5,1 \\
5,0 \\
4,7 \\
4,6 \\
4,6 \\
4,5 \\
4,5 \\
4,5 \\
4,5 \\
4,4 \\
4,1 \\
4,1 \\
4,1 \\
4,1 \\
4,0 \\
4,0 \\
4,0 \\
3,9 \\
3,9 \\
3,8 \\
3,7 \\
3,7 \\
3,6 \\
3,5 \\
3,3 \\
2,9 \\
2,1\end{array}$ \\
\hline
\end{tabular}


Tabela 15 - Valores da evapotranspiração de referência para os períodos de 10,15 e 30 dias do mês de setembro, para um intervalo de 30 anos.

Evapotranspiração de referência (mm/dia)

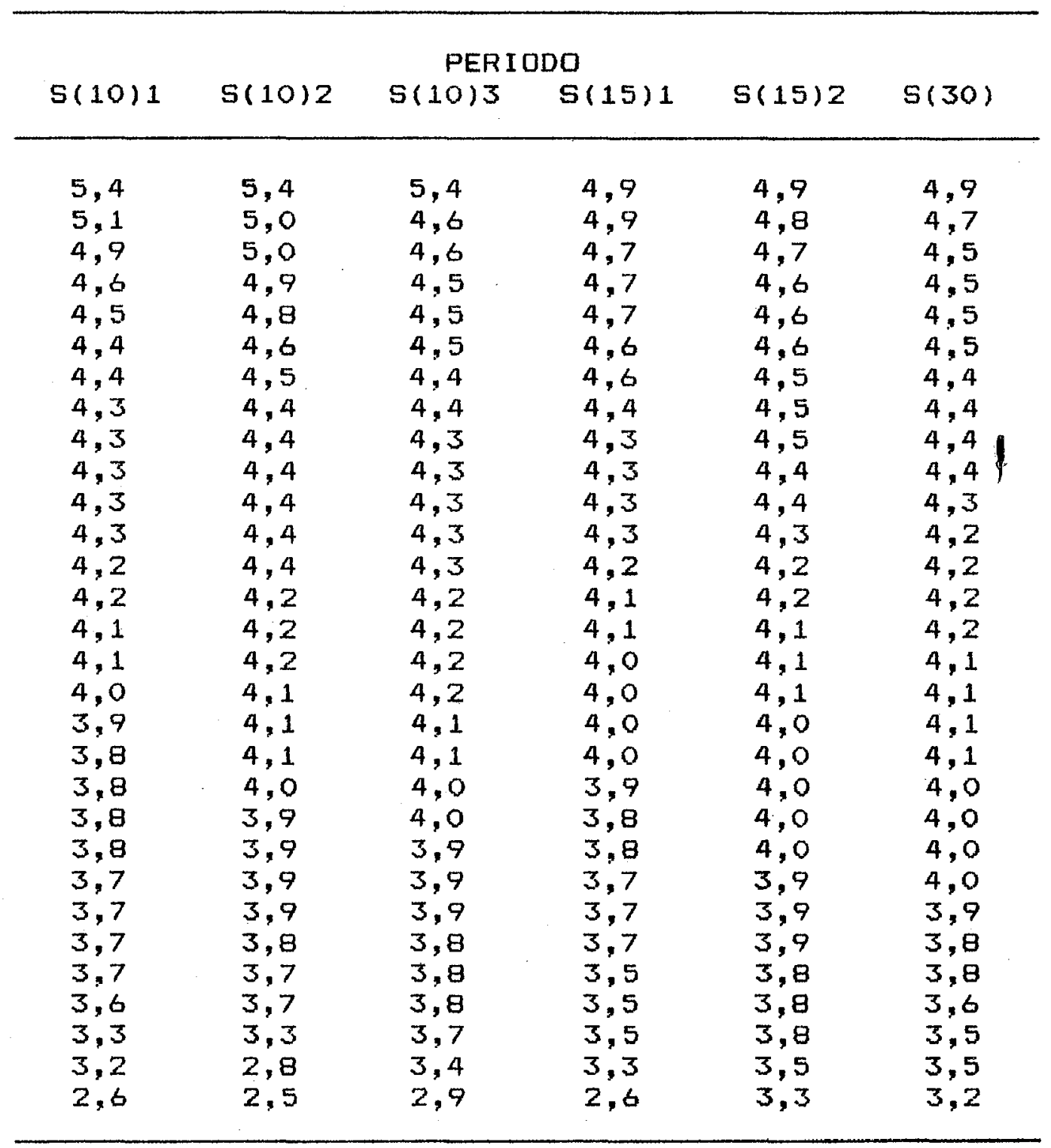


culturas irrigadas plantadas em abril ou maio, da mesma forma que o mess de março seria para as culturas plantadas em torno de outubro.

Na Tabela 16 encontram-se os parámetros estatisticos dos dados de evapotranspiração para os diferentes periodos, onde se verifica que, à semelhança de março, as estimativas tèm uma pequena amplitude de variação e pequena variação, conforme indicam os coeficientes de variaçăo.

Os parâmetros da runção densisidade de probabilidade da distribuição Beta encontram-se na Tabela 17, sendo que todos os periodos apresentam $p>1$ e $q>1$, indicando que a curva tem um pico, com excegăo da quarta pentada que apresenta $p>1$ e $q<1$, tendo a curva a forma de um I, conforme pode ser observado na Figura 4 .

Aplicando-se a distribuigão Beta aos dados da evapotranspiração para o mes de setembro, obtiveram-se os diferentes níveis de probabilidades de ocorrencia, para os vários periodos analisados (Tabelas 18 e 19), à semelhança do que foi feito para o mês de março.

Comparando os valores da evapotranspiraçăo dos diferentes periodos, para um mesmo nivel de probabilidade, verifica-se a mesma tendência observada em março, de aumento do valor da estimativa com a redução do número de dias. Em setembro, para o nivel de $75 \%$ de probabilidade (Tabela 20 , a variação dos valores da evapotranspiração em relação ao valor mensal, ficou entre 
Tabela 16 - Parânetros estatísticos referentes aos dados de evapotranspiração do mês de setembro, para os períodos de $5,10,15$ e 30 dias, de um intervalo de 30 anos.

\begin{tabular}{|c|c|c|c|c|c|}
\hline PERIODO & $\begin{array}{l}\text { AMPLI- } \\
\text { TUDE } \\
(\mathrm{mm} / \mathrm{da})\end{array}$ & $\begin{array}{l}\text { MEDIA } \\
(\mathrm{mm} / \mathrm{dia})\end{array}$ & $\begin{array}{l}\text { DESVIO } \\
\text { PADRAO }\end{array}$ & VARI I ANCIA & $\begin{array}{c}\text { COEF. DE } \\
\text { VAR IACAO } \\
(\%)\end{array}$ \\
\hline $5(5) 1$ & 2,7 & 4,0 & 0,649 & 0,421 & 16,3 \\
\hline $5(5) 2$ & 3,1 & 4,1 & 0,703 & 0,494 & 17,0 \\
\hline $5(5) 3$ & 3,1 & 4,1 & 0,721 & 0,520 & 17,5 \\
\hline $5(5) 4$ & 2,8 & 4,2 & 0,727 & 0,528 & 17,2 \\
\hline$S(5) 5$ & 2,5 & 4,1 & 0,648 & 0,419 & 15,7 \\
\hline $5(5) 6$ & 3,4 & 4,2 & 0,705 & 0,497 & 16,9 \\
\hline $5(10) 1$ & 2,8 & 4,1 & 0,552 & 0,305 & 13,6 \\
\hline $5(10) 2$ & 2,7 & 4,2 & 0,605 & 0,366 & 14,5 \\
\hline $5(10) 3$ & 2,5 & 4,2 & 0,432 & 0,186 & 10,4 \\
\hline$S(15) 1$ & 2,3 & 4,1 & 0,507 & 0,257 & 12,4 \\
\hline$s(15) 2$ & 1,6 & 4,2 & 0,375 & 0,141 & 9,0 \\
\hline $5(30)$ & 1,7 & 4,1 & 0,368 & 0,135 & 8,7 \\
\hline
\end{tabular}


Tabela 17 - Parâmetros $p$ e $q$ da distribui ção Beta para os dados de evapotranspiração do mês de setembro, para os períodos de $5,10,15$ e 30 dias.

\begin{tabular}{lll}
\hline PEFIODO & $\hat{p}$ & $\hat{a}$ \\
\hline$S(5) 1$ & 1,739336 & 1,514041 \\
$S(5) 2$ & 1,747549 & 2,000983 \\
$S(5) 3$ & 1,889252 & 1,599939 \\
$S(5) 4$ & 1,480274 & 0,848578 \\
$S(5) 5$ & 1,258178 & 1,319413 \\
$S(5) 6$ & 2,700321 & 1,716747 \\
$S(10) 1$ & 2,723676 & 2,527829 \\
$S(10) 2$ & 2,700001 & 1,907332 \\
$S(10) 3$ & 3,620399 & 3,616995 \\
$S(15) 1$ & 2,397844 & 1,422121 \\
$S(15) 2$ & 1,961177 & 1,486335 \\
$S(30)$ & 2,371713 & 1,961099 \\
\hline
\end{tabular}




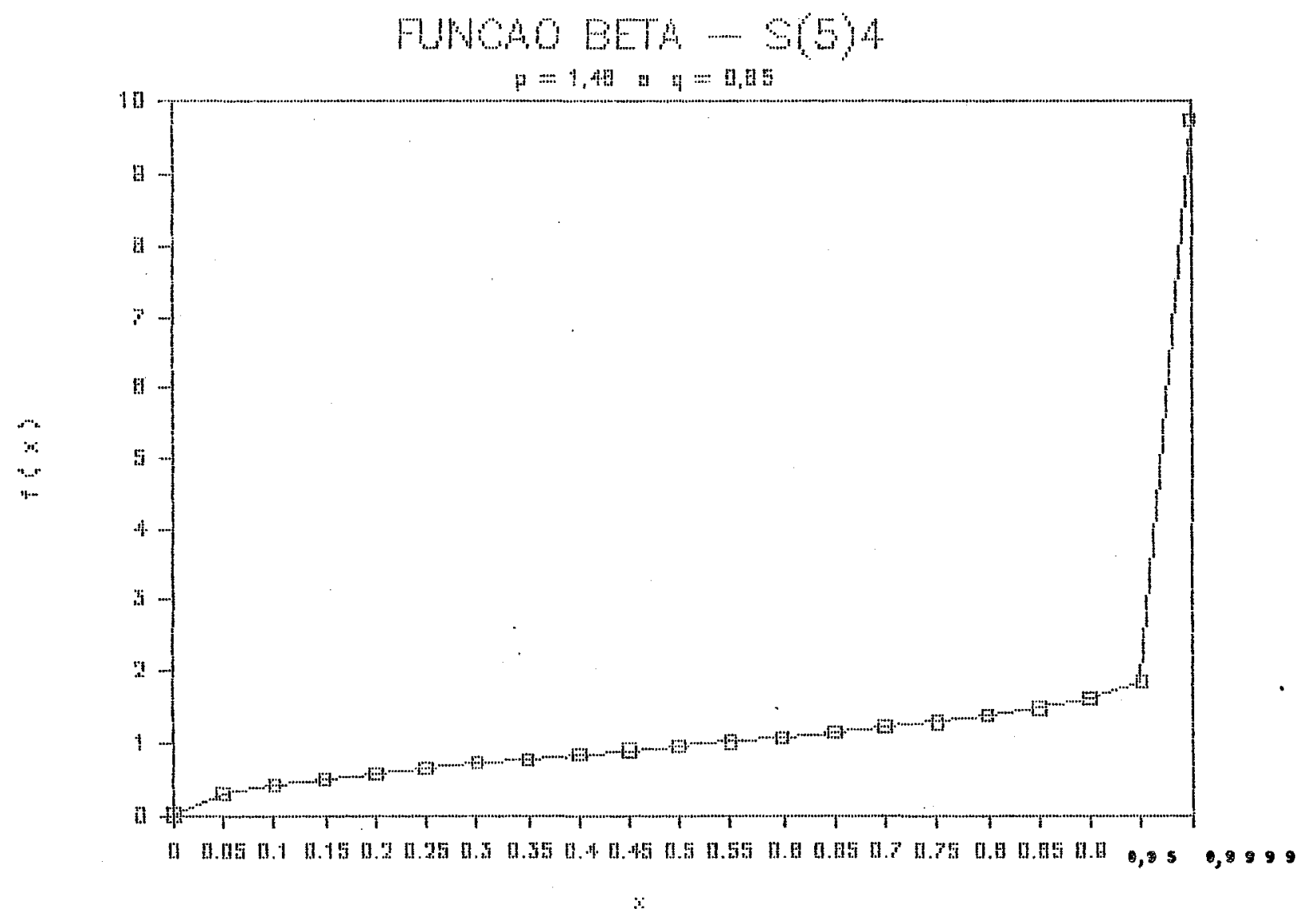

Figura 4 - Função densidade da distribuição Beta aplicada à evapotranspiração para a quarta pentada do mês de setembro. 
Tabela 18 - Evapotranspiração de referência calculada através da distribuição Beta para as pentadas do mês de setembro, en função dos diversos níveis de probabilidade de ocorrência.

NIVEL DE PROBAB I LI DADE

(\%)

10

20

25

30

40

50

60

70

75

80

90

95

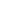

0

5

o

0

o

5

80

0

EVAPOTRANSPIRACAO DE REFERENCIA (mm/dia)

$\begin{array}{llllll} & \text { PERIODO } & & \\ 5(5) 1 & 5(5) 2 & S(5) 3 & 5(5) 4 & 5(5) 5 & S(5) 6\end{array}$

2,7

3,0

2,9

2,7

3,1

2,9

3,1

3,2

3,1

3,1

3,3

3,1

3,4

3,5

3,4

3,5

3,5

3,5

3,5

3,6

3,5

3,7

3,6

3,7

3,6

3,7

3,7

3,8

3,7

3,8

3,9

3,9

4,1

3,9

4,0

4,0

4,1

4,1

4.3

4,1

4,2

4,3

4,4

4,6

4,4

4,4

4,4

4,6

4,6

4,8

4,6

4,6

4,5

4,7

4,7

4,9

4,7

4,7

4,6

4,8

4,8

5,0

4,8

4,8

4,9

5,1

5,1

5,1

5,1

5,1

5,3

5,2

5,2

5,2

5,2 
Tabela 19 - Evapotranspiração de referência obtida através da distribuição Beta para os períodos de $10,15 \mathrm{e} 30$ dias do mês de setembro, em função dos diversos níveis de probabilidade de ocorrência.

NIVEL DE PROBAB I LIDADE

(\%)
EVAPOTRANSPIRACAO DE REFERENCIA ( $\mathrm{mm} / \mathrm{dia})$
$\begin{array}{llllll}S(10) 1 & S(10) 2 & S(10) 3 & S(15) 1 & S(15) 2 & S(30)\end{array}$

\begin{tabular}{lllllll}
\hline 5 & 3,1 & 3,0 & 3,4 & 3,0 & 3,5 & 3,5 \\
10 & 3,3 & 3,3 & 3,5 & 3,4 & 3,6 & 3,6 \\
20 & 3,6 & 3,6 & 3,8 & 3,6 & 3,8 & 3,8 \\
25 & 3,7 & 3,7 & 3,8 & 3,7 & 3,9 & 3,8 \\
30 & 3,8 & 3,8 & 3,9 & 3,8 & 4,0 & 3,9 \\
40 & 3,9 & 4,0 & 4,0 & 4,0 & 4,1 & 4,0 \\
50 & 4,1 & 4,2 & 4,2 & 4,1 & 4,2 & 4,1 \\
60 & 4,2 & 4,4 & 4,3 & 4,3 & 4,3 & 4,3 \\
70 & 4,4 & 4,5 & 4,4 & 4,4 & 4,4 & 4,4 \\
75 & 4,5 & 4,6 & 4,5 & 4,5 & 4,5 & 4,4 \\
80 & 4,6 & 4,7 & 4,6 & 4,6 & 4,6 & 4,5 \\
90 & 4,8 & 5,0 & 4,9 & 4,7 & 4,7 & 4,6 \\
95 & 5,0 & 5,1 & 5,1 & 4,8 & 4,8 & 4,7 \\
\hline
\end{tabular}


Tabela 20 - Relação entre a evapotranspiração ao nivel de $75 \%$ de probabilidade em um determinado período e a evapotranspiração a $75 \%$ de probabilidade para o período de 30 dias, para o mês de setembro.

\begin{tabular}{|c|c|c|}
\hline PER IODO & $\begin{array}{l}\text { ETo a } 75 \% \\
(\mathrm{~mm} / \mathrm{dia})\end{array}$ & $\begin{array}{l}\text { \% em relacao a ETo a } 75 \% \\
\text { do periodo de } 30 \text { dias }\end{array}$ \\
\hline$S(5) 1$ & 4,5 & $2,3 \%$ \\
\hline$S(5) 2$ & 4,7 & 6,8 \\
\hline$S(5) 3$ & 4,7 & $6, \theta$ \\
\hline $5(5) 4$ & 4,9 & 11,4 \\
\hline $5(5) 5$ & 4.7 & 6,8 \\
\hline $5(5) 6$ & 4,7 & 6,8 \\
\hline$S(10) 1$ & 4,5 & 2,3 \\
\hline $5(10) 2$ & 4,6 & 4,5 \\
\hline$S(10) 3$ & 4,5 & 2,3 \\
\hline$S(15) 1$ & 4,5 & 2,3 \\
\hline $5(15) 2$ & 4,5 & 2,3 \\
\hline$S(30)$ & 4,4 & 0,0 \\
\hline
\end{tabular}


$2,3 \odot 11,4 \%$

Fazendo a relaçäo entre a evapotranspiraçäo ao nível de $75 \%$ de probabilidade e o valor médio, verifica-se uma variação mínima de $7,1 \%$ e uma variação máxima de $16,7 \%$ (Tabela 21 ).

As figuras 5 e 6 ilustram o ajuste entre os dados observados de evapotranspiraçăo e aqueles estimados segundo a distribuiçăo Beta.

Os valores de ETo para os diferentes niveis de probabilidade, "segundo a distribuição Normal, encontram-se nas Tabelas 22 e 23 , sendo bastante próximos daqueles encontrados através da distribução Beta.

Os resultados obtidos em setembro são coerentes com aqueles obtidos em março, o que vem a confirmar as afirmaçöes e as recomendaçöes já efetuadas, e que valem, tambem, para setembro. 
Tabela 21 - Estudo comparativo entre a evapotranspiração ao nível de $75 \%$ de probabilidade e a evapotranspiração média, para os períodos de $5,10,15$ e 30 dias do mês de setembro.

PERIODO

ETo a $75 \%$

(mm/dia)
ETo media

( $\mathrm{mm} / \mathrm{dia}$ )
ETo media ETo a $75 \%$ probabili- ETo media dade $(\%)$

\begin{tabular}{lllll}
\hline $5(5) 1$ & 4,5 & 4,0 & 50 & 1,125 \\
$5(5) 2$ & 4,7 & 4,1 & 50 & 1,146 \\
$5(5) 3$ & 4,7 & 4,1 & 50 & 1,146 \\
$S(5) 4$ & 4,9 & 4,2 & 45 & 1,167 \\
$5(5) 5$ & 4,7 & 4,1 & 50 & 1,146 \\
$5(5) 6$ & 4,7 & 4,2 & 50 & 1,119 \\
$5(10) 1$ & 4,5 & 4,1 & 50 & 1,098 \\
$5(10) 2$ & 4,6 & 4,2 & 50 & 1,095 \\
$5(10) 3$ & 4,5 & 4,2 & 50 & 1,071 \\
$5(15) 1$ & 4,5 & 4,1 & 50 & 1,098 \\
$5(15) 2$ & 4,5 & 4,2 & 50 & 1,071 \\
$S(30)$ & 4,4 & 4,1 & 50 & 1,073 \\
\hline
\end{tabular}


(5)

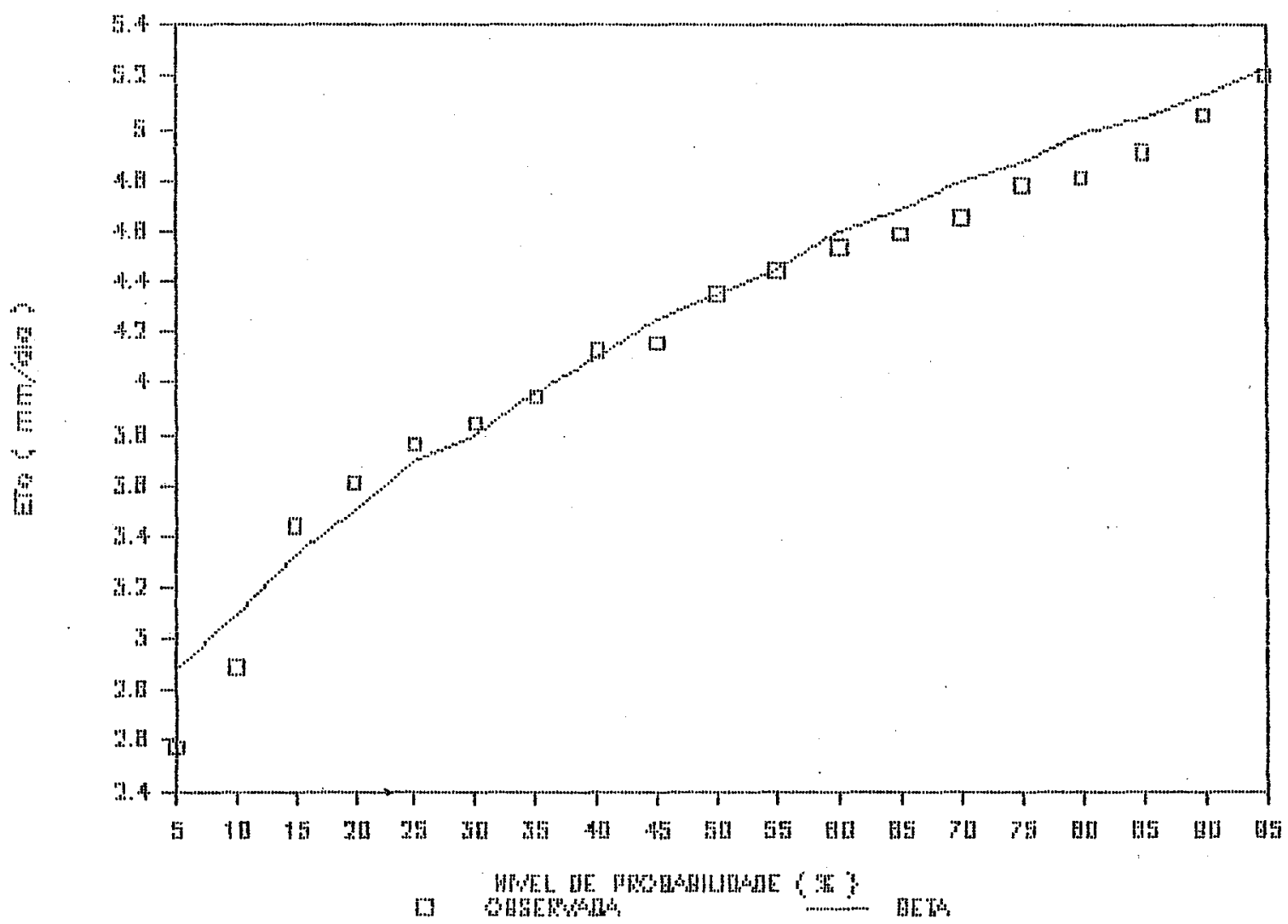

Figura 5 - Evapotranspiração para os diferentes níveis de probabilidade obtida através da distribui.ção Beta, e evapotranspiração observada para a quarta pentada de setembro. 
76.

s(15)

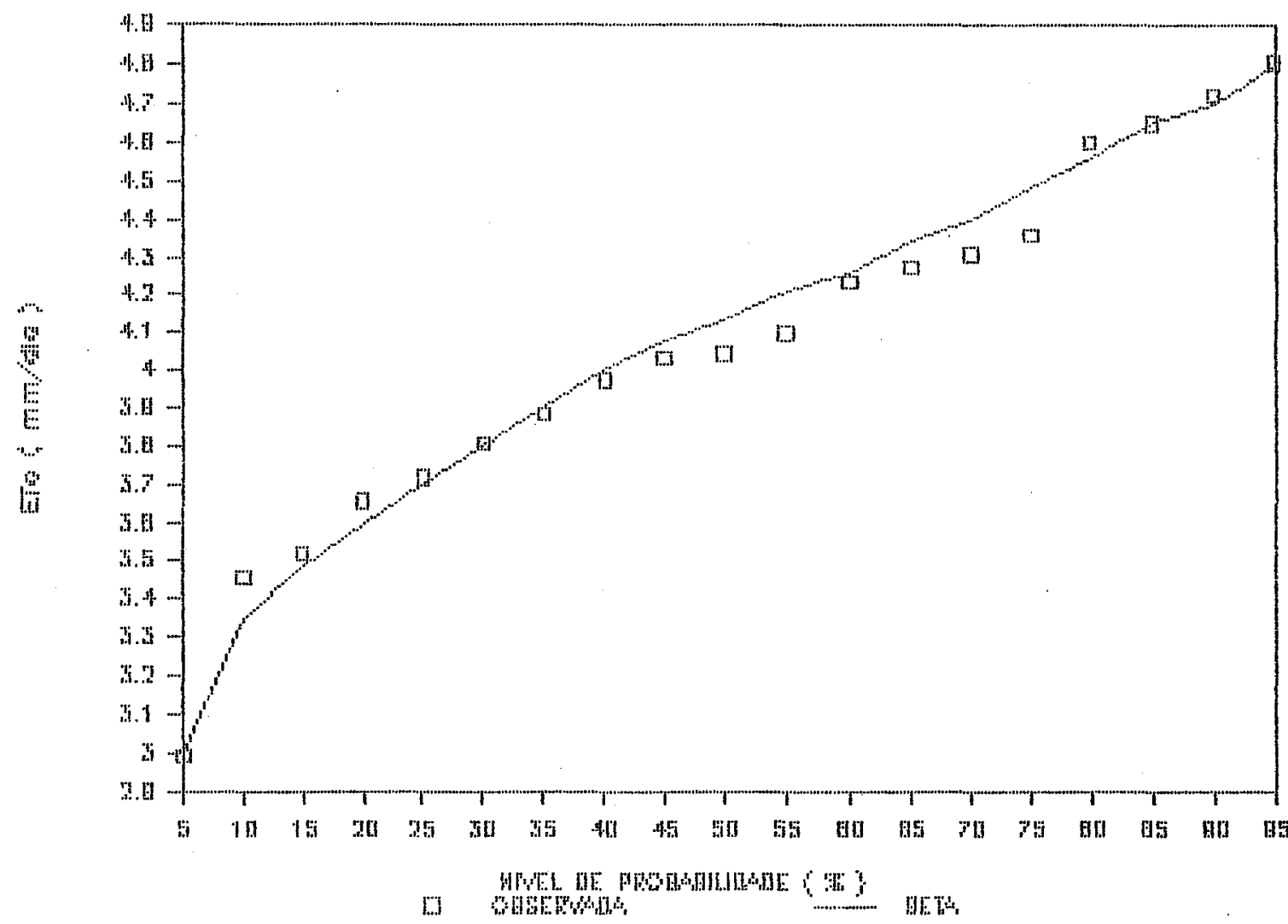

Figura 6 - Evapotranspiração para os diferentes níveis de probabilidade obtida através da distribuição Beta, e evapotranspiração observada para a primeira quinzena do mês de setembro. 
Tabela 22 - Evapotranspiração de referência obtida através da distribuição Normal para as pentadas do mês de setembro, em função de diversos niveis de probabilidade de ocorrência.

NIVEL DE PROBABI LIDADE

(\%)

EVAPOTRANSPIRACAO DE REFERENCIA (mm/dia)

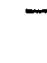

PERIODO

$5(5) 1 \quad 5(5) 2$

$5(5) 4$

$5(5) 5$

$5(5) 6$

\section{5}

$$
2,9
$$

3,0

2,9

3,0

3,1

3, 0

10

3, 2

3,2

3,2

3.3

3,3

3,3

20

$$
3,4
$$

3,5

3,5

3,6

3,6

3,6

25

$$
3,6
$$

3,6

3,6

3,7

3,7

3,7

30

3,7

3,7

3,7

3,8

3,8

3,8

40

3,8

3,9

3,9

4,0

4,0

4,0

50

4,0

4,1

4,1

4,2

4,1

4,2

60

4,2

4,3

4,3

4,4

4,3

4,3

70

4,3

4,5

4,5

4,6

4,5

4,5

75

4,4

4,6

4,6

4,7

4,6

4,6

80

4,5

4,7

4,7

4,8

4,7

4,8

90

4,8

5,0

5,0

5,2

5,0

5,1

95

5,1

5,3

5,3

5,4

5,2

5,3 
Tabela 23 - Evapotranspiração de referência obtida através da distribuição Normal para os períodos de 10,15 e 30 dias do mês de setembro, em função de diversos níveis de probabilidade de ocorrência.

NIVEL DE PROBABI LIDADE

(\%)

5

10

20

25

30

40

50

60

70

75

80

90

95
EVAPOTRANSPIRACAO DE REFERENCIA ( $\mathrm{mm} / \mathrm{dia})$

PERIODO

$\begin{array}{llllll}S(10) 1 & S(10) 2 & 5(10) 3 & S(15) 1 & 5(15) 2 & 5(30)\end{array}$

3,2

3,4

3,2

3,6

3,5

3,4

3,6

3,4

3,7

3,7

3,7

3,8

3,7

3,9

3,8

3,8

3,9

3,7

3,9

3,9

3,8

3,9

3,8

4,0

3,9

4,0

4,0

4,0

4,1

4,0

4,2

4,2

4,1

4,2

4,1

4,3

4,3

4,2

4,3

4,2

4,5

4,4

4,3

4,4

4,3

4,6

4,5

4,4

4,4

4,4

4,7

4,5

4,5

4,5

4,4

4,9

4,7

4,7

4,7

4,6

5,2

4.9

4,9

4,8

4,7 


\subsection{Precipitação pluvial}

- teste de Kolmogorov-Smirnov foi aplicado às distribuiçöes Normal e Mista, para verificar se as mesmas se ajustavam aos dados de precipitaçăo pluvial dos meses de março e setembro. A distribuição Normal não forneceu resultados estatisticamente significativos para os periodos analisados. Já a distribuição Mista utilizando a distribuição Gama, teve a hipotese Ho aceita em todos os periodos analisados, ao nível de significância de $5 \%$, estando, portanto, apta para representar os dados de precipitação de ambos os meses estudados.

\subsubsection{Precipitação pluvial para o mês de março}

o mès de março é o período que sucede à estação chuvosa para a região de Piracicaba, SP, conforme pode ser verificado em OMETTO (1989). E, também, o periodo de máxima exigència hidrica de grande número das culturas plantadas em outubro, pois coincide com os estádios de maior necessidade de asua das mesmas (floraçăo, enchimento dos cräios, etc.s. Os valores da precipitação para os diferentes periodos encontram-se ordenados de forma decrescente nas Tabelas 24 e 25.

Na Tabela 26 estăo alguns parâmetros estatisticos referentes aos dados de precipitação para os diferentes periodos. Analisando estes valores, verifica-se 
80.

Tabela 24 - Valores da precipitação pluvial, en ordem decrescente, para as pentadas do mês de narço, para un periodo de 71 anos.

PRECIPITACAO PLUVIOMETRICA OBSERVADA (mm)

\begin{tabular}{|c|c|c|c|c|c|}
\hline \multirow[b]{2}{*}{$M(5) 1$} & \multirow[b]{2}{*}{$M(5) 2$} & \multicolumn{2}{|c|}{ PERIODO } & \multirow[b]{2}{*}{$M(5) 5$} & \multirow[b]{2}{*}{$M(5) 6$} \\
\hline & & $M(5) 3$ & $M(5) 4$ & & \\
\hline 107,6 & 150,8 & 184,3 & 122,1 & 98,6 & 123,8 \\
\hline 91,7 & 95,4 & 124,7 & 103,1 & 96,5 & 99,8 \\
\hline 88,3 & 79,6 & 86,1 & 85,6 & 80,8 & 78,4 \\
\hline 84,3 & 78,4 & 83,0 & 84,5 & 62,4 & 68,7 \\
\hline 84,0 & 77,2 & 82,6 & 82,0 & 60,8 & 63,9 \\
\hline 84,0 & 72,6 & 71,4 & 79,8 & 57,7 & 60,0 \\
\hline 78,5 & 70,5 & 63,2 & 69.9 & 55,5 & 56,6 \\
\hline 77,2 & 67,8 & 61,1 & 53,3 & 50,0 & 50,0 \\
\hline 73,5 & 65,5 & 54,8 & 49,4 & 42,9 & 47,7 \\
\hline 72,2 & 59,6 & 50,8 & 46,8 & 41,8 & 47,5 \\
\hline 69,8 & 59,2 & 48,9 & 44,9 & 39.7 & 37,2 \\
\hline 64,2 & 54,9 & 47,2 & 40,8 & 38,5 & 36,3 \\
\hline 63,2 & 49,4 & 46,0 & 38,1 & 38,5 & 35,7 \\
\hline 53,9 & 43,6 & 40,5 & 38,1 & 37,8 & 33,7 \\
\hline 53,6 & 42,5 & 38,8 & 36,5 & 34,3 & 33,5 \\
\hline 52,4 & 40,7 & 37,2 & 36,4 & 34,0 & 32,5 \\
\hline 48,3 & 40,7 & 37,1 & 33,8 & 32,7 & 32,1 \\
\hline 43,8 & 34,6 & 36,5 & 33,5 & 32,2 & 31,9 \\
\hline 43,1 & 34,0 & 36,2 & 32,3 & 30,9 & 30,4 \\
\hline 39,1 & 33,6 & 35,2 & 32,2 & 27,3 & 29,7 \\
\hline 38,1 & 30,2 & 33,0 & 31,1 & 26,0 & 29,0 \\
\hline 36,8 & 29,7 & 32,7 & 30,2 & 25,5 & $2 \theta, 8$ \\
\hline 33,0 & 26,5 & 31,5 & 29,2 & 19,0 & 28,0 \\
\hline 22,8 & 26,0 & 31,1 & 26,0 & 18,9 & 27,5 \\
\hline 19,5 & 23,6 & 30,8 & 25,9 & 18,1 & 25,7 \\
\hline 16,9 & 20,4 & 28,2 & 21,6 & 16,4 & 25,3 \\
\hline 14,1 & 19,8 & 28,0 & 18,3 & 15,1 & 24,5 \\
\hline 13,5 & 19,5 & 26,7 & 17,0 & 12,1 & 22,0 \\
\hline
\end{tabular}


Tabela 24 - Valores da precipitação pluvial, em ordem decrescente, para as pentadas do mês de março, para um período de 71 anos.

\begin{tabular}{|c|c|c|c|c|c|}
\hline 12,6 & 19,4 & 25,7 & 16,5 & 10,6 & 22,0 \\
\hline 12,1 & 18,9 & 25,5 & 16,4 & 9,7 & 21,6 \\
\hline 11,9 & 18,2 & 25,3 & 16,0 & 8,7 & 21,5 \\
\hline 11,7 & 17,0 & 25,2 & 14,6 & 8,5 & 20,1 \\
\hline 11,4 & 16,9 & 24,0 & 14,4 & 7,8 & 17,8 \\
\hline 10,8 & 16,3 & 22,4 & 14,4 & 7,8 & 17,1 \\
\hline 9,9 & 16,2 & 21,9 & 14,2 & 7,0 & 10,2 \\
\hline 9,9 & 15,4 & 21,5 & 12,0 & 6,0 & 9,2 \\
\hline 9,0 & 14,3 & 20,4 & 12,0 & 5,0 & 7,7 \\
\hline 9,0 & 13,8 & 20,3 & 11,7 & 4,0 & 7,0 \\
\hline 8,5 & 12,9 & 17,4 & 10,7 & 3,8 & 6,7 \\
\hline 8,2 & 12,5 & 18,2 & 10,5 & 3,1 & 6,1 \\
\hline 6,6 & 11,6 & 18,1 & 8,1 & 2,6 & 4,9 \\
\hline 6,5 & 10,8 & 16,6 & 8,0 & 1,0 & 4,6 \\
\hline 6,3 & 9,6 & 15,5 & 7,9 & 1,0 & 3,5 \\
\hline 6,1 & 8,5 & 14,0 & 7,5 & 1,0 & 3,2 \\
\hline 5,8 & 6,0 & 13,3 & 7,2 & 1,0 & 3,1 \\
\hline 5,3 & 5,8 & 11,4 & 7,2 & 0,0 & 2,8 \\
\hline 5,0 & 5,7 & 11,3 & 6,5 & 0,0 & 2,3 \\
\hline 4,7 & 5,6 & 9,4 & 5,8 & 0,0 & 1,6 \\
\hline 4,3 & 5,5 & 7,0 & 5,7 & 0,0 & 1,5 \\
\hline 3,7 & 4,2 & 5,0 & 4,0 & 0,0 & 1,0 \\
\hline 3,7 & 4,1 & 3,1 & 3,7 & 0,0 & 1,0 \\
\hline 3,5 & 2,3 & 3,0 & 3,4 & 0,0 & 0,0 \\
\hline 2,5 & 1,1 & 2,9 & 3,0 & 0,0 & 0,0 \\
\hline 2,3 & 1,0 & 2,4 & 2,9 & 0,0 & 0,0 \\
\hline 1,6 & 1,0 & 1,4 & 2,6 & 0,0 & 0,0 \\
\hline 1,0 & 1,0 & 1,3 & 2,2 & 0,0 & 0,0 \\
\hline 1,0 & 0,0 & 1,2 & 2,0 & 0,0 & 0,0 \\
\hline 1,0 & 0,0 & 1,0 & 0,0 & 0,0 & 0,0 \\
\hline 1,0 & 0,0 & 1,0 & 0,0 & 0.0 & 0,0 \\
\hline 0,0 & 0,0 & 1,0 & 0,0 & 0,0 & 0,0 \\
\hline 0,0 & 0,0 & 1,0 & 0,0 & 0,0 & 0,0 \\
\hline 0,0 & 0,0 & 0,0 & 0,0 & 0,0 & 0,0 \\
\hline 0,0 & 0,0 & 0,0 & 0,0 & 0,0 & 0,0 \\
\hline 0,0 & 0,0 & 0,0 & 0,0 & 0,0 & 0,0 \\
\hline 0,0 & 0,0 & 0,0 & 0,0 & 0,0 & 0,0 \\
\hline 0,0 & 0,0 & 0,0 & 0,0 & 0,0 & 0,0 \\
\hline 0,0 & 0,0 & 0,0 & 0,0 & 0,0 & 0,0 \\
\hline 0,0 & 0,0 & 0,0 & 0,0 & 0,0 & 0,0 \\
\hline 0,0 & 0,0 & 0,0 & 0,0 & 0,0 & 0,0 \\
\hline 0,0 & 0,0 & 0,0 & 0,0 & 0,0 & 0,0 \\
\hline 0,0 & 0,0 & 0,0 & 0,0 & 0,0 & 0,0 \\
\hline
\end{tabular}


Tabela 25 - Valores da precipitação pluvial, em ordem decrescente, para os períodos de $10,15 \mathrm{e}$ 30 dias do mês de marģo, para um intervalo de 71 anos.

PRECIPITACAO PLUVIAL OBSERVADA (mm)

\begin{tabular}{|c|c|c|c|c|c|}
\hline \multirow[b]{2}{*}{$M(10) 1$} & \multicolumn{4}{|c|}{ PERIODO } & \multirow[b]{2}{*}{$M(30)$} \\
\hline & $M(10) 2$ & $M(10) 3$ & $M(15) 1$ & $M(15) 2$ & \\
\hline 215,0 & 268,8 & 162,5 & 243,9 & 177,1 & 329,0 \\
\hline 162,4 & 227,8 & 132,2 & 232,3 & 150,6 & 320,8 \\
\hline 160,9 & 122,1 & 130,7 & 222,0 & 149,2 & 311,4 \\
\hline 133,2 & $11 \theta, 4$ & 123,8 & 189,1 & 143,7 & 301,3 \\
\hline 114,3 & 118,3 & 114,3 & 175,5 & 135,9 & 269,8 \\
\hline 111,8 & 110,4 & 107,2 & 150,7 & 131,7 & 225,6 \\
\hline 111,7 & 105,3 & 89,8 & 150,6 & 130,7 & 214,4 \\
\hline 108,7 & 93,3 & 79,7 & 138,2 & 130,0 & 206,7 \\
\hline 96,0 & 86,3 & 78,4 & 136,9 & 126,2 & 206,2 \\
\hline 95,4 & 84,1 & 75,6 & 132,2 & 122,1 & 203,1 \\
\hline 92,9 & 83,0 & 73,2 & 131,2 & 105,7 & 202,4 \\
\hline 92,2 & 81,9 & 68,9 & 122,3 & 100,5 & 200,8 \\
\hline 87,5 & 81,0 & 62,4 & 115,8 & 90,1 & 196,2 \\
\hline 84,7 & $7 \overrightarrow{8,6}$ & 60,8 & 115,7 & 89,5 & 194,5 \\
\hline 84,3 & 71,4 & 60,2 & 114,3 & 89,4 & 194,3 \\
\hline 82,7 & 69,7 & 60,0 & 113,5 & 89,4 & 189,6 \\
\hline 77,2 & 67.2 & 57,9 & 113,0 & 88,7 & 185,6 \\
\hline 76,5 & 66,0 & 57,8 & 113,0 & 86,1 & 184,3 \\
\hline 76,3 & 63,7 & 57,2 & 111,6 & 85,1 & 183,2 \\
\hline 76,3 & 63,2 & 55,9 & 110,0 & 78,7 & 182,9 \\
\hline 72,7 & 63,0 & 55,3 & 109,8 & 76,1 & 173,8 \\
\hline 72,2 & 62,2 & 55,2 & 107,7 & 75,6 & 173,5 \\
\hline 69,8 & 60,4 & 55,0 & 97.9 & 75,0 & 169.9 \\
\hline 64,5 & 56,9 & 48,5 & 96,8 & 72,3 & 167.6 \\
\hline 61,5 & 54,8 & 48,0 & 96,6 & 72,0 & 164,0 \\
\hline 59,6 & 54,4 & 47,9 & 90,5 & 71,6 & 162,3 \\
\hline 52,6 & 49.7 & 47,5 & 81,8 & 71,0 & 160.4 \\
\hline 50.7 & 49.4 & 43.9 & 81. 3 & 68.9 & 160,1 \\
\hline 45,4 & 47,4 & $\begin{array}{l}40,7 \\
39.7\end{array}$ & 75.8 & $\begin{array}{l}00,7 \\
64,2\end{array}$ & $\begin{array}{l}100,1 \\
155,2\end{array}$ \\
\hline 45.0 & 45,6 & 37,5 & 73,1 & 61,8 & 152,9 \\
\hline 43,1 & 43,7 & 35,9 & 72,2 & 59,2 & 152,1 \\
\hline 43,0 & 40,8 & 35,0 & 70,7 & 56,5 & 147,6 \\
\hline
\end{tabular}


Tabela 25 - Valores da precipitação pluvial, em ordem decrescente, para os períodos de 10, 15 e 30 dias do mês de março, para um intervalo de 71 anos.

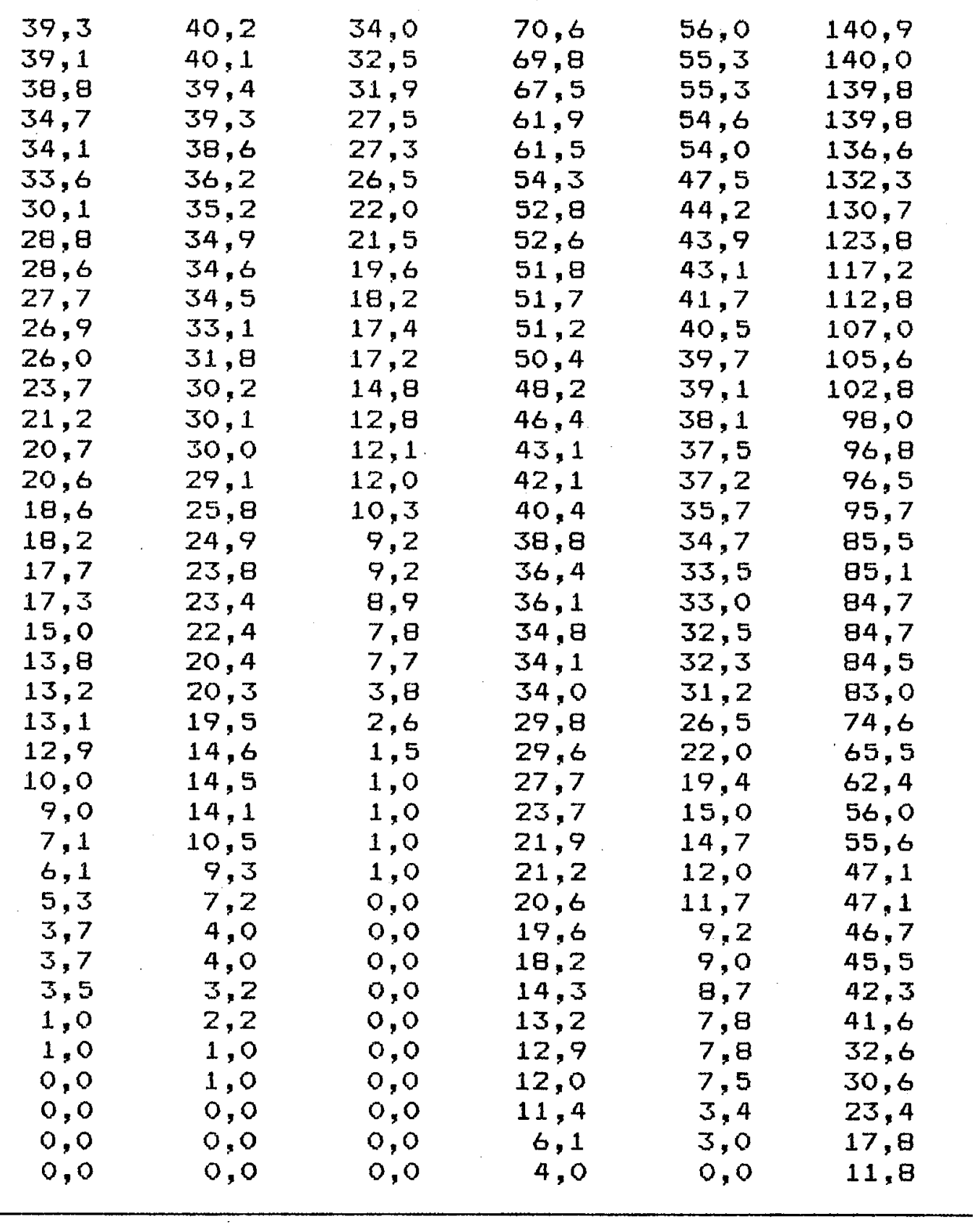


Tabela 26 - Parâmetros estatísticos referentes aos dados da pre cipitação pluvial do mês de março, para os períodos de $5,10,15$ e 30 dias, de um intervalo de 71 anos.

\begin{tabular}{lccccc}
\hline & $\begin{array}{c}\text { AMPLI } \\
\text { TUDE } \\
(\mathrm{mm})\end{array}$ & $\begin{array}{c}\text { MEDIA } \\
(\mathrm{mm})\end{array}$ & $\begin{array}{c}\text { DESVIO } \\
\text { PADRAO }\end{array}$ & $\begin{array}{c}\text { VARIANCIA VARIACAO } \\
(\%)\end{array}$ \\
\hline$M(5) 1$ & 107,6 & 24,8 & 30,067 & 904,030 & 121,2 \\
$M(5) 2$ & 150,8 & 24,2 & 28,919 & 836,297 & 119,5 \\
$M(5) 3$ & 184,3 & 27,0 & 31,157 & 970,735 & 115,4 \\
$M(5) 4$ & 122,1 & 22,4 & 26,869 & 721,932 & 120,0 \\
$M(5) 5$ & 98,6 & 17,4 & 23,740 & 563,574 & 136,4 \\
$M(5) 6$ & 123,8 & 20,2 & 25,075 & 628,753 & 124,1 \\
$M(10) 1$ & 215,0 & 49,1 & 44,404 & 1971,731 & 90,4 \\
$M(10) 2$ & 268,8 & 49,5 & 46,149 & 2129,701 & 93,2 \\
$M(10) 3$ & 162,5 & 37,6 & 37,407 & 1399,257 & 99,5 \\
$M(15) 1$ & 239,9 & 76,1 & 54,786 & 3001,545 & 72,0 \\
$M(15) 2$ & 177,1 & 60,0 & 41,991 & 1763,267 & 70,0 \\
$M(30)$ & 317,2 & 136,1 & 73,391 & 5386,256 & 53,9 \\
\hline
\end{tabular}


que existe uma srande amplitude de variação dos dados e que os coeficientes de variação variaram de 53,9 a $136,4 \%$, indicando que os dados estão muito dispersos e que o estudo de frequiência de distribuiçăo é bastante oportuno.

Comparando os coeficientes de variação da evapotranspiração para o mès de março Cvariaram de 9,6 a $21,7 \%$ com os da precipitação para o mesmo més (variaram de 53,9 a $136,4 \%$, verifica-se o porque da afirmação de que a precipitação é o parâmetro mais variável. Além disto, verifica-se que os dados de precipitação requerem, necessariamente, um estudo de frequência de distribuição.

A distribuição Mista foi aplicada aos dados de precipitação, sendo que os parámetros $\alpha$ e $\beta$ da distribuição Gama estão relacionados na Tabela 27.

As Tabelas 28 e 29 fornecem as probabilidades da precipitação ser igual ou maior que o valor apresentado, nos niveis de $5,10,15,20,25,30$, $40,50,60,70,75,80,90$ e $95 \%$. Assim, para o período mensal, existe a probabilidade de $75 \%$ de que a precipitação seja igual ou maior que $76,4 \mathrm{~mm}$. Outra forma de interpretação consiste em dizer que em três de cada quatro anos, a precipitação será igual ou maior que $70,4 \mathrm{~mm}$.

$$
\text { o valor da precipitação dependente, }
$$

geralmente recomendado para fins de dimensionamento de sistemas de irrigaçăo, e aquele correspondente ao nivel de 75\% de probabilidade MAROUELLI \& SEDIYAMA, 1987 ; MATUTE 
Tabela 27 - Parâmetros a e B da distribuição Ga ma utilizada na distribuiçăo Mista, para os dados de precipitaç̃o pluvial do mês de março, para os períodos de $5,10,15$ e 30 dias.

\begin{tabular}{lcc}
\hline PERIODO & $\hat{\alpha}$ & $\hat{\beta}$ \\
\hline$M(5) 1$ & 0,83803 & 35,68192 \\
$M(5) 2$ & 1,13268 & 27,62391 \\
$M(5) 3$ & 0,99383 & 31,64274 \\
$M(5) 4$ & 1,16475 & 24,00183 \\
$M(5) 5$ & 0,55312 & 49,51896 \\
$M(5) 6$ & 1,06971 & 26,33475 \\
$M(10) 1$ & 1,20377 & 43,19957 \\
$M(10) 2$ & 1,32067 & 39,10905 \\
$M(10) 3$ & 1,07027 & 40,89928 \\
$M(15) 1$ & 1,78534 & 42,62161 \\
$M(15) 2$ & 1,70891 & 35,63615 \\
$M(30)$ & 2,80641 & 48,50878 \\
\hline
\end{tabular}


Tabela 28 - Precipitação pluvial obtida através da distribuição Mista para as pentadas do mês de março, em função dos diversos niveis de probabilidade de ocorrência.

NIVEL DE PROBABI LIDADE (\%)
PRECIPITACAO PLUVIAL DEPENDENTE (mm)

PERIODO

\begin{abstract}
$M(5) 3$
\end{abstract}

$M(5) 5$

$M(5) 6$

$$
91,9
$$$$
74,4
$$$$
82,6
$$$$
74,0
$$

10

$$
65,8
$$

68,0

68,0

57,3

54,3

55,0

20

25

30

40

50

60

70

75

80

90

95
42,7

42,4

45,9

38,8

33,1

24,0

17,0

11,2

6,4

2,2

2,2

0

0
$3 \theta, 8$

28,5

36,1

33,0

21,1

30,0

28,2

15,2

25,0

20,6

7,2

17,2

14,6

2,5

10,8

9,4

1

$4, \theta$

o

2,6

1,7

0

0
0

0

0

0
5,6

1

$0 \quad 0 \quad i \quad 0 \quad 00$


Tabela 29 - Precipitação pluvial obtida através da distribuição Mista para os períodos de 10,15 e 30 dias do nês de março, em função de diversos níveis de probabilidade de ocorrência.

NIVEL DE PROBABI LIDADE

(\%)

\begin{tabular}{lcccccc}
\hline 5 & 145,4 & 160,3 & 121,9 & 202,3 & 151,7 & 293,6 \\
10 & 111,8 & 109,2 & 93,3 & 152,3 & 122,4 & 248,4 \\
20 & 79,7 & 79,1 & 63,7 & 115,7 & 92,4 & 195,7 \\
25 & 69,1 & 69,2 & 54,3 & 103,4 & 82,3 & 178,9 \\
30 & 60,4 & 61,0 & 46,5 & 93,0 & 73,8 & 164,5 \\
40 & 46,7 & 47,8 & 34,2 & 76,2 & 59,3 & 140,5 \\
50 & 35,7 & 37,3 & 24,6 & 62,5 & 48,9 & 120,4 \\
60 & 26,4 & 28,4 & 16,6 & 50,5 & 39,1 & 102,2 \\
70 & 18,4 & 20,4 & 9,8 & 39,6 & 30,2 & 85,0 \\
75 & 14,6 & 16,7 & 6,6 & 34,3 & 25,9 & 76,4 \\
80 & 11,0 & 13,0 & 3,6 & 28,5 & 21,6 & 67,5 \\
90 & 3,8 & 5,6 & 0 & 18,1 & 12,6 & 47,7 \\
95 & 0 & 1 & 0 & 11,8 & 7,1 & 34,7 \\
\hline
\end{tabular}

\section{PRECIPITACAO PLUVIAL DEPENDENTE (mm)}

PERIODO

$\begin{array}{llllll}M(10) 1 & M(10) 2 & M(10) 3 & M(15) 1 & M(15) 2 & M(30)\end{array}$


\& HACHEM, 1983). Outros autores recomendam niveis: de probabilidade entre $75 e 80 \%$ CDOORENBOS \& PRUITT, 1984), ou até mesmo variando de 50 a $90 \%$ (DASTANE, 1974), dependendo da necessidade da cultura, seu valor económico, estáadio de desenvolvimento e da disponibilidade de recursos hidricos, ou seja, dependendo de um estudo criterioso. Estes niveis de probabilidade representam a quantidade de precipitaçäo igual a ou maior que um valor provavel que se espera ocorrer, aproximadamente, em tres de cada quatro anos. $O$ que se verifica na pratica e o uso do valor médio mensial, o que não é um critério recomendável, pois ao se analisar a Tabela 30 , é possivel constatar que existe uma grande diferença entre a precipitação dependente ao nivel de $75 \%$ caritério recomendado) e a precipitaçăo media. Nota-se, também, que as precipitações médias para os diferentes periodos estão compreendidas entre os niveis de probabilidade de 28 e 42\%, bastante inferiores em relação ao nivel recomendado para fins de dimensionamento de sistemas de irrigaçăo (75\%). Isto e decorrente do fato dos dados de precipitaçäo pluvial terem se ajustado a uma distribuição $($ Mista) que utiliza a distribuição Gama, uma vez que esta e positivamente assimetrica, ou seja, o ramo mais longo da curva rica a direita (Figura 11 ).

A Tabela 30 permite, ainda, que se verifique que, em termos médios, ass probabilidadess referentes ds precipitaçốs médias dos periodos de 5,10 , 
Tabela 30 - Estudo comparativo entre a precipitação pluvial ao nível de 75\% e a precipilação pluvial média, para os períodos de 5, 10, 15 e 30 dias do mês de março.

\section{PRECIPITACAO}

\begin{tabular}{lccc} 
PERIODO & $\begin{array}{c}\text { MEDIA } \\
(\mathrm{mm})\end{array}$ & $\begin{array}{c}\text { MEDIA } \\
(\mathrm{mm})\end{array}$ & $\begin{array}{c}\text { probabilidade } \\
(\%)\end{array}$ \\
\hline$M(5) 1$ & 2,1 & 24,9 & 35 \\
$M(5) 2$ & 1,4 & 24,2 & 37 \\
$M(5) 3$ & 2,2 & 27,0 & 36 \\
$M(5) 4$ & 2,6 & 22,4 & 37 \\
$M(5) 5$ & 0 & 17,4 & 36 \\
$M(5) 6$ & 14,6 & 20,2 & 38 \\
$M(10) 1$ & 16,7 & 49,1 & 39 \\
$M(10) 2$ & 6,6 & 49,5 & 37 \\
$M(10) 3$ & 34,3 & 37,6 & 40 \\
$M(15) 1$ & 25,9 & 76,1 & 40 \\
$M(15) 2$ & 76,4 & 60,0 & 42 \\
$M(30)$ & 0 & 136,1 & 36 \\
\hline
\end{tabular}


15 e 30 dias, foram de $35,38,40$ e $42 \%$, respectivamente. Isto revela que à medida que diminui o periodo, aumenta a diferenga entre o nivel de probabilidade correspondente à precipitação média e o nível de probabilidade recomendado (75\%), ou seja, a medida que diminui o periodo, maior o erro ao se utilizar a precipitação média para fins de dimensionamento de sistemas de irrigação.

A análise dos valores de probabilidade de ocorrência de precipitaçăo pluvial permite que se conclua que a estimativa da exigencia em água para fins de dimensionamento de sistemas de irrigação não deve estar fundamentada no valor minimo de precipitação (95\%), visto que isto resultaria, para a maioria dos anos, num projeto superdimensionado. Por outro lado, também não deve estar baseada na precipitaçăo média, e muito menos na máxima $\langle 5 \%$, , que acarretaria um subdimensionamento do projeto de irrigação. O valor de $75 \%$ de probabilidade parece bastante razoável, ou mesmo outros valores, sempre pautados numa análise de distribuição dos dados de precipitação e em justificativas racionais.

Pode-se dizer que, de una maneira geral, o uso de valores de precipitação obtidos em função de periodos coerentes com a duração do intervalo de máxima exigència hídrica da cultura e de níveis de probabilidade em torno de $75 \%$, constitui-se no procedimento mais recomendado para fins de dimensionamento de sistemas de irrigação. 
o ajuste da distribuição Mista aos dados observados de precipitaçăo pode ser visualizado através das Figuras 7 e 8 . Cabe salientar que a probabilidade dos dados observados (distribuição empírica ou natural) foi calculada através da equação de Kimball.

\subsubsection{Precipitaçăo pluvial para o més de setembro}

Os dados de precipitação pluvial para o més de setembro, para periodos de 5, 10, 15 dias e mensal, encontram-se ordenados de forma decrescente nas Tabelas 31 e 32 . Segundo OMETTO (1989) o més de setembro, para a região de Piracicaba, SP, apresenta precipitação pluvial média mensal de $60 \mathrm{~mm}$, enquanto o mêss de março caracteriza-se pelo valor de $136 \mathrm{~mm}$.

Analisando os parâmetros estatísticos dos dados observados, apresentados na Tabela 33 , verifica-se uma grande amplitude dos mesmos e elevados valores de coeficente de variaçäo, variando de 93,6 a $209,0 \%$, caracterizando uma crande dispersăo dos dados. Mais uma vez fica evidente a necessidade de se proceder estudos de distribuição de frequèencia para uma análise criteriosa dos dados.

Comparando os dados de precipitação de marģo com aqueles de setembro, verifica-se que, embora as amplitudes sejam maiores no primeiro mês, os maiores 
(1) 5

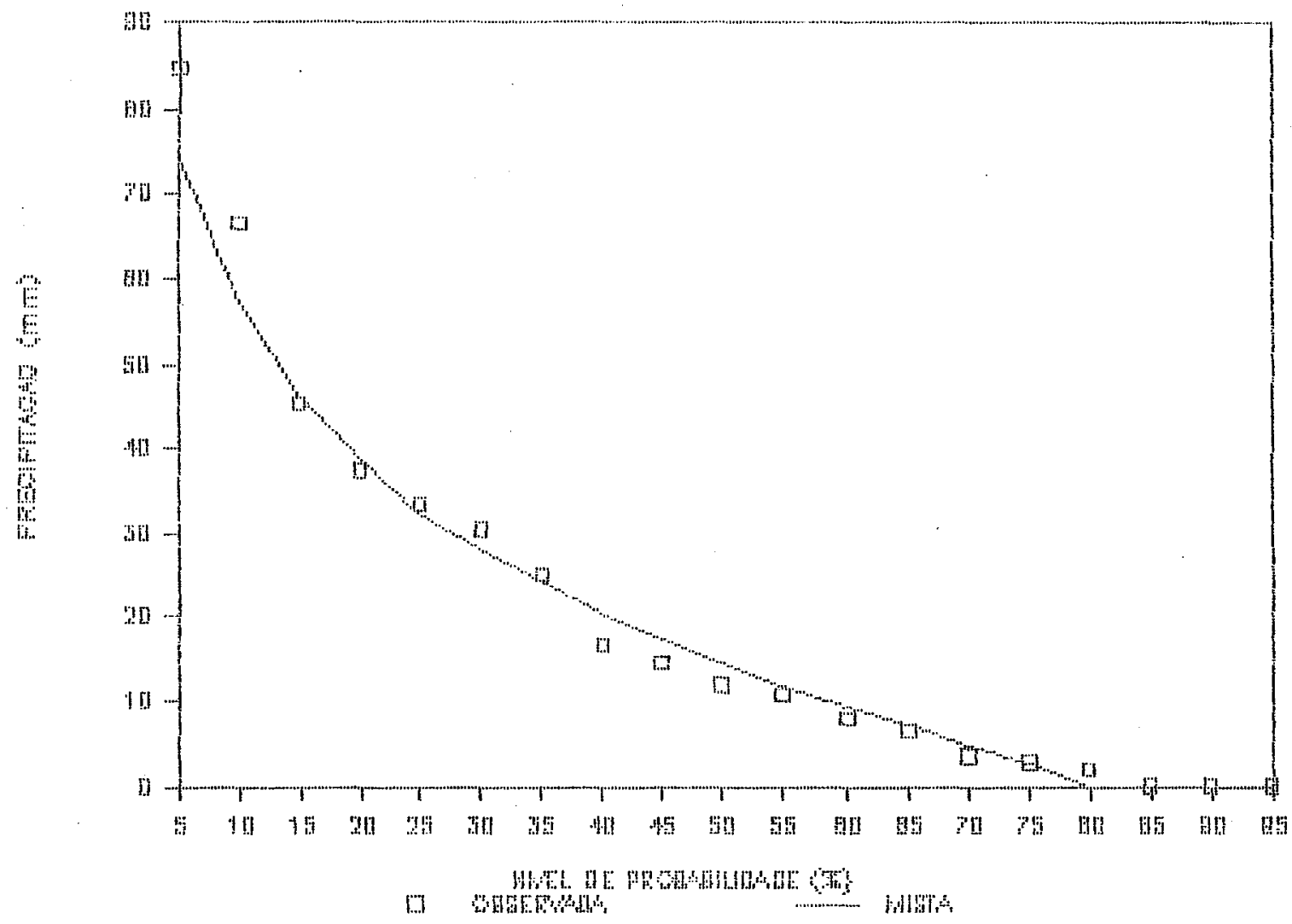

Figura 7 - Precipitação pluvial dependente obtida através da distribuição Mista, e precipitação observada para a quarta pentada do mês de março. 
MI 19

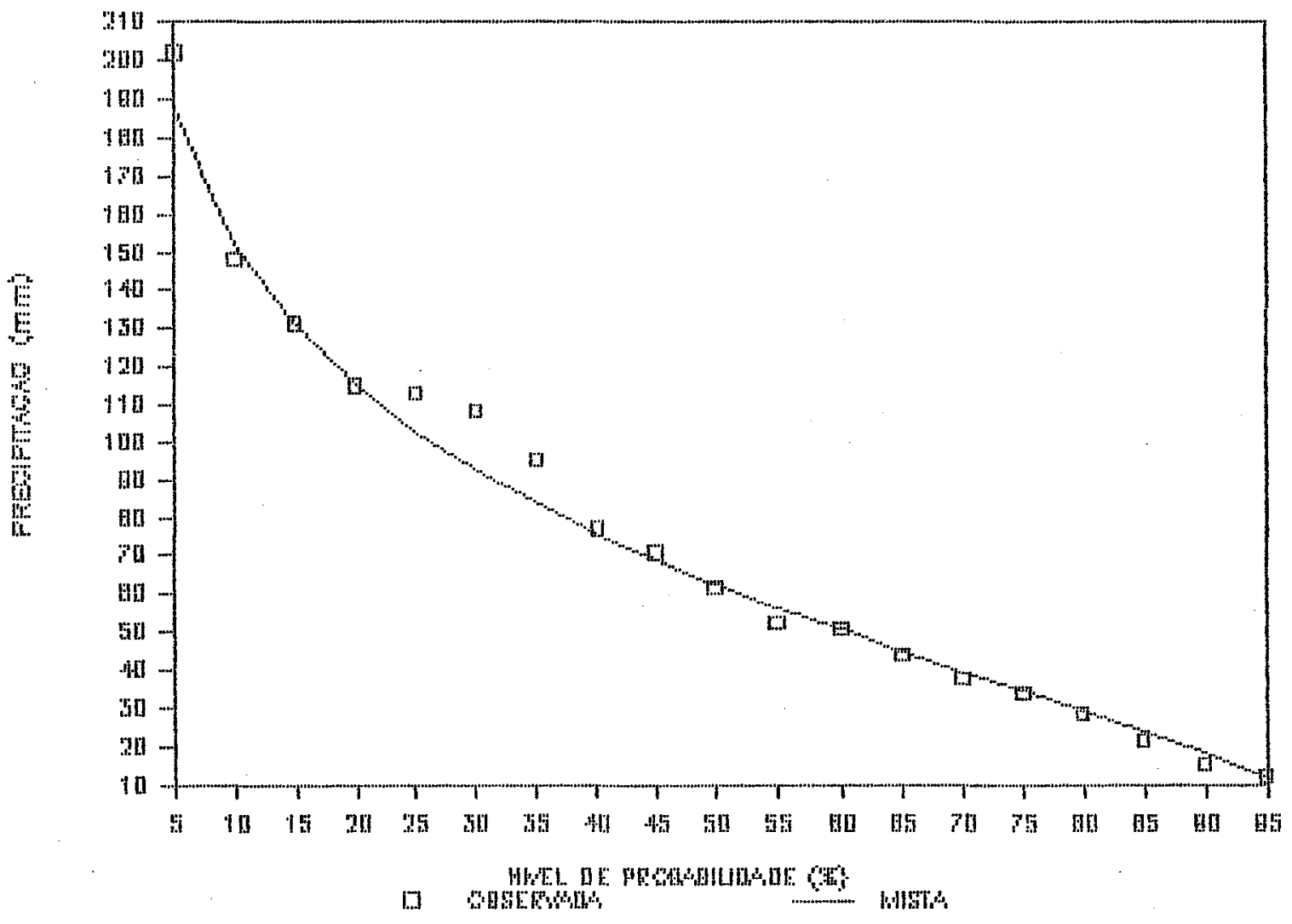

Figura 8 - Precipitação pluvial dependente obtida através da distribuição Mista, e precipitação observada para a primeira quinzena do mês de março. 
95.

Tabela 31 - Valores da precipitação pluvial, em ordem decrescente, para as pentadas do inês de se tembro, para um período de 71 anos.

PRECIPITACAO PLUVIAL OBSERVADA (mm)

\begin{tabular}{|c|c|c|c|c|c|}
\hline \multicolumn{6}{|c|}{ PER IODO } \\
\hline$S(5) 1$ & $S(5) 2$ & $5(5) 3$ & $5(5) 4$ & $5(5) 5$ & $5(5) 6$ \\
\hline 70,5 & 99,4 & 119,9 & 60,2 & 70,8 & 64.0 \\
\hline 60,4 & 76,5 & 106,5 & 53,0 & 54,8 & 61,6 \\
\hline 50,5 & 59,2 & 70,0 & 48,8 & 47,5 & 51,3 \\
\hline 46,8 & 52,2 & 64,2 & 44,0 & 39,1 & 50,7 \\
\hline 42,5 & 48,4 & 55,0 & 34,0 & 38,7 & 46,9 \\
\hline 41,2 & 41,2 & 45,8 & 30,5 & 34,9 & 44,9 \\
\hline 40,5 & 38,0 & 42,1 & 30,0 & 30,0 & 42,0 \\
\hline 33,6 & 32,4 & 37,3 & 29,3 & 29,8 & 40,6 \\
\hline 31,4 & 31,0 & 35,1 & $2 \theta, 6$ & 27,6 & 40,5 \\
\hline 26,1 & 30,1 & 32,2 & 26,9 & 25,6 & 35,9 \\
\hline 12,0 & 28,0 & 31,8 & 25,5 & 23,0 & 29,2 \\
\hline 12,0 & 25,7 & 31,6 & 25,3 & 22,2 & 26,6 \\
\hline 9,1 & 23,1 & 30,2 & 25,0 & 20,5 & 24,0 \\
\hline 日, 4 & 19,0 & 28,2 & 24,9 & 19,3 & $22, \theta$ \\
\hline 8,0 & 18,5 & 26,0 & 20,9 & 13,2 & 19,0 \\
\hline 6,7 & 14,6 & 21,8 & 20,8 & 12,1 & 18,7 \\
\hline 4,7 & 14,0 & 17,0 & 19,0 & 11,7 & 16,6 \\
\hline 4,6 & 12,3 & 15,2 & 18,9 & 10,7 & 16,6 \\
\hline 3,9 & 12,2 & 12,2 & 17.9 & 10,4 & 15,4 \\
\hline 3,6 & 10,4 & 11,2 & 17,4 & 10,2 & 14,5 \\
\hline 3,4 & 9,1 & 8,8 & 14,4 & 9,5 & 13,6 \\
\hline 3,2 & 8,0 & 8,6 & 13,6 & 7,5 & 13,6 \\
\hline 2,8 & 7.0 & 8,0 & 13,2 & 9,4 & 12,0 \\
\hline 1,6 & 6,6 & 4,6 & 9,5 & 9,0 & 10,2 \\
\hline 1,4 & 6,3 & 4,3 & 7,7 & 8,5 & 10,1 \\
\hline 1,4 & 6,1 & 4,0 & 6,9 & 7,7 & 8,1 \\
\hline 1,2 & 4,7 & 3,1 & 5,0 & 7,3 & 7,0 \\
\hline 1,0 & 4,2 & 2,7 & 4,7 & 6,9 & 5,3 \\
\hline 1,0 & 3,5 & 2,2 & 4,0 & 6,3 & 5,2 \\
\hline 1,0 & 2,8 & 2,0 & 3,5 & 6,2 & 5,0 \\
\hline 1,0 & $1, \theta$ & 1,4 & 3,0 & 5,5 & 4,7 \\
\hline 1,0 & 1,7 & 1,4 & 3,0 & 5,2 & 4,6 \\
\hline
\end{tabular}


96.

Tabela 31 - Valores da precipitação pluvial, em ordem decrescente, para as pentadas do mês de se tembro, para um período de 71 anos.

$\begin{array}{llllll}0,0 & 0,0 & 1,2 & 2,2 & 4,0 & 3,5 \\ 0,0 & 0,0 & 1,0 & 2,1 & 3,7 & 2,5 \\ 0,0 & 0,0 & 1,0 & 2,0 & 3,0 & 2,2 \\ 0,0 & 0,0 & 0,0 & 1,3 & 1,0 & 1,7 \\ 0,0 & 0,0 & 0,0 & 1,2 & 1,0 & 1,0 \\ 0,0 & 0,0 & 0,0 & 1,2 & 1,5 & 1,0 \\ 0,0 & 0,0 & 0,0 & 1,1 & 0,0 & 1,0 \\ 0,0 & 0,0 & 0,0 & 1,0 & 0,0 & 1,0 \\ 0,0 & 0,0 & 0,0 & 1,0 & 0,0 & 0,0 \\ 0,0 & 0,0 & 0,0 & 0,0 & 0,0 & 0,0 \\ 0,0 & 0,0 & 0,0 & 0,0 & 0,0 & 0,0 \\ 0,0 & 0,0 & 0,0 & 0,0 & 0,0 & 0,0 \\ 0,0 & 0,0 & 0,0 & 0,0 & 0,0 & 0,0 \\ 0,0 & 0,0 & 0,0 & 0,0 & 0,0 & 0,0 \\ 0,0 & 0,0 & 0,0 & 0,0 & 0,0 & 0,0 \\ 0,0 & 0,0 & 0,0 & 0,0 & 0,0 & 0,0 \\ 0,0 & 0,0 & 0,0 & 0,0 & 0,0 & 0,0 \\ 0,0 & 0,0 & 0,0 & 0,0 & 0,0 & 0,0 \\ 0,0 & 0,0 & 0,0 & 0,0 & 0,0 & 0,0 \\ 0,0 & 0,0 & 0,0 & 0,0 & 0,0 & 0,0 \\ 0,0 & 0,0 & 0,0 & 0,0 & 0,0 & 0,0 \\ 0,0 & 0,0 & 0,0 & 0,0 & 0,0 & 0,0 \\ 0,0 & 0,0 & 0,0 & 0,0 & 0,0 & 0,0 \\ 0,0 & 0,0 & 0,0 & 0,0 & 0,0 & 0,0 \\ 0,0 & 0,0 & 0,0 & 0,0 & 0,0 & 0,0 \\ 0,0 & 0,0 & 0,0 & 0,0 & 0,0 & 0,0 \\ 0,0 & 0,0 & 0,0 & 0,0 & 0,0 & 0,0 \\ 0,0 & 0,0 & 0,0 & 0,0 & 0,0 & 0,0 \\ 0,0 & 0,0 & 0,0 & 0,0 & 0,0 & 0,0 \\ 0,0 & 0,0 & 0,0 & 0,0 & 0,0 & 0,0 \\ 0,0 & 0,0 & 0,0 & 0,0 & 0,0 & 0,0 \\ 0,0 & 0,0 & 0,0 & 0,0 & 0,0 & 0,0 \\ 0,0 & 0,0 & 0,0 & 0,0 & 0,0 & 0,0 \\ 0,0 & 0,0 & 0,0 & 0,0 & 0,0 & 0,0 \\ 0,0 & 0,0 & 0,0 & 0,0 & 0,0 & 0,0 \\ 0,0 & 0,0 & 0,0 & 0,0 & 0,0 & 0,0 \\ 0,0 & 0,0 & 0,0 & 0,0 & 0,0 & 0,0 \\ 0,0 & 0,0 & 0,0 & 0,0 & 0,0 & 0,0 \\ 0,0 & 0,0 & 0,0 & 0,0 & 0,0 & 0,0\end{array}$


Tabela 32 - Valores da precipitação pluvial, em ordem decrescente, para os períodos de 10, $15 \mathrm{e}$ 30 dias do mês de setembro, para um intervalo de 71 anos.

PRECIPITACAO PLUVIAL OBSERVADA ( $\mathrm{mm}$ )

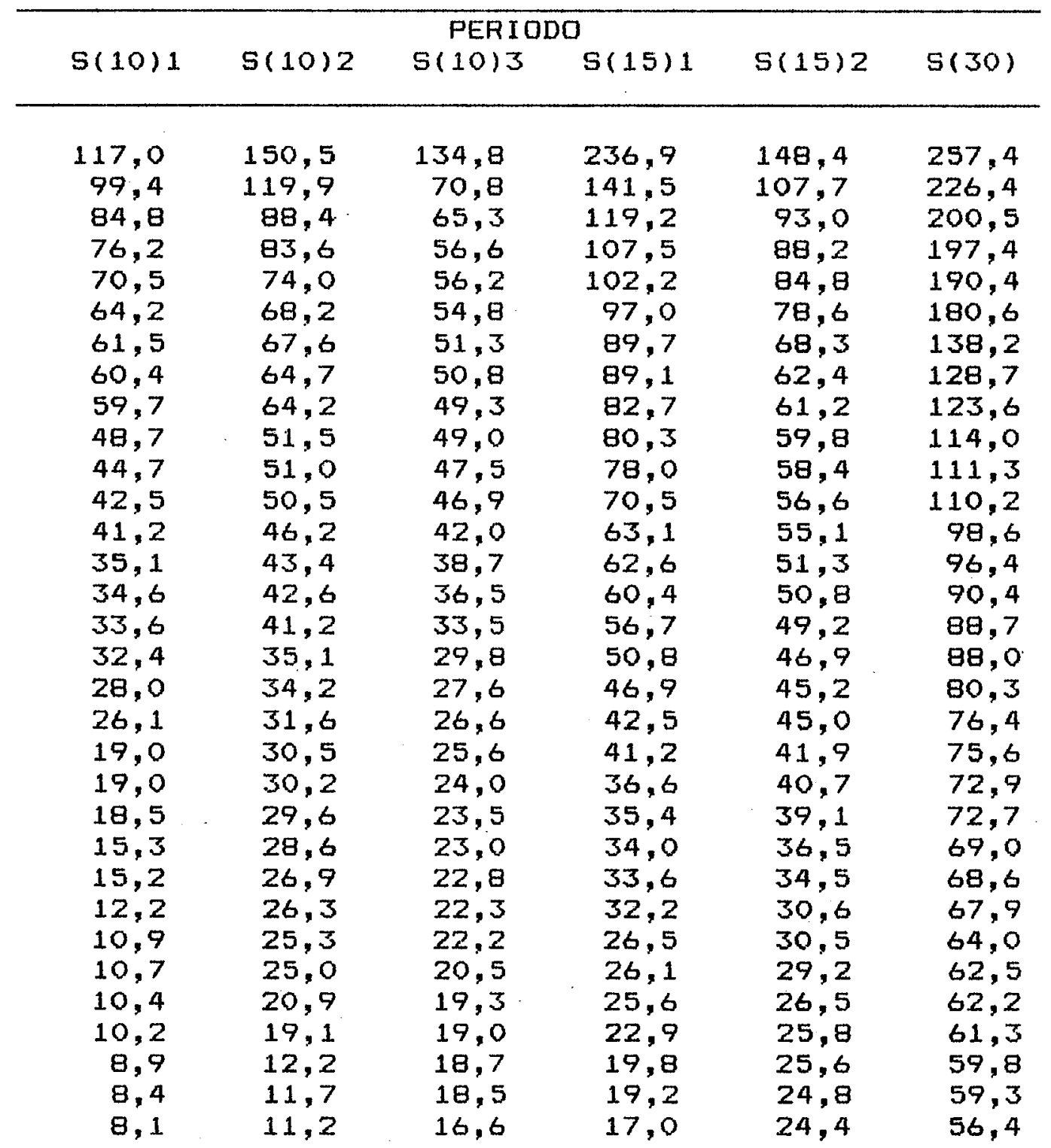


Tabela 32 - Valores da precipitação pluvial, em ordem decrescente, para os periodos de $10,15 \mathrm{e}$ 30 dias do mês de setembro, para um intervalo de 71 anos.

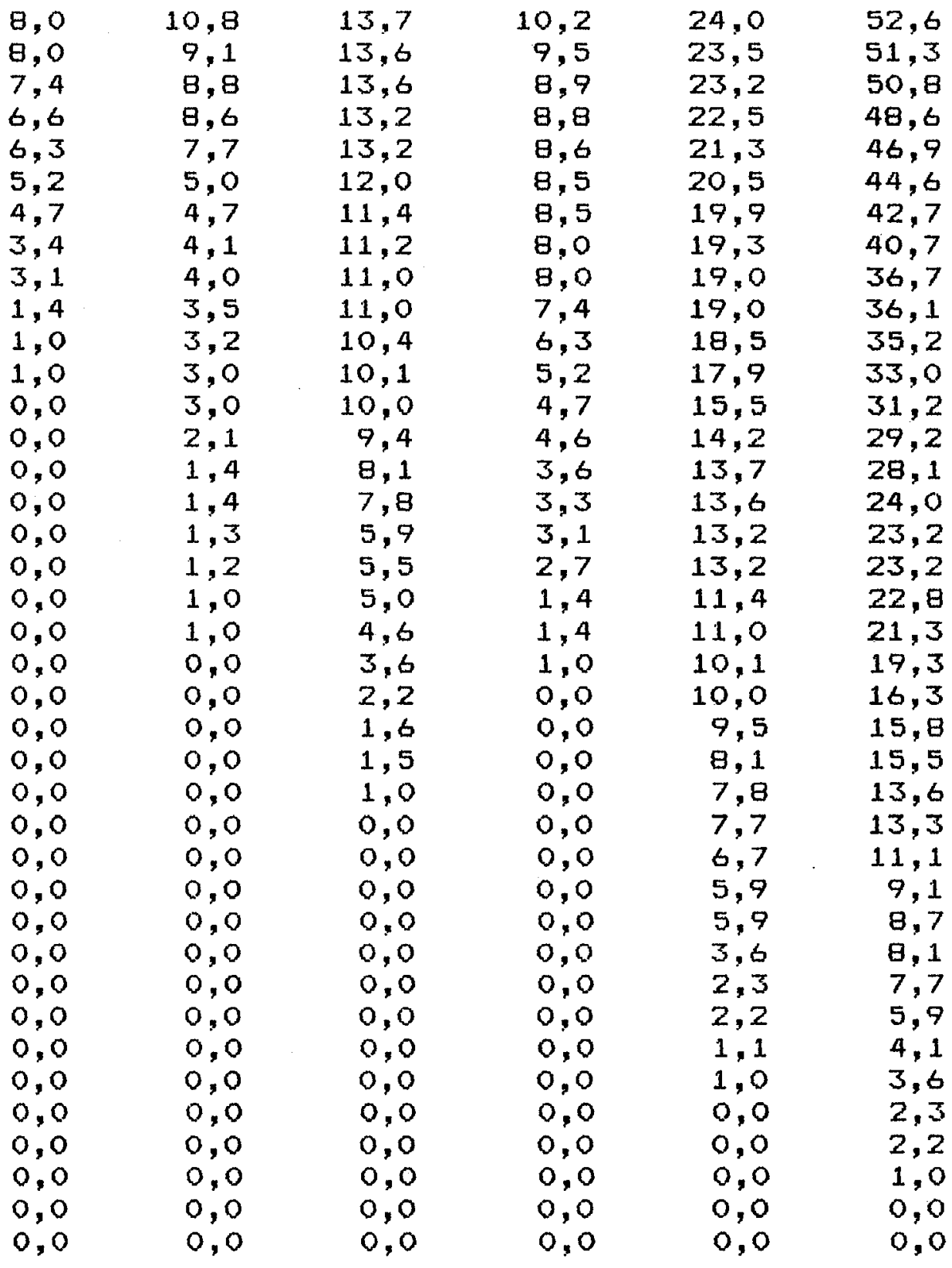


Tabela 33 - Parâmetros estatísticos referentes aos dados de precipitação pluvial do mês de setembro, para os períodos de $5,10,15$ e 30 dias, de um intervalo de 71 anos.

\begin{tabular}{lccccc}
\hline & $\begin{array}{c}\text { AMPLI } \\
\text { TUDE } \\
(\mathrm{mm})\end{array}$ & $\begin{array}{c}\text { MEDIA } \\
(\mathrm{mm})\end{array}$ & $\begin{array}{c}\text { DESVIO } \\
\text { PADRAD }\end{array}$ & $\begin{array}{c}\text { VARIANCIA VARIACAO } \\
(\%)\end{array}$ \\
\hline S(5)1 & 70,5 & 7,6 & 15,892 & 252,243 & 209,0 \\
$S(5) 2$ & 99,4 & 10,5 & 19,270 & 371,317 & 183,5 \\
$S(5) 3$ & 119,9 & 12,5 & 23,785 & 565,713 & 190,3 \\
$S(5) 4$ & 60,2 & 9,9 & 14,443 & 208,595 & 145,9 \\
$S(5) 5$ & 70,8 & 9,3 & 14,518 & 210,777 & 156,1 \\
$S(5) 6$ & 64,0 & 11,2 & 16,820 & 282,920 & 150,2 \\
$S(10) 1$ & 117,0 & 18,1 & 26,558 & 705,310 & 146,7 \\
$S(10) 2$ & 150,5 & 22,4 & 30,466 & 928,156 & 136,0 \\
$S(10) 3$ & 134,8 & 20,5 & 23,054 & 531,499 & 112,5 \\
$S(15) 1$ & 236,9 & 30,6 & 42,652 & 1819,201 & 139,4 \\
$S(15) 2$ & 148,4 & 30,4 & 28,569 & 816,170 & 94,0 \\
$S(30)$ & 257,4 & 61,0 & 57,111 & 3261,696 & 93,6 \\
\hline
\end{tabular}


valores do coeficiente de variação foram apresentados pelo mês de setembro, indicando que neste mês houve maior dispersão dos dados.

A distribuição Mista foi aplicada aos valores observados de precipitação, tendo sido estimados os parâmetros de escala $(\beta)$ e de forma $(\alpha)$ da distribuição Gama, apresentados na Tabela 34.

As Tabelas 35 e 36 fornecem a precipitação dependente para os níveis de probabilidade de 5, 10, 20, $25,30,40,50,60,70,75,80,90$ e $95 \%$, para os diferentes periodos em estudo. Gabe salientar que estes niveis de probabilidade referem-se à probabilidade de ser igual ou superior a um valor provável de precipitação.

Analisando a Tabela 36 , verifica-se uma grande diferença entre a precipitaçăo dependente para o nivel de $75 \%$ e a precipitação média, conforme já havia ocorrido no mès de março. As precipitaçóes médias dos diferentes periodos correspondem a niveis de probabilidade compreendidos entre 26 e $39 \%$, bastante distantes do nível de $75 \%$ recomendado.

Ainda, analisando a Tabela 37 , verifica-se que, em termos médios, as probabilidades correspondentes às precipitações médias dos periodos de $5,10,15$ e 30 dias, foram de $30,35,36$, $38 \%$, respectivamente. Portanto, para o mês de setembro, também se verificou a tendència de que à medida que diminui a periodo, aumenta o erro no uso da precipitação média para fins de 
Tabela 34 - Parãmetros $\alpha$ e $\beta$ da distribuição Gama utilizada na distribuição Mista para os dados de precipitação pluvial do mês de setembro, para os períodos de $5,10,15$ e 30 dias.

\begin{tabular}{lll}
\hline PERIODO & $\hat{\alpha}$ & $\hat{\beta}$ \\
\hline$S(5) 1$ & 0,686670 & 24,41584 \\
$S(5) 2$ & 1,150473 & 20,31772 \\
$S(5) 3$ & 0,776728 & 32,64976 \\
$S(5) 4$ & 0,970447 & 17,65593 \\
$S(5) 5$ & 1,354659 & 12,80959 \\
$S(5) 6$ & 1,016587 & 19,56792 \\
$S(10) 1$ & 1,010951 & 28,85495 \\
$S(10) 2$ & 0,834963 & 36,63967 \\
$S(10) 3$ & 1,350024 & 18,90351 \\
$S(15) 1$ & 0,857676 & 47,76959 \\
$S(15) 2$ & 1,340953 & 24,37651 \\
$S(30)$ & 1,135788 & 55,24731 \\
\hline
\end{tabular}


Tabela 35 - Precipitação pluvial obtida através da distribuição Mista para as pentadas do mês de setembro, em função de diversos niveis de probabilidade de ocorrência.

NIVEL DE

PROBABI -

LIDADE

(\%)

5

10

20

25

30

40

50

60

70

75

80

90

95
PRECIPITACAO PLUVIAL DEPENDENTE (mm)

PERIODO

$\begin{array}{llllll}5(5) 1 & 5(5) 2 & 5(5) 3 & 5(5) 4 & 5(5) 5 & 5(5) 6\end{array}$

40,1

$49,9 \quad 62,0$

42,6

38,1

48,0

35,1

41,2

30,2

28,2

34,5

$19,8 \quad 21,4$

18,1

18,0

20,7

$14,7 \quad 15,3$

14,2

14,6

16,2

11,2

11,5

12,6

3,5

3,7

6,2

6,6

6,9

2,4

2,1

2,4

o

0

0

0

0

o

0

0

0

0

0

o

0

o

0

0

0

0

0

0 
Tabela 36 - Precipitação pluvial obtida através da distribuição Mista para os períodos de 10, 15 e 30 dias do mês de setembro, em função de diversos níveis de probabilidade de ocorrência.

NIVEL DE

PROBABI -

LIDADE

$(\%)$

5

10

20

25

30

40

50

60

70

75

80

90

95
PRECIPITACAO PLUVIAL DEPENDENTE $(\mathrm{mm})$

\section{PERIODO}

$\begin{array}{llllll}5(10) 1 & 5(10) 2 & 5(10) 3 & 5(15) 1 & 5(15) 2 & S(30)\end{array}$

$73,3 \quad 86,9 \quad 64,5 \quad 116,5 \quad 90,1 \quad 178,9$

53,6

63,1

50,0

84,8

67,1

138,4

33,0

39,5

35,2

53,8

49,2

98,2

26,6

32,0

30,3

43,9

43,0

85,3

26,2

35,9

37,8

74,4

17,0

19,7

23,7

29,5

57,3

10,0

14,3

14,6

22,8

43,9

7,3

17,1

32,7

1

5,3

1,8

12,0

23,0

0

3,1

0

9,6

18,5

0

1

0

7,3

14,3

0

0

o

2,2

6,2

0

0

2,1 
Tabela 37 - Estudo comparativo entre a precipitação pluvial ao nível de $75 \%$ de probabilidade e a precipitação pluvial média, para os períodos de $5,10,15$ e 30 dias do mês de setembro.

PREC I P I TACAO

\begin{tabular}{lccc} 
PERIODO & $\begin{array}{c}\text { ( } \begin{array}{c}\text { MEDIA } \\
(\mathrm{mm})\end{array} \\
(\mathrm{mm})\end{array}$ & $\begin{array}{c}\text { MEDIA } \\
\text { probabilidade } \\
(\%)\end{array}$ \\
\hline$S(5) 1$ & 0 & 7,6 & 26 \\
$S(5) 2$ & 0 & 10,5 & 30 \\
$S(5) 3$ & 0 & 12,5 & 28 \\
$S(5) 4$ & 0 & 9,9 & 32 \\
$S(5) 5$ & 0 & 9,3 & 34 \\
$S(5) 6$ & 0 & 11,2 & 32 \\
$S(10) 1$ & 0 & 18,1 & 33 \\
$S(10) 2$ & 0 & 22,4 & 34 \\
$S(10) 3$ & 3,1 & 20,5 & 39 \\
$S(15) 1$ & 0 & 30,6 & 39 \\
$S(15) 2$ & 9,8 & 30,4 & 38,0 \\
$S(30)$ & 18 & 61,0 & 39 \\
\hline
\end{tabular}


Tabela 36 - Precipitação pluvial obtida através da distribuição Mista para os períodos de 10, 15 e 30 dias do mês de setembro, em função de diversos níveis de probabilidade de ocorrência.

NIVEL DE

PROBABI -

LIDADE

$(\%)$

5

10

20

25

30

40

50

60

70

75

80

90

95
PRECIPITACAO PLUVIAL DEPENDENTE $(\mathrm{mm})$

\section{PERIODO}

$\begin{array}{llllll}5(10) 1 & 5(10) 2 & 5(10) 3 & 5(15) 1 & 5(15) 2 & S(30)\end{array}$

$73,3 \quad 86,9 \quad 64,5 \quad 116,5 \quad 90,1 \quad 178,9$

53,6

63,1

50,0

84,8

67,1

138,4

33,0

39,5

35,2

53,8

49,2

98,2

26,6

32,0

30,3

43,9

43,0

85,3

26,2

35,9

37,8

74,4

17,0

19,7

23,7

29,5

57,3

10,0

14,3

14,6

22,8

43,9

7,3

17,1

32,7

1

5,3

1,8

12,0

23,0

0

3,1

0

9,6

18,5

0

1

0

7,3

14,3

0

0

o

2,2

6,2

0

0

2,1 


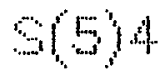

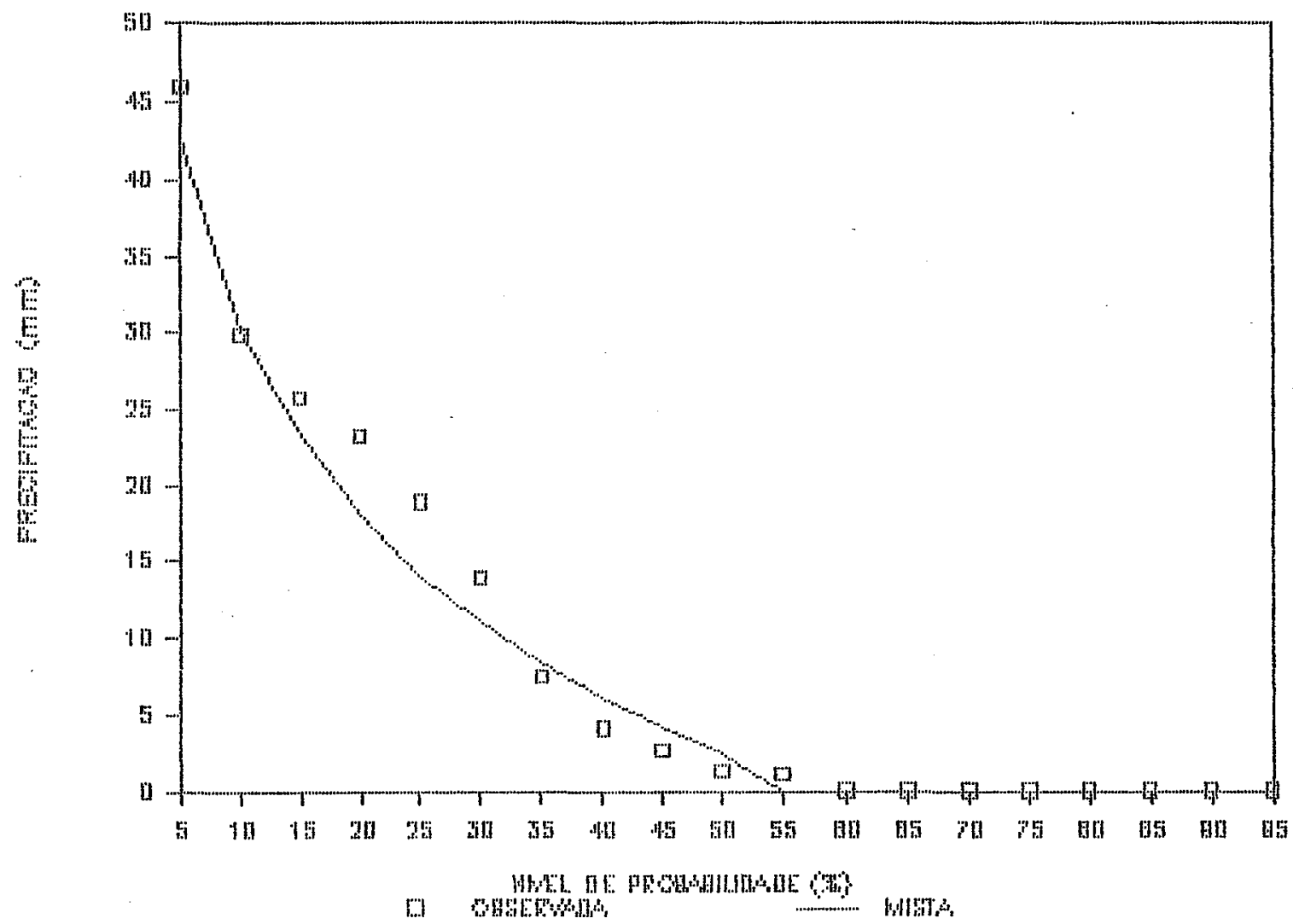

Figura 9 - Precipitação pluvial dependente obtida através da distribuição Mista, e precipitação observada para a quarta pentada do mês de setembro. 
4151

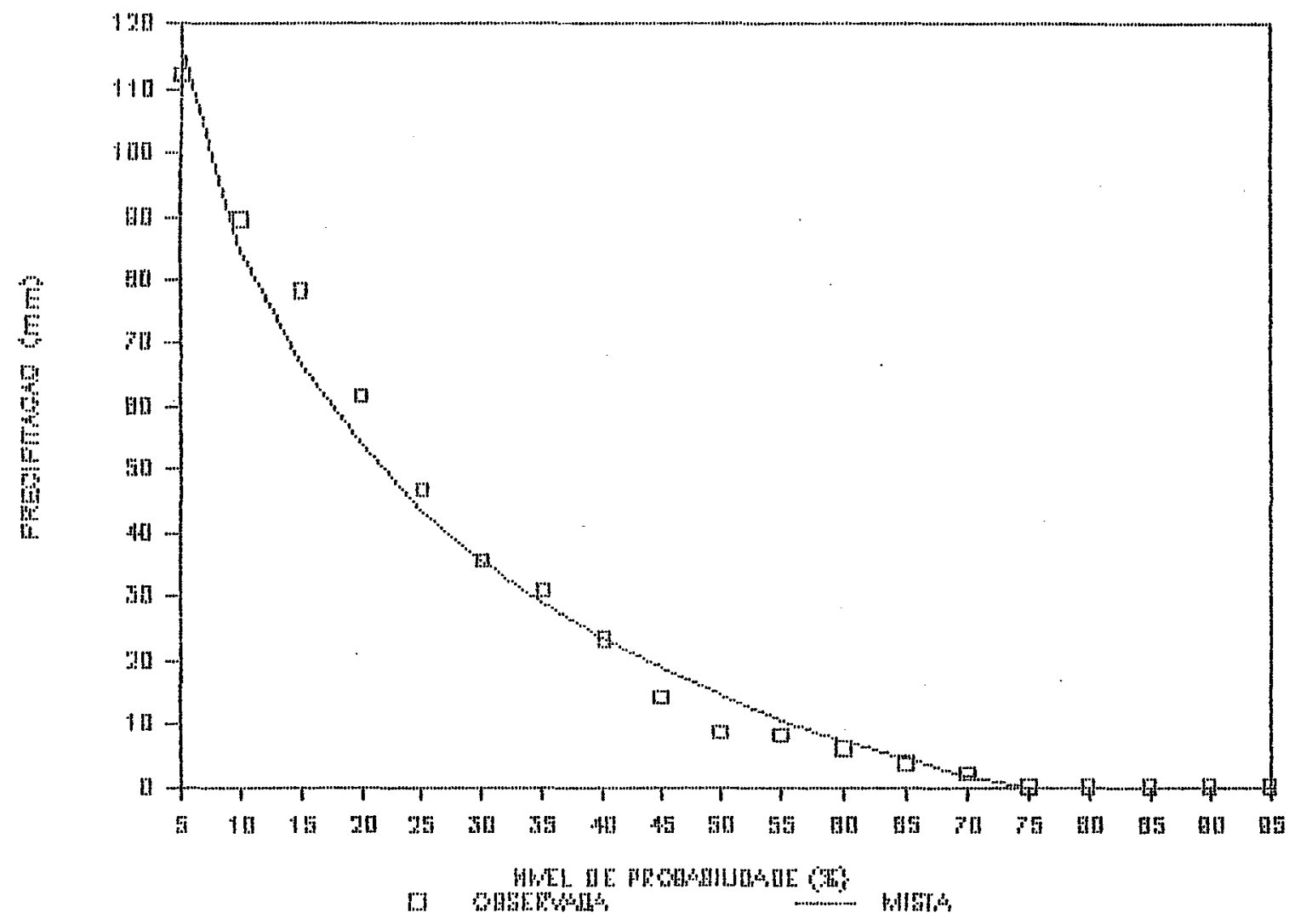

Figura 10 - Precipitação pluvial dependente obtida através da distribuição Mista, e precipitação observada para a primeira quinzena do mês de setembro. 


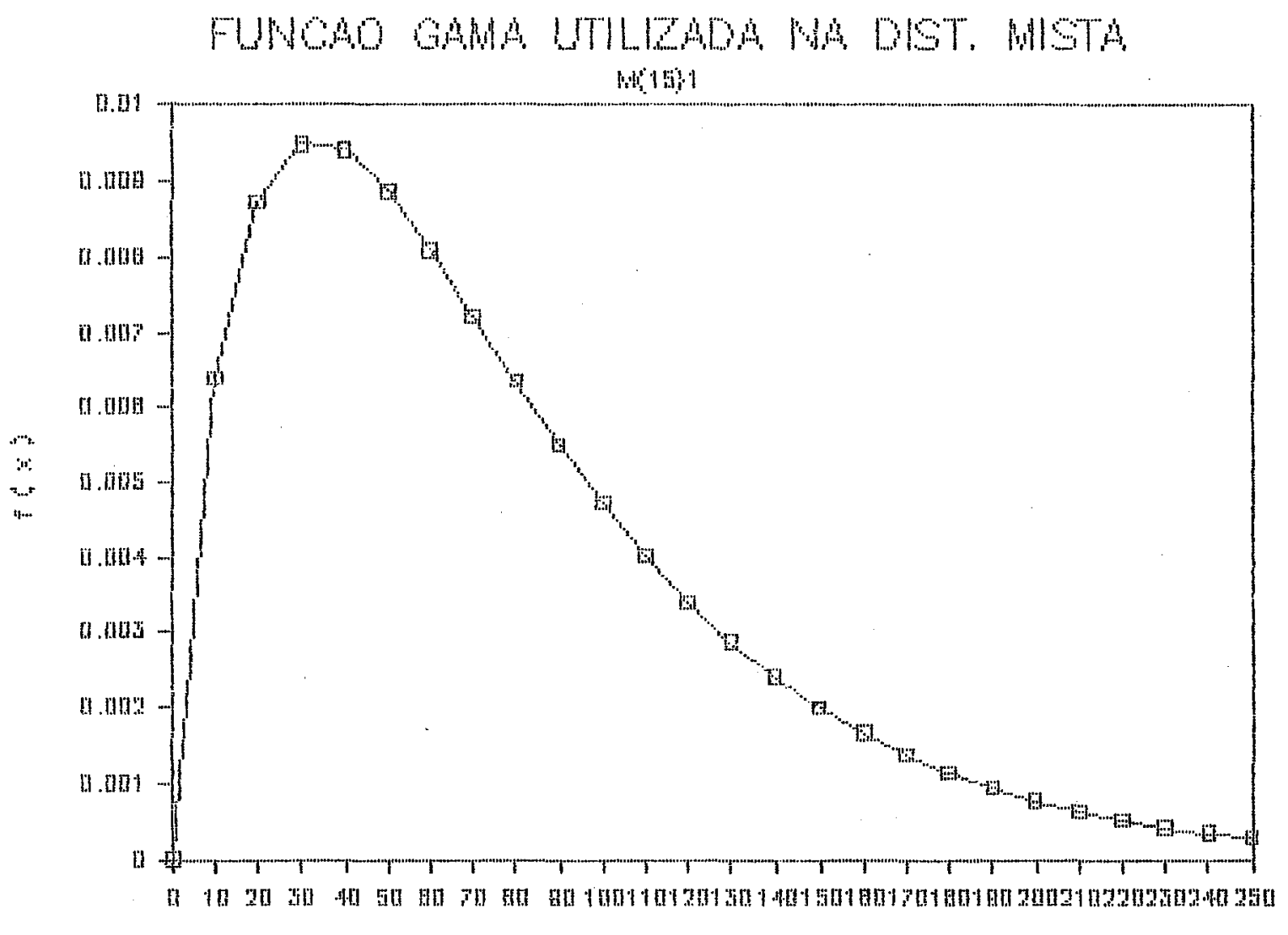

Figura 11 - Função densidade da distribuição Gama utilizada na distribuição Mista aplicada aos dados de precipitação da primeira quinzena do mês de março. 
FUNGAO GAMA LTILIZADA WA DISTR, MISTA

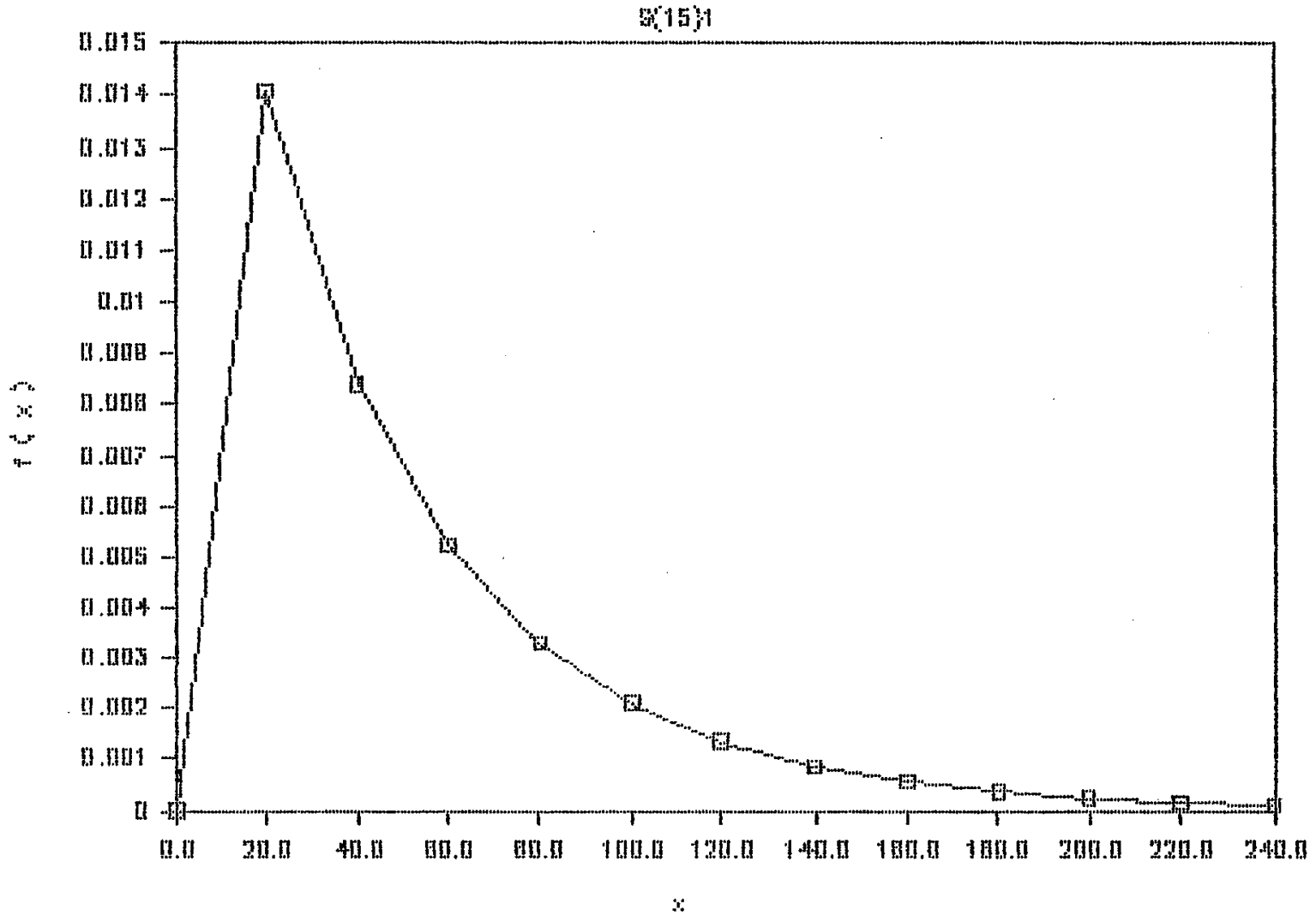

Figura 12 - Função densidade da distribuição Gama utilizada na distribuição Mista aplicada aos dados de precipitação da primeira quinzena do mês de setembro. 


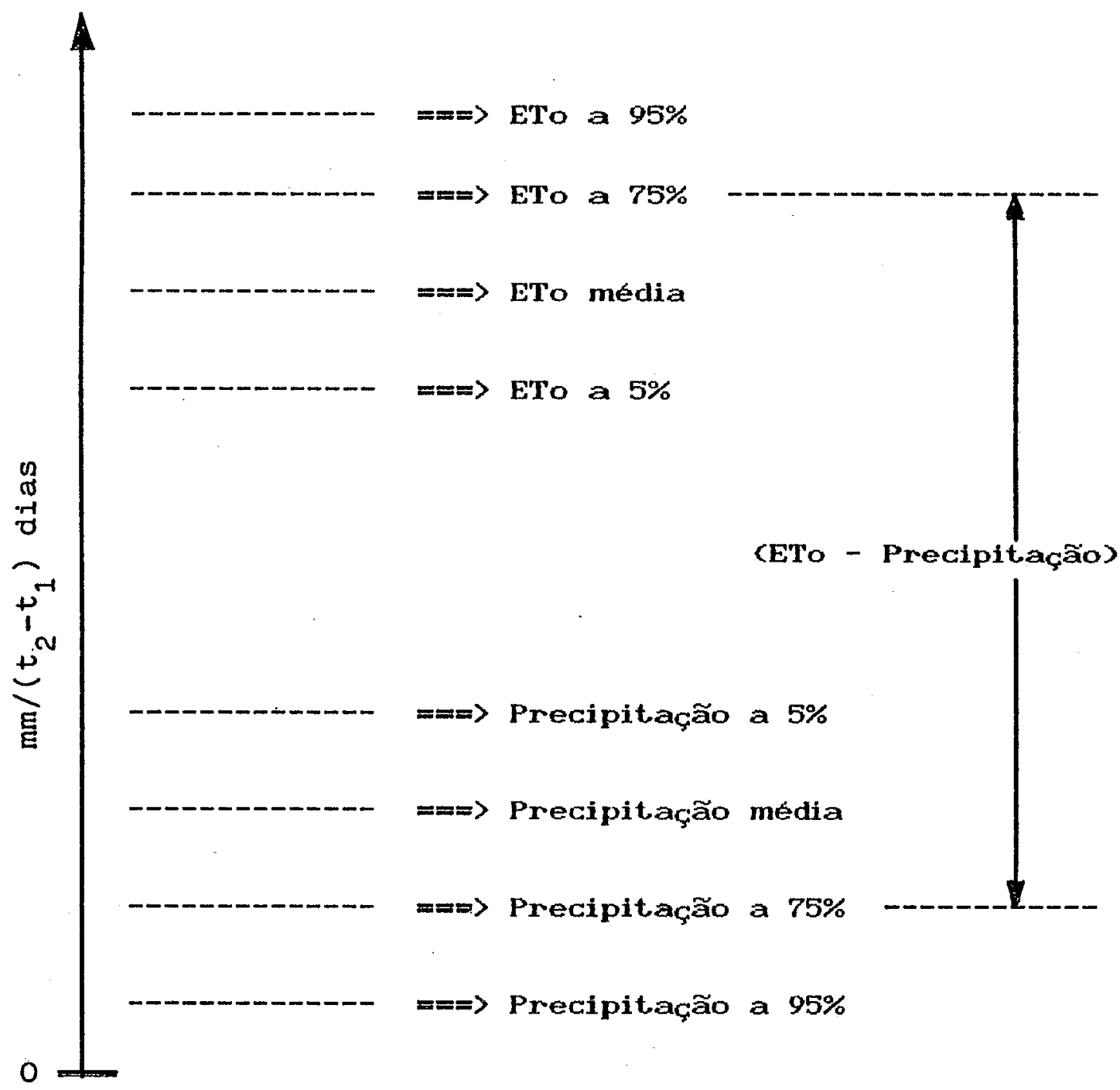

Figura 13 - Esquema mostrando o balanço entre a evapotranspiração ao nível de $75 \%$ de probabilidade e a precipitação ao nivel de $75 \%$ de probabilidade, visando a estimativa da exigência em água para fins de dimensionamento de sistemas de irrigação. 
pela eq. (14). Convém firisar que, no caso da evapotranspiração, o nível de probabilidade refere-se a probabilidade de que a evapotranspiragăo seja menor ou igual a um determinado valor, enquanto que, para a precipitaģăo pluvial, indica a probabilidade de que a precipitação seja maior ou igual a um determinado valor.

o nivel de probabilidade e a duraçăo. do período de máxima exigência hidrica a serem adotados, dependem de um estudo criterioso das condiçós especificas de cada projeto de irrigagäo. 


\section{CONCLUSOES}

Considerando os resultados obtidos nesta pesquisa para a refião de Plracicaba, SP, estabeleceram-se as seguintes conclusöes :

5.1. Baseado no teste de Kolmogorov-Smimnov, o ajuste das distribuiçớs Beta e Normal aos dados da evapotranspiração de referencia foi eficiente, em razão da hipotese de mulidade năo ter sido rejeitada ao nivel de $5 \%$ de. significáncia, em nenhum dos periodos estudados aplicando as duas distribuiçốs. A distribuição Beta tem maior capacidade de adaptaçăo e a distribuição Normal apresenta maior facilidade de utilização, dai ser a mais recomendada para fins práticos.

5.2. A relação entre a evapotranspiração estimada pela distribuição Beta ao nivel de $75 \%$ de probabilidade e o valor médio, variou de 9,1 a $18,6 \%$ para o mes de março, e de $7,1 \%$ a $16,7 \%$ para o mês de set.embro. 
5.3. Verificou-se que, $\Rightarrow$ medida que diminui o intervalo de dias analisados, aumenta o valor da evapotranspiração de referencia para o nivel de probabilidade de $75 \%$. Para o mês de março esta variação ricou entre 0,0 e $8,3 \%$ e, para setembro, oscilou de 2,3 e $11,4 \%$

5.4. Analisando-se os parametros estatisticos referentes às estimativas da evapotranspiração para os diferentes periodos, bem como as conclusóses 5.2. e 5.3., conclui-se que os dados de evapotranspiraçäo apresentaram-se bastante agrupados, porém, o uso de estimativas medias de periodos muito reduzidos (5 dias $)$ ou muito grandes (mensais), associado a metodos pouco precisos de calculo da evapotranspiraçăio, pode conduzir a emos significativos no dimensionamento de sistemas de irrifaçăo.

8.5. Analisando-se os dados de precipitaçäo para os mesies de março e setembro, verificou-se uma grande dispersão dos mesmos, o que tornou evidente a necessidade de se proceder a análise de rrequiência visando a sua utilização criteriosa. 
5.6. A distribuição Mista, utilizando a distribuição Gama, apresentou-se estatisticamente adequada para a estimativa das frequencias de distribuição das precipitações, para os periodos de 5 dias, 10 dias, 15 dias e 30 dias, dos meses de março e setembro.

5.7. O uso da precipitaçăo media para fins de dimensionamento de sistemas de irrigaçäo resulta em projetos subdimensionados, uma vez que as probabilidades correspondentes as precipitaçöes médias para os diferentes periodos variaram de 28 a $42 \%$ para o mess de março, e de 26 a $39 \%$ para o més de setembro, sendo que o valor recomendado está em torno de $75 \%$.

5.8. Tanto para o mes de março como para o mês de setembro, verificou-se que, a medida que diminui o periodo, aumenta o erro decorrente do uso da precipitação média no dimensionamento de sistemas de irrigação, considerando que o procedimento correto é aquele que utiliza a precipitação dependente em torno de $75 \%$. 


\section{REFERENGIAS BIBLIOGRAFICAS}

ALLEN, R.G. A Penman for all seasons. Iournal of Irrigation and Drainase Engineering, New York, 112(4): $348-68,1986$.

ARRUDA, F.B. \& BARROSO, L.F.S. Estimativa do uso de água para fins de projetos de irrigação, em funçăo da evaporação de taanque, em Ribeirão Preto; Bragantia, Campinas, $43(2): 677-82,1984$.

BARGER, R.L. \& THOM, H.G.S. Evaluation of drough harzard. Asronomy Iournal, Madison, 41(11): 519-26, 1949.

BERNARDO, S. A computerized model to predict suplemental irrigation in tropical and subtropical climate. Logan, 1975. 155p. (PhD. - Utah State University).

BISHNOI, O.P. The behavior of moisture adequacy index and its utilization for exploiting the agricultural potential in Punjab and Haryana. Mausam, New Delhi, 31(1): $157-64,1980$. 
BOSEN, J.F. A formula for aproximation of saturation vapor pressure over water. Monthly Weather Review, Boston, $88(8): 275-6,1960$.

BRUNT, D. Pluysical and dynamical meteorology. 2.ed. Gambridge, University Press, 1952. 428 p.

BURMAN, R.D.; NIXON, P.R.; WRIGHT, J.L.; PRUITT, W.O. Water requirements. In: JENSEN, M.E., ed. Design and operation of farm irrigation systems. St. Joseph, ASAE, 1983. p.189-232. (ASAE Monograph, 3).

CAMARGO, A.P. de; PINTO, H.S.; BRUNINI, O.; PEDRO JUNIOR, M.I.; ORTOLANI, A.A.; ALFONSI, R.R. Glima do Estado de São Paulo. In: SX̃o PAULO (Estado). Secretaria da Agricultura. Zoneamento agriciala do Estado de Săo Paulo. São Paulo, 1974. v.1, cap.2, p.51-87.

CAMPOS, H. Estatistica experimental näo-parametrica. 4.ed. Piracicaba, ESALQ, 1993. $349 \mathrm{p}$.

GERVELlinI, A.; SALATI, E.; FERRAZ, E.S.B.; VILLA NóVA, N.A.; REICHARDT, K.; DEGICO, A.; OMETTO, J.G.; PEDRO JUNIOR, M.J. Analise dos dados meteorológicos de Piracicaba. Piracicaba, ESALQ/USP, $1973 . \quad 26 p$. (Boletim Gientífico, 36). 
GUENGA, R.H. \& NIGHOLSON, M.T. Application of Penman equation wind function. Journal of Irrigation and Drainage Division, New York, 108(1): 13-23, 1982.

DASTANE, N.G. Precipitation effectiva; en la agricultura de regadío. Roma, FAO, 1974. 68p. (FAO. Estudio sobre Riego y Avenamiento, 25 ).

DOORENBOS, J. \& PRUITT, W.O. Guidelines for predicting crop water requirements. Rome, FAO, $1984 . \quad 144 p$. CFAO. Irrigation and Drainage Paper, 24 .

DOSS, B.D.; BENNEETT, O.L.; ASHLEY, D.A. Moisture use by forage species as related to pan evaporation and net radiation. Soil Science, Baltimore, gg(5): 322-7, 1964.

FALLS, L.W. The Beta distribution: a statistical model for world cloud cover. Alabama, NASA, 1973. p.1-6. (NASA Technical Memorandum, TMX-64714).

FRIEDMAN, D.G. \& JANES, B.E. Estimation of rainfall probabilities. University of Connecticut, 1957. (Coll. of Agr. Bull., 332). 
FRIzZONE, J.A. Análise de cinco modelos para o cálculo da distribuiçäo e frequència de precipitaçöes na região de Viçosa, MG. Viçosa, 1979. 100p. CMestrado Universidade Federal de Viçosas.

GALATE, R.S. Estudo das preciptaçöes pluviais no municipio de Belém - PA, através da distribuição sama. Piracicaba, 1987. 70p. Mestrado - Escola Superior de Agricultura "Luiz de Queiroz"/USP).

GOODWIN, J.B. \& SANS, L.M.A. Analise de interaçäo da data de plantio, probabilidade de chuvas e consumo de água pela cultura do milho. In: REUNIX̃o BRASILEIRA DE MILHO E SORGO, 11., Piracicaba, 1976. Anais. Piracicaba, ESALQ, 1970.

HAAN, C.T. \& BARFIELD, B.J. Data simulation from probability distributions. Triansactions of the ASAE, St. Joseph, 16(2): $374-7,1973$.

HARGREAVES, G.H. Monthly precipitation probabilities for Northeast Brazil. Losan, Dep. of Agricultural and Irrigation Engeneering, 1973. 432p.

HoLTZ, A.G.T. Precipitaçöes. In: _-. Hidrologia de superficie. Săo Paulo, Edgard Blucher, 1973. p.7-33. 
JENSEN, M.E. Consumptive use of water and irrigation water requirements. New York, ASGE, 1974. $215 p$.

MAROUELLI, W.A. \& SEDIYAMA, G.C. Balanģo hidrico visando ao máximo a precipitação natural. In: SEDIYAMA, G.c. Necessidade de água para os cultivos. Brasilia, ABEAS, 1987. p.86-127.

MATU'E, E. \& HACHEM, A.M: Necessidade de agua para irigạão. Brasillia, PROVARZEAS/PROFIR, 1983. $24 p$.

MILLER, M.E. \& WEAVER, G.R. Monthly and annual precipitation probabilities for climatic divisions in Ohio. Wooster, Ohio Agricultural Research and Development Center, 1968. 11p. CResearch Bulletin, $1005)$.

MONTEITH, J.L. Principles of environmental physics. New York, American Elsevier, 1973. 241p.

NIXON; P.R.; LAWLESS, G.P.; RICHARDSON, G.V. Coastal Galifornia evapotranspiration frequencies. Journal of the Irrigation and Drainage Livision, New York, 98(IR2): 182-91, 1972.

OMETTo, J.G. Bioclimatologia vesetal. Săo Paulo, Agronômica Ceres, 1981. 440p. 
OMETTO, J.G. Registros e estimativas dos parâmetros meteorológicos da regiäo de Piracicaba, SP. Piracicaba, FEALQ, 1989. 76p.

PEARSON, $k$. Tables of the incomplete Beta-function. London, University Gollege, Biometrika office, 1934. 494p.

PELTON, W.L.; KING, K.M.; TANNER, G.B. An evaluation of the Thornthwaite and mean temperature methods for determining potential evapotranspiration. Agronomy Journal, Madison, 52(5): 387-95, 1960.

PENMAN, H.L. Natural evaporation from open water, bare soil and grass. Proceedings Royal Society of London, London, A193: 120-146, 1948.

PISKOUNov, N. Gálaulo diferencial e integral. 7.ed. Porto, Livraria Lopes da Silva, 1984. v.2, 457p.

PRUITT, W.o.; OETTINGEN, S. von; MORGAN, D.L. Central California evapotranspiration frequences. Iournal of the Irrigation and Drainage Division, New York, 98(IR2): $177-84,1972$.

RAVELO, A.C. \& DECKER, W.L. The probability distribution of a soil moisture index. Agricultural Meteorologx, 
Amsterdam, 20: 301-12, 1979.

REICHARDT, $K$. A água nos sistemas agricolas. São Paulo, Manole, 1987. $188 \mathrm{p}$.

SAAD, J.G.G. \& SCALOPPI, E.J. Análise dos principais metodos climatológicos para estimativa da evapotranspiração. In: CONGRESSO NACIONAL DE IRRIGAÇXo E DRENAGEM, .8, Flonianópolis, $1988 . \quad$ Anais. Florianópolis, ABID, 1988a. v.2, p.999-1021.

SAAD, J.C.C. \& SGALOPPI, E.J. Frequiencia de distribuiçăo de evapotranspiração de referéncia para dimensionamento de sistemas de irrigaçäo. In: CoNGREsSo NAGIONAL DE IRRIGAĢAO E DRENAGEM, 8., Florianópolis, ABID, $1988 \mathrm{~b}$. v.2, p.1037-52.

SAAD, J.C.C. \& SGALOPPI, E.J. Programa multi-alternativo para estimativa da evapotranspiraçăo de referéncia. In: CONGRESSO BRASILEIRO DE ENGENHARIA AGRTCOLA, 17., Iperó, SBEA, 1988c. v.1, p.115-30.

SILVA, W.L.G. o método combinado para estimar a evapotranspiraçăo e sua sensiibilidade e variaçőes no termo aerodinâmico. In: CONGRESSO NACIONAL DE IRRIGAÇO E DRENAGEM, 7., Brasilia, $1986 . \quad$ Anais. Brasilia, ABID, 1986. v.1, p.185-203. 
SPIEGEL, M.R. Gálculo avançado. São Paulo, McGraw-Hill do Brasil, 1976. 500p.

SPIEGEL, M.R. Estatística. 2.ed. São Paulo, McGraw-Hill do Brasil, 1985. 453p.

TANNER, G.B. Evaporation of water from plants and soil. In: KoZLowSKI, T.T., ed. Water deficits and plant arowth. New York, Academic Press, $1968 . \quad$ v.1, p. $73-106$.

THOM, H.C.S. A frequency distribution for precipitation. Bulletin of American Meteorolomical Society, Boston, 32(10): $397,1951$.

THOM, H.C.S. A note on the Gamma distribution. Monthly Weather Review, Boston, g6(4): 117-22, Apr. 1958.

THOM, H.C.S. Direct and inverse tables of the bamma distribution. Washington, Department of Commerce. Environmental Data Sexvice. 1968. 30p.

THOM, H.C.5. Some methods of climatological analysis. Geneva, World Meteorological Organization, s.d. $53 p$. (WMO. Technical Note, 81) (WMO, 199.TP, 103 ). 
TOLEDo FILHO, M.R. Probabilidade de suprimento da demanda hídrica ideal da cultura de cana-de-açúcar Saccharum spp.? através da precipitaçăo pluvial na zona canavieira do Estado de Alagoas. Piracicaba, 1988. 72p. Mestrado - Escola Superior de Agricultura "Luiz de Queiroz" $/$ USP).

TUBELIS, A. \& NASGIMENTO, F.J.L. Meteorologia descritiva; fundamentos e aplicaç̋̃es brasileiras. São Paulo, Nobel, 1980. $374 \mathrm{p}$.

VIVALDI, L.J. Utilizaçăo da distribuição gama em dados pluviometricos. Piracicaba, 1973. 73p. Mestrado Escola Superior de Agricultura "Luiz de Queiroz"/USPS.

WEAVER, C.R. \& MILLER, M. A precipitation probabilitie computer program. Ohio, Agricultural Research and Development Genter, 1967. 10p. CResearch Gircular, 155).

WRIGHT, J.l. New evapotranspiration crop coefficients. Journal of the Irrigation and Drainage Division, New York, 108(IR2): 57-74, 1982.

WRIGHT, J.L. \& JENSEN, M.E. Peak water requirements in Southern Idaho. Iournal of the Irrigation and Drainage Division, New York, gB(IRZ): 193-201, 1972. 
YAO, A.Y.M. The $R$ index for plant water requirement. Agricultural Meteorology, Amsterdam, 6: 259-73, 1969.

YAO, A.Y.M. A statistical model for the surface relative humidity. Journal of Applied Meteorolosy, 13: 17-21, 1974. 